\title{
II. Wandel von Landnutzungen und deren Konsequenzen für Wasserressourcen
}

\author{
Einleitung \\ Inge Broer, Alfred Pühler, Mihaiela Rus
}

Einer der wesentlichen Faktoren, die vom globalen Wandel beeinflusst werden und ihn andererseits auch selbst ursächlich mit beeinflussen, ist die Landnutzung, d.h. jegliche Art der Inanspruchnahme von Böden und Landflächen durch den Menschen. Das schließt intensiv oder extensiv bearbeitete Agrarflächen und Wälder bzw. Forste genauso ein wie Siedlungs- und Verkehrsinfrastruktur. Die Art und das Ausmaß der Kultivierung land- und forstwirtschaftlicher Nutzflächen werden dabei auf regionaler und überregionaler Ebene bestimmt durch Agrarmarktpolitik, Weltwirtschaft, Bevölkerungsentwicklung und technische Innovationen. Wandel von Landnutzung bezieht sich nicht nur auf die Änderung der Landbedeckung, sondern auch darauf, wie die Bevölkerung die natürlichen Ressourcen Wasser, Vegetation und Boden nutzt und auf diese einwirkt, etwa durch Bewässerungs-, Entwässerungs- und Düngepraktiken, Ausmaß und Art der Bodenbearbeitung. Das Thema Landnutzung steht in unmittelbarem Zusammenhang mit dem Landschaftswasserhaushalt, der Ernährung, der Produktion nachwachsender Rohstoffe, der Fixierung von $\mathrm{CO}_{2}$ aus der Atmosphäre und der Abgabe von Treibhausgasen, aber auch mit der Erhaltung eines vertrauten Landschaftsbildes, dem Heimatgefühl und den Bereichen Erholung und Tourismus.

Landnutzung beeinflusst den Naturhaushalt, insbesondere die Böden und den Wasserhaushalt, aber auch ökosystemare Prozesse, die Artenvielfalt und das Standortklima. Die Eigenschaften der Bodenoberfläche, an der Energie, Wasser und Spurengase mit der Atmosphäre ausgetauscht werden, können die Art und Intensität der Luftbewegung verändern. Die Entscheidung, ob eine Fläche mit Getreide bepflanzt wird, brachliegt, gepflügt wird oder durch Gebäude und Straßen bedeckt ist, entscheidet also mit über das lokale Klima sowie die Wasser- und Stoffkreisläufe. Treibhausgase werden durch unterschiedliche Prozesse bei der Landnutzung freigesetzt, in jüngster Zeit beispielsweise vermehrt durch die Umwandlung landwirtschaftlich nicht genutzter Ökosysteme in Anbauflächen, aber auch durch die jeweils genutzte Technik bei der Landbearbeitung und die Viehhaltung. Landnutzung muss sich daher wandeln und anpassen, um negative bzw. verstärkende Effekte des globalen Wandels abzuschwächen. Die prognostizierten und zum Teil bereits eintretenden klimatischen Veränderungen wie etwa die Zunahme von Extrembedingungen und Wasserverknappungen während der Hauptvegetationsperiode erfordern zum einen den Anbau von stresstoleranten Nutzpflanzen und zum anderen die Anpassung von Bewässerungs-, Entwässerungs- und Anbaustrategien. Schließlich verlangt der 
Wandel der Agrarmärkte eine Anpassung der Produktauswahl und der Produktionsbedingungen.

Als weitere relevante Effekte beeinflussen neue gesellschaftliche Ansprüche wie Umwelt- und Ressourcenschutz, Produkt- und Prozessqualität, Tierschutz und multifunktionale Landnutzung bereits heute die Landnutzung. Aber auch die Internationalisierung, die eine Liberalisierung der Agrarpolitik und die Integration des Agrarsektors in die internationale Agrarwirtschaft zur Folge hat, wirkt sich auf die Landnutzung in der Fokusregion aus und wird dies in Zukunft voraussichtlich in noch stärkerem Maße tun. Neue Technologien wie die genetische Modifikation von Organismen, Precision Farming und die Nutzung nachwachsender Rohstoffe können dazu beitragen, diesen Herausforderungen zu begegnen, sie stellen jedoch gleichzeitig auch eine Triebkraft des Wandels dar.

In Regionen, in denen eine ungünstige Wasserbilanz während der Vegetationsperiode zu Problemen bei der Landnutzung führt, wie in Teilen von Brandenburg, wird sich die Situation verschärfen, weil sich mit den steigenden Temperaturen nicht nur die Evaporation, sondern auch der Wasserbedarf der Pflanzen erhöht und sich nach längeren Trockenperioden die Wasseraufnahmefähigkeit infolge von Austrocknung und Benetzungshemmung der Böden verringern kann (Buczko $\&$ Bens 2006). So kann es bei Pflanzen mit niedrigerem Temperaturoptimum zu Ertragseinbußen kommen (LUA 2003). Auch die Forstflächen, vor allem schon heute nicht standortgerechte Wälder, werden durch den zunehmenden Hitze- und Trockenstress beeinträchtigt und dadurch in ihrer Senkenfunktion für $\mathrm{CO}_{2}$ geschädigt. Viele Studien raten dazu, die Umstellung auf einen naturnahen Waldbau auch aus Gründen der Anpassung an den Klimawandel verstärkt zu betreiben (Breckle 2005; Hanke 2005).

Vor dem Hintergrund des globalen Wandels und damit einhergehender Landnutzungsänderungen ist es das Ziel dieses Kapitels, geeignete Anpassungsstrategien zur verbesserten Nutzung und Optimierung agrarischer Ökosysteme zu entwickeln. Solche Strategien werden umso wichtiger, je mehr der Einfluss des globalen Wandels - besonders als Klimawandel und Landnutzungswandel - sichtbar wird. Dieses Kapitel versucht, die Folgen dieser Entwicklungen für die Landnutzung in der Fokusregion zu analysieren und Strategien vorzustellen, die mögliche negative Auswirkungen auf die Landbewirtschaftung mildern und die Wettbewerbsfähigkeit des Sektors sichern können.

Die Strategien, mit denen man den unerwünschten Entwicklungen begegnen kann, werden dabei von unterschiedlichen gesellschaftlichen Anforderungen bestimmt. Die wirtschaftlichen Rahmenbedingungen und ihre regionalen Auswirkungen legen den Bereich fest, in dem die Landnutzung dem globalen Wandel begegnen kann. Der Beitrag von Konrad Hagedorn setzt sich deshalb mit den Triebkräften des Marktes ebenso wie mit den politischen Bedingungen auseinander und versucht, die Anforderungen an die Agrarpolitik, die sich daraus ergeben, zu definieren. Zugleich müssen aber auch die Auswirkungen auf die Landschaft und ihre Rolle als Erholungsraum berücksichtigt werden. Änderungen in der Landnutzung werden Einwohner der Region nur dann annehmen, wenn den Bedürfnissen nach Heimat und dem touristischen Wert der Landschaft ausreichend Rechnung 
getragen wird. Werner Konold entwirft daher einen möglichen Rahmen für die Entwicklung der Kulturlandschaften von morgen. All diesen ökonomischen, ökologischen und sozioökonomischen Anforderungen müssen die Maßnahmen zur Anpassung an den globalen Wandel nachkommen. Der Umgang mit Wasser ist hier eine zentrale Aufgabe. Starkniederschläge, Staunässe im Frühjahr und Herbst und intensive Trockenheit während der Sommermonate sind Teil des Szenarios, das in Kapitel 2 beschrieben wurde. Vor diesem Hintergrund entwickelt Joachim Quast Strategien zum Integrierten Land- und Wasserressourcenmanagement im märkischen Feuchtgebietsgürtel Oderbruch-Havelland. In dieses Management gliedert sich die Waldbewirtschaftung ein, für die Ralf Kätzel und Klaus Höppner Szenarien unter den Bedingungen des Klimawandels in Brandenburg beschreiben. Darüber hinaus sind Änderungen im Wassermanagement in der Landwirtschaft erforderlich. Hier zeigen Katrin Drastig, Annette Prochnow und Reiner Brunsch Maßnahmen auf, die sowohl in der Pflanzen- als auch in der Tierproduktion zu einem reduzierten Wassergebrauch und gleichzeitig zu stabilen Erträgen unter Wassermangelbedingungen führen. Eine nachhaltige Produktion schließt zukünftig verstärkt auch eine lokale bzw. regionale Vermarktung ein. Hans Kögl beschäftigt sich daher mit der Vermarktung von landwirtschaftlichen Produkten aus Brandenburg in Berlin. Auf diesen ökonomischen und agrarischen Erkenntnissen fußen Überlegungen von Inge Broer und Reiner Brunsch zu den Eigenschaften, die in der Fokusregion BerlinBrandenburg erzeugte Kulturpflanzen haben sollten, und zu den Anbauverfahren, die geeignet wären, um regional nachgefragte Produkte nachhaltig zu produzieren. 


\title{
Regionale Landwirtschaft im globalen Wandel
}

\author{
Konrad Hagedorn
}

\section{Kann sich Brandenburgs Landwirtschaft der Globalisierung entziehen?}

Landwirtschaftliche und gärtnerische Produkte sind weitgehend Massengüter, die sich profitabel über große Distanzen handeln lassen. Auch landwirtschaftliche Produktionsfaktoren - soweit sie nicht zu den standortgebundenen natürlichen Ressourcen wie Wasser und Boden gehören - sind international mobil, wie der Landmaschinenhandel und auch die starken Migrationsströme landwirtschaftlicher Arbeitskräfte belegen. Ereignisse mit globalen Auswirkungen auf die Nahrungsmittel- und Energiebereitstellung wie Trockenheit, Missernten, Naturkatastrophen, Energieverknappung, Wirtschaftskrisen, (Bürger-)Kriege und anthropogene Ressourcendegradierung können daher die Bedingungen der Agrarproduktion lokal und regional mehr oder weniger stark beeinträchtigen und bilden eine Quelle der Unsicherheit für die regionale Landwirtschaft. Da gerade der Umgang mit Unsicherheit eine der größten Herausforderungen unternehmerischer Tätigkeit ist, ist der Wunsch nach Abschottung vor Globalisierungseffekten erklärbar.

Aber kann sich die Landwirtschaft in einer Region wie Brandenburg unerwünschten Einflüssen der Globalisierung entziehen? Diese Frage kann im Rahmen dieses Beitrags gewiss nur angerissen werden. Zuvor ist zu klären, was in dem vorliegenden Zusammenhang mit Globalisierung gemeint ist und ob die brandenburgische Landwirtschaft tatsächlich spürbaren Globalisierungseffekten ausgesetzt ist.

\section{Bedeutung und Charakteristika der Globalisierung}

\section{Triebkräfte der Globalisierung}

Um eine Vorstellung von der Bedeutung des Begriffs Globalisierung zu gewinnen, erscheinen drei Triebkräfte erwähnenswert (Moreira 2004):

- Zunehmende Marktintegration in Entwicklungsländern: In zahlreichen Ländern waren große Teile der Wirtschaft und Bevölkerung noch nicht in die nationalen oder überregionalen Märkte integriert, sondern es herrschten lokale und regionale Systeme der Versorgung und des Austausches. Dies trifft nicht nur für die Marktintegration zu, sondern auch für die Strukturen kollektiven Handelns und 
die Kommunikations- und Informationssysteme. Diese Isolation hat in den letzten Jahrzehnten rasch abgenommen.

- Internationale Liberalisierung und Ausweitung der Märkte: Durch staatliche Entscheidungen sowohl in entwickelten Ländern als auch in Entwicklungsländern wurde die Liberalisierung des internationalen Handels stark gefördert, verbunden mit Prozessen der Privatisierung und Deregulierung. Dieser Prozess war begleitet von einer zunehmenden weltweiten Anerkennung oder gar Hegemonie von Begründungen zur Handelsliberalisierung.

- Informationstechnologien und Kommunikationsnetzwerke, Fortschritte im Transport: Zunehmende Marktintegration und internationaler Handel gingen einher mit erheblichen Fortschritten und Kosteneinsparungen im Transport. Ferner haben neue Informationstechnologien und Kommunikationsnetzwerke den internationalen Austausch und die internationale Koordination der Globalisierungsprozesse wesentlich erleichtert. Dies gilt analog für den Bereich der internationalen Ausbreitung von Wissen und Innovationen.

\section{Grundsätzliche Effekte der Globalisierung}

Folge der Globalisierung sind vielfältige Transformationsprozesse auf mehreren Ebenen:

- Nationale Regierungen sahen sich zunehmend gezwungen, das „Urteil“ der internationalen Marktkräfte (Moreira 2004: 18) zu akzeptieren. Ihr Spielraum, Wirtschaftsabläufe und Finanzströme zu regulieren, wurde dadurch entscheidend eingeschränkt. Die Forderung der internationalisierten Wirtschaft, die Nationalstaaten müssten sich der Marktdisziplin beugen, ist mit der Tendenz verbunden, dass Regierungen von Regulierern zu Förderern einer globalisierten Wirtschaft werden.

- Die negativen Nebenwirkungen dieser Entwicklung bestehen in einer wachsenden makroökonomischen Verwundbarkeit einzelner Staaten oder Staatengruppen, wie die jüngste Finanzkrise (2008 bis 2011) zeigt. Der Mainstream der Wirtschaftswissenschaften thematisierte jedoch weniger Gefahren, sondern mehr die erwarteten Gewinne der Globalisierung, die sich aus erhöhter Arbeitsteilung und verbessertem Zugang zu Gütern und Dienstleistungen ergeben.

- Die Beziehungen zwischen den transnationalen Unternehmen und ihrer Belegschaft änderten sich, weil es für Erstere sehr viel leichter wurde, die Produktion ganz oder teilweise zu ,delokalisieren“. Die Aufrechterhaltung von Beschäftigungssicherheit und sozialer Sicherheit wurde dadurch schwieriger. Dies nährte Befürchtungen, der Sozialvertrag zwischen Arbeit und Kapital könne Schaden nehmen.

- Die Globalisierungsprozesse offenbarten nicht selten eine doppelte Moral, die sich in einer Diskrepanz zwischen der Liberalisierungsrhetorik der wohlhabenden Länder und ihrem konkreten Verhalten zeigte. Sie schützen gewöhnlich ihre Schlüsselindustrien und ihre Nahrungsmittelkonzerne, wenn diese durch einen Zollabbau bedroht sind, häufig durch sogenannte ,non-tarrif barriers“, z. B. sanitäre Handelsbarrieren. 
- Durch eine wachsende internationale Vereinheitlichung von Lebensmitteln und Ernährungsgewohnheiten - bedingt durch die zunehmende Herausbildung transnationaler Konzerne, die einem hohen Wettbewerbsdruck und daher einem ökonomischen Anreiz zur Standardisierung unterliegen - werden die Nahrungsmittel weltweit immer ähnlicher. Dies führt zur Annäherung von Ernährungsgewohnheiten (Moreira 2004: 18).

Die Haupttriebkraft der Globalisierung war die zunehmende Ausstattung der Welthandelsorganisation (WTO) mit Kompetenzen. Das Ziel der WTO besteht darin, einen durchgehend freien Weltmarkt zu etablieren. Dabei ist es wichtig, zu erkennen, dass sich Globalisierung über den Bereich der globalisierten Märkte hinaus erstreckt. Eine globalisierte Wirtschaft wird zugleich die „globale Ökologie“ und „globale Gesellschaft“ beeinflussen (Ikerd 2004).

\section{Globalisierung aus institutioneller und evolutionärer Sicht}

Was sind die Implikationen der weitgehenden Aufhebung wirtschaftlicher Grenzen zwischen einzelnen Staaten? Um diese Frage zu beantworten, ist es sinnvoll, den Charakter von Abgrenzungen zwischen Ländern und Gesellschaften zu betrachten. Der Globalisierung entgegenstehende Barrieren können beispielsweise natürliche Grenzen sein, die durch erdgeschichtliche Prozesse entstanden sind (Ozeane, Gebirge, Flüsse usw.). Sie schaffen biologische Diversität, die eine Voraussetzung für die Aufrechterhaltung der Artenvielfalt ist und Lebensgemeinschaften stark macht. Ohne Diversität wäre die Natur nicht in der Lage, Leben aufrechtzuerhalten, einschließlich des menschlichen Lebens (Ikerd 2004).

Kulturelle und politische Grenzen definieren unterschiedliche Gemeinschaften von Menschen, beispielsweise Städte, Staaten oder Nationen. Sie sind entstanden, um die Herstellung und Aufrechterhaltung von Beziehungen zwischen Menschen dadurch zu erleichtern, dass nach internen und externen Beziehungen differenziert wird. Die Einbindung in Gemeinschaft ist für Menschen lebenswichtig, sie vermittelt Sicherheit und Möglichkeiten der Interaktion, auch im Dienste wirtschaftlicher Existenzsicherung.

Kulturelle Diversität zwischen Gemeinschaften ist wichtig. In historischer Perspektive standen immer dann, wenn eine Kultur oder Gesellschaft nach einer Dominanzphase zusammenbrach, alternative Gesellschaften zur Verfügung, um die Menschen aufzufangen. Ohne kulturelle Diversität wäre dies nicht möglich gewesen (Ikerd 2004).

Die von ökonomischen Kriterien dominierte Tendenz zur Globalisierung scheint ihre Achillesverse darin zu haben, Diversität zu verringern. Die Menschheit setzt sozusagen alle ihre ökonomischen Pläne auf eine Karte. Ikerd (2004) stellt fest, dass dies in der Vergangenheit anders war: „Humanity has not been willing to put all of its 'economic eggs' in one basket". Die Frage erhebt sich, weshalb ökonomische und politische Akteure sich so verhalten.

Eine ebenso plausible wie hypothetische Antwort ist, dass sie in erster Linie durch eng gefasste ökonomische Überlegungen motiviert sind und weniger durch 
weiter gefasste Ziele mit Blick auf kulturelle Entwicklungen, institutionellen Wandel und Veränderungen der natürlichen Umwelt. In die Bereitstellung von ,commodities“ (dem Handel mit „Waren“) scheint also immer weniger soziale, kulturelle und ökologische Verantwortung integriert zu sein. Dem kann nur durch explizit darauf ausgerichtete Gestaltung von Institutionen (d. h. Systemen von Regeln) und Governance-Strukturen (d.h. Formen der Organisation, um sie in die Praxis umzusetzen) begegnet werden. Ein Beispiel hierfür ist die Konvention für Biologische Vielfalt und deren Implementierung in den Mitgliedstaaten.

Wenn es zutrifft, dass Globalisierung zu einer zunehmenden Segregation von Handlungsfolgen führt, wie soll dann deren Integration (soweit für eine nachhaltige Entwicklung sinnvoll und nötig) bewerkstelligt werden, und wer trägt hierfür die Kosten? Nachhaltigkeit erfordert einen systematischen Kompromiss zwischen Integration und Segregation durch geeignete Institutionen und Governance-Strukturen (Hagedorn 2008).

\section{Regionale Globalisierungseinflüsse in Brandenburg}

\section{Agrarpreise}

Die Realpreise für ausgewählte landwirtschaftliche Produkte werden künftig nach den internationalen Marktprognosen von Witzke et al. (2009: 6ff.) erheblich steigen. Die Autoren sagen für den Zeitraum von 2003/05 bis 2015/17 Preissteigerungen von $72 \%$ für Weizen, 110 \% für Mais, 51 \% für andere Getreidearten, 71 \% für Ölsaaten und $97 \%$ für Zucker voraus. Denn für die Agrarproduktion geeignete natürliche Ressourcen, insbesondere Boden, können kaum noch zusätzlich erschlossen werden, um die aufgrund des Bevölkerungswachstums zunehmende Nahrungsmittelnachfrage durch zusätzliche Produktionskapazitäten zu decken. Weltweit hat die je Einwohner verfügbare landwirtschaftliche Nutzfläche von 0,4 ha im Jahre 1961/63 auf 0,25 ha $1997 / 98$ abgenommen. Ferner ist das durch die grüne Revolution ausgelöste Produktivitätswachstum, das 1980 bei $4 \%$ lag, bis zum Jahre 2007 auf $1 \%$ gesunken.

Da die Preisentwicklungen als steigende Realpreise auf den regionalen Agrarmarkt durchschlagen, wird die brandenburgische Landwirtschaft von der Globalisierung profitieren. $\mathrm{Zu}$ bedenken ist allerdings, dass sich starke Preisschwankungen ergeben, nicht nur durch Dürren und Missernten, sondern auch weil die Preise auf den globalen Energiemärkten aufgrund unterschiedlichster Einflüsse (Kriege, Spekulation, Rezession usw.) erheblichen Fluktuationen unterliegen und die Nahrungsmittelpreise dann parallel zu den Energiepreisen schwanken. Auf dem Weltagrarmarkt hat sich aus diesen Gründen von 2006 bis 2008 der Reispreis verdoppelt, der Weizenpreis ist um $80 \%$ und der Preis für Ölsaaten, wie Raps und Sonnenblumen, ist ca. auf das Dreifache gestiegen (Schumacher \& Chilla 2009). Entsprechend sind in Brandenburg gegenüber dem Vorjahr im Jahre 2008/09 die Preise bei Getreide um 65,4 \% und bei Ölpflanzen um 31,7 \% gestiegen (MIL 2010). Dagegen fiel der Milchpreis in Brandenburg zwischen 2007 und 2009 (Mai) von 40 auf 22 Cent je Liter, um dann wieder anzusteigen. Der Preisindex für Schlachtvieh legte im Jahre 2008/09 gegenüber dem 
Vorjahr um $+3,8 \mathrm{zu}$ (MIL 2010). Hier schwankten die Preise offenbar weniger, weil auf diesen Märkten komplizierte Zollsysteme eine beachtliche Protektion bewirkten (2007 betrug der Nettoprotektionskoeffizient für Rind- und Kalbfleisch 1,7, für Geflügelfleisch 2,0 und für Schweinefleisch 1,2; Efken et al. 2009: 58).

\section{Boden}

Während bislang in Ostdeutschland die Boden- und Pachtpreise für landwirtschaftlich genutzte Flächen im Vergleich zu Westdeutschland niedrig waren (MIL 2010), setzt insbesondere seit 2007 eine deutliche Aufwärtsentwicklung ein. Aufgrund des hohen Pachtanteils der Landwirtschaft in Ostdeutschland von knapp 80 \% (MIL 2010) und wegen der an Marktpreisen orientierten Privatisierungsverkäufe der Bodenverwertungs- und -verwaltungs $\mathrm{GmbH}$ (BVVG) ist dies für die brandenburgische Landwirtschaft durchaus relevant. Hinzu kommt als preiserhöhender Faktor die Flächenkonkurrenz zwischen Nahrungsmittel- und Bioenergieproduktion (Grundmann \& Kimmich 2008). Zu erwarten ist ferner, dass auch der weltweite Wettbewerb um Boden (,land grabbing“) nicht vor Brandenburg haltmacht. Es ist davon auszugehen, dass Eigentum an Boden (statt Pacht) für die landwirtschaftlichen Einkommen in Brandenburg zunehmend wichtig wird.

\section{Arbeitskräfte}

Die Zahl der Beschäftigten in Brandenburgs landwirtschaftlichen Betrieben sinkt. Nach Ergebnissen einer Erhebung zur Agrarstruktur im Mai 2007 gab es rund 38.000 Mitarbeiter in den 6.700 Unternehmen, was einen Rückgang gegenüber 2005 um 1.100 Beschäftigte oder rund $3 \%$ bedeutet. Von den erfassten Erwerbstätigen waren 8.400 Familienarbeitskräfte, was einem Anstieg um fast $2 \%$ im Vergleich zu 2005 entspricht. Unter die 30.200 familienfremden Arbeitskräfte fallen auch 12.800 Saisonarbeiter (Fock \& Müller 2002). Der Hauptanteil der Beschäftigten liegt mit zusammen 74,4 \% in den Altersklassen 30-39 (23,8 \%), 40-49 (36,4\%) und 50-54 $(14,2 \%)$. Die Altersgruppe 50-59 entspricht mit 23,4\% der Größe nach der Altersgruppe $30-39(23,8 \%)$.

Dagegen sind die vorgelagerten jüngeren und nachgelagerten älteren Gruppierungen relativ schwach besetzt. Die für die Reproduktion des Fachkräftebedarfs wichtigen Altersklassen sind unterbesetzt (Fock \& Müller 2002). Ebenfalls problematisch ist der geringe Nachwuchs an Arbeitskräften mit höherer Qualifikation (Hoch- und Fachschulabschluss sowie Meister). Es besteht ein deutliches Defizit unterhalb der Altersgruppe 40 (22,8 \%) gegenüber derjenigen über 50 (38,5\%). Etwas günstiger gestalten sich diese Relationen für die Facharbeiter, auch wenn die Altersklassen unter 30 Jahre mit 8,3\% den Anteil der über 50-jährigen mit 26,4 \% nicht absichern können (Fock \& Müller 2002). Besonders gravierend ist die Nachwuchslücke bei Betriebsleitern.

In einigen Branchen Ostdeutschlands, z. B. im Spargelanbau, sind zahlreiche Saisonarbeiter beschäftigt (insgesamt 2005: 13.565, 2007: 12.837; MIL 2010), die 
vor allem aus Polen kommen. Ihre Anwerbung erfolgt nicht durch die deutsche oder ausländische Arbeitsverwaltung, sondern informell über Netzwerke in den Heimatländern, die ein hohes organisatorisches Potenzial haben.

Offenbar reichen diese Netzwerke von Saisonarbeitern nicht nur zu den Betrieben nach Deutschland, sondern auch in andere europäische Länder und sind wiederum miteinander verbunden und verflochten. Die Arbeitsuchenden können somit zwischen der Vermittlungsfunktion verschiedener Netzwerke wählen. Dadurch haben sie eine reale organisatorische Option, in das eine oder das andere Land zu gehen. Da sich die Beschäftigungsmöglichkeiten und Lohnsätze für Saisonarbeiter in den EU-Ländern nicht gleichmäßig entwickeln, sondern gerade durch die Effekte der Globalisierung schwanken, werden Saisonarbeiter in manchen Jahren aus Ostdeutschland abgezogen werden, in anderen wieder vermehrt dorthin strömen. Dies hat beispielsweise der Einbruch bei den Spargelstechern in den Jahren 2007 und 2008 gezeigt. Aufgrund der positiven Entwicklung der Arbeitskräftenachfrage und der Löhne in Irland 2007/2008 zogen zahlreiche polnische Spargelstecher Irland Brandenburg vor. Als dann die internationale Finanzkrise Irland besonders hart traf, kehrten sie im Folgejahr wieder nach Brandenburg zurück (Bock und Polach 2011). Man kann hier von einem ausgeprägten Globalisierungseffekt sprechen.

\section{Betriebsmittel}

Unter den Betriebsmitteln sind insbesondere Düngemittel und Energie- und Schmierstoffe (wegen unmittelbarer Abhängigkeit von den Energiepreisen) sowie Futtermittel (indirekt durch Energiepreise und besonders durch Missernten beeinflusst) anfällig gegenüber globalen Schwankungen. So stieg der Preisindex 2007/08 (2008/09) in Brandenburg gegenüber dem Vorjahr für Düngemittel um 32,8 \% $(80,0 \%)$, für Energie- und Schmierstoffe um 9,7 \% (1,5\%), für Futtermittel um $36,4 \%$ (-6,9 \%) (MIL 2010). Die Milchproduktion unterliegt demnach mehrfach globalisierungsbedingten Unsicherheiten: hinsichtlich der Milch- und Kraftfutterpreise sowie der Düngungskosten für Grünland und Maisanbau.

\section{Regionaler Schutz vor unerwünschten Globalisierungseffekten?}

Es gibt sowohl physische oder natürliche Gründe (z. B. rasche Verderblichkeit und hohe Transportkosten) als auch institutionelle Gründe (z. B. politisch institutionalisierte Handelsbarrieren) dafür, dass in einer Region konsumierte Agrargüter auch dort produziert werden. Sollte allerdings eine Abschirmung der regionalen Landwirtschaft vor unerwünschten Globalisierungseffekten angedacht werden, so bedarf dies einer differenzierten Betrachtung. Bevor politische Akteure hier zur Tat schreiten, sollten sie sich fragen, ob die eingesetzten Regeln und Organisationsformen die Bedingungen der Konsistenz, Kompatibilität und Kohärenz im Sinne des „,fit, scale and interplay" nach Oran Young (2002) erfüllen. 
Von besonderem Interesse erscheint hierbei die Frage, ob die Umstellung auf eine regionale Versorgung der Fokusregion Berlin-Brandenburg im Sinne einer nachhaltigen Ressourcennutzung durch die Landwirtschaft eine realistische und zu rechtfertigende Option ist. Entsprechende Regionalprodukte beanspruchen in Brandenburg nach Kögl (2010: 30) von den 1.327.100 ha landwirtschaftlicher Nutzfläche (MLUV 2001: 41) ca. 72.000 ha und damit nur 5,4 \%. Diesen geringen Flächenanteil und damit die geringe Bedeutung für eine nachhaltige Ressourcenbewirtschaftung zu erhöhen, erscheint schwierig: ,Weil mittelfristig weder ein Nachlassen der hohen Wettbewerbsintensität im Lebensmitteleinzelhandel noch ein Anstieg der mengenmäßigen Lebensmittelnachfrage insgesamt oder signifikante Kostenvorteile für regionale Nahrungsmittel gegenüber global gehandelten Produkten zu erwarten sind, wird der Marktanteil regionaler Produkte nur dann signifikant steigen, wenn die Präferenz der Konsumenten für dieses Segment zunimmt“ (Kögl 2010: 44). Stattdessen das Kaufverhalten der Konsumenten zugunsten von Regionalprodukten zu dirigieren, indem man Regeln vorgibt, d. h. einen ,institutional fit“ herbeizuführen, liegt wohl außerhalb des faktisch Machbaren und auch des normativ Vertretbaren.

Ebenso stößt der Versuch einer politischen Agrarprotektion auf regionaler Ebene auf ein unüberwindbares „,problem of scale“, da solche politischen Interventionen aus Gründen, die hier nicht näher erläutert zu werden brauchen, auf höheren Governance-Ebenen angesiedelt sind, insbesondere der EU-Ebene. Selbst eine nationale preispolitische Agrarprotektion - zuletzt in der EG mühsam in Zeiten des „Grenzausgleichs" institutionalisiert - würde heute wohl kein politischer Akteur ernsthaft in Erwägung ziehen. Hier bliebe nur die EU, die sich allerdings zu einer schrittweise weitergehenden Liberalisierung der Agrarpolitik entschlossen hat, etwa durch die angekündigte Abschaffung der Milchquotenregelung.

"Institutional interplay" ist besonders im internationalen Zusammenhang zu beachten. Will ein Entwicklungsland seine Bevölkerung vor hohen Nahrungsmittelpreisen schützen, indem es Preisobergrenzen oder Exportbarrieren schafft, führt dies zu einem Preisanstieg zulasten der Konsumenten in anderen Entwicklungsländern. Möchte ein entwickeltes Land seine Landwirte gegen einen Preisverfall durch Preisuntergrenzen oder Importbarrieren schützen, fallen unter Umständen die Weltmarktpreise zulasten von Erzeugern in anderen Ländern.

Von Braun (2008) schlägt daher ein koordiniertes Vorgehen nationaler Regierungen und internationaler Organisationen unter Einbeziehung von Organisationen der Zivilgesellschaft vor, um verschiedene Maßnahmen kohärent zu implementieren. „Sie wirken sich für die Armen, für die Landwirtschaft und für die Wirtschaft als Ganzes sofort oder zeitlich verzögert aus. Die erste Gruppe von Maßnahmen - das Notfallpaket - zielt ab auf die sofortigen Bedürfnisse nach Nahrungsmittel- und Geldhilfe und erhöhter Nahrungsmittelverfügbarkeit. Die zweite Reihe von Maßnahmen - das Nachhaltigkeitspaket - zielt auf die Notwendigkeit ab, ein nachhaltigeres Nahrungsmittelsystem aufzubauen, das die derzeitigen und zukünftigen Aufgaben meistern kann.“ Das unumgänglich anspruchsvolle ,institutional design“ und die langwierige Konsensbildung, die die Realisierung eines solchen Konzepts erfordern würde, machen deutlich, wie wenig erfolgreich singuläre Eingriffe letztlich sein können. 


\section{Den Rahmen setzen für die Entwicklung der Kulturlandschaften von morgen. Regionale Antworten auf globale Herausforderungen finden*}

Werner Konold

\section{Was ist Landschaft?}

Landschaft ist etwas außerordentlich Komplexes, nicht nur von ihrer Ausstattung her, sondern auch hinsichtlich der Ansprüche, die an sie gestellt werden. In den Ansprüchen sind seit mindestens zweihundert Jahren Konflikte angelegt, die nicht prinzipiell lösbar sind.

Zum Ersten ist Landschaft:

- Wirtschaftsraum - und zwar seit Jahrtausenden - für Land-, Forst- und Wasserwirtschaft, für Rohstoffabbau,

- Siedlungsraum,

- Matrix für Infrastruktur,

- eine Ansammlung von Biotopen und Lebensgemeinschaften,

- Matrix für Prozesse, zum Beispiel für Stoffverlagerung und -ablagerung, und für Informationen.

Diese Betrachtung von Landschaft ist geschichtslos, auf aktuelle Funktionalität ausgerichtet; die Kausalitäten scheinen klar zu sein, Abläufe sind wiederholbar.

Zum Zweiten besitzt Landschaft eine historische Dimension. Wenn diese erkannt und gefühlt wird, dann wird Landschaft zur Kulturlandschaft (zwei im Grunde gleichbedeutende Begriffe; vgl. Haber 2000) und zur Heimat und hat eine große emotionale, sinnliche und soziale, eine soziokulturelle Bedeutung. Diese Landschaft ist Projektionsraum, dessen Geschichtlichkeit immer wieder in gleicher Weise erfahren werden will. Während an den spezifischen Gestaltwert einer Wirtschaftslandschaft keine Anforderungen gestellt werden, benötigt die Kultur- oder Heimatlandschaft kollektive und individuelle Erinnerungsstücke, Symbole, Formen der Vertrautheit, auch Ordnung und Wegsamkeit, also Formen der Orientierung, und hier und dort unverrückbare und nicht ersetzbare Örtlichkeiten, die den genius loci in sich tragen (Krause 1999; Valena 2005). Die jeweils eigenartigen Formen und Spuren stammen aus unterschiedlichen Zeitschichten und haben teilweise direkten Anschluss an die Gegenwart.

\footnotetext{
* Der Aufsatz ist eine verkürzte und etwas veränderte Fassung des Beitrags „Moderne Kulturlandschaften gestalten heißt, den Spagat zwischen Vertrautheit und Gewöhnungsbedürftigkeit wagen", erschienen in den Berichten und Abhandlungen der Berlin-Brandenburgischen Akademie der Wissenschaften, Band 13 (2007), S. 43-60.
} 


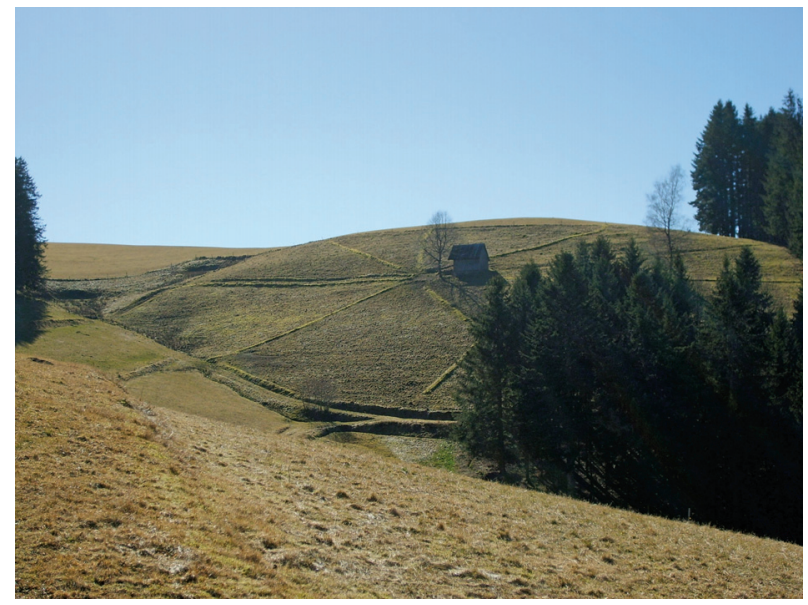

Abb. 17. Historische Kulturlandschaften spiegeln eine differenzierte Nutzung und die Agrarstruktur wider

Man findet Gewordenes, Gewachsenes (,gewachsene Kulturlandschaft"), Nebenprodukte der Nutzung (Ton- oder Kiesgrube, Torfstich), zweckvoll Gestaltetes, z.B. eine trocken gesetzte Mauer, und artifiziell Gestaltetes - und zwar in unterschiedlichen Mischungsverhältnissen. Hinzu kommen weitere Elemente wie Feld- und Sühnekreuze, Gedenksteine, Brunnen, Grenzmarkierungen, militärische Hinterlassenschaften. Kulturlandschaft spiegelt - von einer übergeordneten Ebene aus betrachtet - Eigentumsverhältnisse, Erbsitten, Rechtsgeschichte, Agrar- und Forsttechnik, den Grad der Landeskultur, Konfession und anderes wider (Abb. 17). Die Landschaft ist lesbar und das geschulte Auge kann diese Lesbarkeit bis in das Mittelalter zurückverfolgen.

\section{Akteure in der Landschaft, Ansprüche an Landschaft}

Vor dem Hintergrund der Ansprüche an Landschaft sind die menschlichen Akteure Subjekte der Nutzung und der Wahrnehmung; es sind stark vereinfacht zwei Gruppen zu unterscheiden:

- hier die Gruppe der Wirtschafter, Erzeuger, zweckorientierten Gestalter (Gestaltung vom Heute aus gesehen) und die Experten um diese Wirtschafter;

- dort die Gruppe der Konsumenten im weitesten Sinne, darunter Spaziergänger, Touristen und die Schützer von Natur und Landschaft.

Für die erste Gruppe ist Landschaft Wirtschaftsraum und Produktionsmittel, wobei bei der Nutzung, etwa der Rohstoffentnahme, immer wieder, wie oben angedeutet, Neben- und Abfallprodukte entstehen, die das Bild der Landschaft mitprägen, aber nicht bewusst gestaltet wurden. Diese Gruppe agiert pragmatisch, einkommensund marktorientiert, reagiert auf sich ändernde politische und wirtschaftliche Rah- 
menbedingungen, ist also prinzipiell änderungsbereit und anpassungsfähig, zukunftsorientiert, wenn auch nicht immer aus eigenem Antrieb heraus. Die zweite Gruppe hat eine andere Beziehung zu Landschaft. Sie erwartet Vielfalt von Arten, Strukturen und Nutzungsformen, erfreut sich an Heiden, verträumten Teichen und Söllen, Hainen, Hutungen, Hecken, an Quellen und Brunnen, Riegeln und Rainen, also an Elementen der Landschaft, die aus ganz unterschiedlichen wirtschaftlichen und funktionalen Zusammenhängen stammen. Die Gruppe pocht auf Statuserhalt, damit auch auf Wiedererkennungswert, ist eher vergangenheitsorientiert bzw. sucht Referenzen in der Vergangenheit. Kaum einer gehört jedoch ausschließlich entweder der einen oder der anderen Gruppe an. Auch ein Kiesunternehmer, ein typischer Wirtschafter, hängt an landschaftlichen Konventionen, braucht den Wiedererkennungswert seines Urlaubsortes in der Märkischen Schweiz oder in den Bayerischen Alpen.

Die einen scheinen immer voranzuschreiten, auch gezwungen zu sein, dieses zu tun, und schaffen neue, moderne, neumodische Landschaften; die Konsumenten scheinen mit mehr oder minder großem Abstand hinterherzulaufen. Ausschlaggebend für die Referenz ist der eigene Erfahrungshorizont, wozu auch der der Elternund teilweise noch der der Großelterngeneration gehört. Noch ältere Landschaftsbilder werden nicht eingefordert.

\section{Neue Kulturlandschaften}

Unsere künftigen Kulturlandschaften werden neben ihrer Funktion als Produktionsraum für hochwertige Lebens- und Futtermittel Spiegelbild der Globalisierung, des Klimawandels (darunter die Veränderungen des Landschaftswasserhaushaltes), der Klimawandelanpassung, des demographischen Wandels, von Migrationsprozessen und der Preissteigerungen fossiler Energieträger sein (dazu z. B. Arge Future Landscapes 2005). Man könnte weitere Trends hinzufügen, etwa den Agrarstrukturwandel und das Auseinanderklaffen der Einkommensschere, das zugleich zur Nachfrage nach Qualität und nach möglichst billigen Lebensmitteln führt. Manche Trends sind beeinflussbar, manche nicht oder nur sehr langfristig.

\section{Zunächst: Der Blick zurück}

Wenn man sich mit Veränderungen in der Kulturlandschaft und mit modernen Kulturlandschaften auseinandersetzt, kann es hilfreich sein, einen Blick auf Landschaftswandelprozesse in früheren Zeiten zu werfen, also auf Landschaften, die heute als harmonische, historische Kulturlandschaften geschätzt werden. Auch in der Vergangenheit gab es bei Weitem nicht nur gewachsene, gewordene Landschaften, sondern genauso mit großem Aufwand gestaltete, geplante, verordnete, was mit sozialen Verwerfungen verbunden war - wie heute auch. Fast alle modernen Landschaften, auch die alten modernen, sind von Geometrien gezeichnet; das Gestaltetsein ist also ablesbar. 
Ein paar wenige Beispiele aus Brandenburg sollen genügen:

In einer sehr detailreichen Studie untersuchte Driescher (1974; neu erschienen 2003) die Einflüsse des Menschen auf die Gewässer und den Landschaftswasserhaushalt mehrerer Einzugsgebiete Brandenburgs seit dem Beginn des Spätmittelalters. Die Einflüsse waren gravierend: Einzugsgebiete wurden vergrößert oder verkleinert, Binneneinzugsgebiete wurden an Entwässerungsnetze angeschlossen, Fließgewässer wurden verlegt und begradigt. All dies wirkte sich auf die Grundwasserstände, die Nutzung der Gewässer und die Landnutzung generell aus. So lagen die Grundwasserstände vor der deutschen Ostkolonisation deutlich tiefer, die Feuchtgebiete nahmen also eine geringere Fläche ein. Die Kolonisierung führte zu einem ,sprunghaften Anstieg“ (Driescher 2003: 134) der Wasserstände und damit auch der Feuchtflächen, ausgelöst durch Mühlenstaue. Es wurden Teiche angelegt, Seen miteinander verbunden und Schleusen gebaut. Weitere größere Eingriffe in den Wasserhaushalt fanden im 16. bis zum Beginn des 17. Jahrhunderts statt und dann nochmals Ende des 17. bis weit ins 18. Jahrhundert hinein, wobei die letzte Phase vom Bau etlicher Kanäle und von Fließen für den Holztransport, der Entwässerung und völligen Neugestaltung der großen Luch- und Bruchgebiete sowie der Fällung und Beseitigung von Seen, um landwirtschaftliche Flächen zu gewinnen, gekennzeichnet war. Der Versuch, einen „Naturzustand“ zu rekonstruieren, sei damit, so Driescher, unmöglich und wenig sinnvoll.

Eindrucksvoll beschreibt Bayerl (2007) den Wandel der Niederlausitz von einer überwiegend ertragsschwachen Agrarlandschaft mit vielseitig genutzten Wäldern zu einer „eigenartigen Industrielandschaft", in der ,,altes und neues Land ... ohne jeden Übergang neben- und durcheinander [liegen]" (Müller 1935: 13, in Bayerl 2007: 10). Der Wandel beginnt mit einer ,allmählichen Industrialisierung“ ab etwa 1850, in deren Zug der Braunkohlenabbau seinen Anfang nimmt. Bis zu Beginn des 20. Jahrhunderts steigt er exponentiell an, hinterlässt Bruchfelder und Grundwasserabsenkungsgebiete und verändert die Landschaft deutlich. Am Ende der Entwicklung steht die hoch technisierte Kohleförderung in großflächigem Tagebau. Erste Rekultivierungen gaben der Landschaft ein neues Gesicht. Zu Zeiten der DDR entwickelte sich die Niederlausitz konsequent weiter zu einer sich permanent verändernden Energielandschaft, gleichermaßen geprägt vom Braunkohlentagebau und Großkraftwerken, angetrieben durch die forcierte Industrialisierungs- und Autarkiepolitik der Staatsregierung. So stieg im Bezirk Cottbus die Förderung der Rohbraunkohle zwischen 1955 und 1990 von 61 Mio. Tonnen auf 195 Mio. Tonnen. Bis zum Beginn der 1980er-Jahre hatten die Grundwasserabsenkungstrichter einen Umfang von $1.300 \mathrm{~km}^{2}$ erreicht; bis 1990 waren rund $800 \mathrm{~km}^{2}$ der niederlausitzischen Landschaft dem Bergbau zum Opfer gefallen. Mit der Vereinigung der beiden deutschen Staaten setzte eine massive Deindustrialisierung und Entvölkerung ein, jedoch ohne dass die Funktion Energielandschaft aufgegeben worden wäre. Aus einer ehemals wasserarmen Landschaft entsteht durch die Flutung der Tagebaurestlöcher eine Seenlandschaft, industrielle Altanlagen werden Bestandteile von Landschaftsparken. Und es wird insofern in den letzten Jahren ein neues Kapitel in der Landschaftsentwicklung aufgeschlagen, als durch den Anbau von Biomasse die Energielandschaft eine weitere Facette erhält. 
Zahlreiche weitere Beispiele zum Wandel verschiedener Landschaften Brandenburgs aus älterer Zeit mit Schwerpunkten auf der Waldentwicklung finden sich bei Krausch (2008).

Große Teile Brandenburgs haben also mehrfach landschaftliche Brüche erfahren und ihr Gesicht erheblich verändert.

\section{Zwischenfazit und Wende des Blicks in die Zukunft}

Neue, jeweils moderne Landschaften sind also wahrlich nichts Neues. Sie sind durch starke Eingriffe und große Rigidität bei der Umsetzung von Ideen entstanden. Ihr Gestaltwert und ihre Geschichtlichkeit sind nicht nur wegen ihres verschiedenen Alters sehr unterschiedlich und ganz offensichtlich stellen sich in jedem Fall Gewöhnungseffekte und Vertrautheit ein. Die Veränderung des geschichtlichen Gehalts von Landschaft gerinnt im Laufe der Zeit selbst zur Geschichte, egal, ob dies additiv geschieht - mehrere Zeitschichten bleiben in einer vielfältigen Landschaft sichtbar - oder radikal neue Bilder entstehen. Je näher die Betrachtung des Landschaftswandels an die Gegenwart heranrückt, umso stärker ist die Verlusterfahrung, zumindest bei den Älteren, bei denen die alten „Baselines“, die Referenzen, noch präsent sind.

Doch Akzeptanz und Vertrautheit dürfen sich heute nicht über „Aussitzen“ und Abwarten, also mittel- bis längerfristige Gewöhnungseffekte einstellen, weil sonst die eingangs genannten Akteursgruppen - die Produzenten und die Konsumenten in immer stärkere Konflikte hinsichtlich der Ansprüche an die Landschaft geraten. Neue Landschaften sollen daher auch Kontinuen, Formen der Vertrautheit aufweisen, wobei kleinflächige oder zeitlich befristete Brüche nicht gegen das Kontinuum stehen, sondern Teil davon sind.

Fasst man Kontinuum und Vertrautheit auf einer abstrakten Ebene in Worte, dann ergeben sich für die Gestaltung von Landschaft folgende Prinzipien:

- Keine großen Maßstabsbrüche begehen.

- Wegsamkeit und Orientierungsmöglichkeit schaffen.

- Marken in der Landschaft setzen.

- Wiederkehrende Motive auftauchen lassen.

- Für Ausblicke und Refugien sorgen.

- Spezifische Sichtbeziehungen schaffen.

Kontinuen tragen Geschichte und Lesbarkeit weiter, Formen der Vertrautheit - auch neu geschaffene - dienen der Identifikation. Landschaften ohne diese Ausstattung sind über längere Zeit geschichtslos und monokausal. Die Idealvorstellung ist, dass sich auf verschiedenen Maßstabsebenen ein raum-zeitliches Muster von Kulturlandschaftsformen erhält oder entwickelt: mehrschichtig, vierdimensional, ein Muster/ eine Mischung von Monofunktionalität und Multifunktionalität, eine Mischung von integrativen und segregativen Formen. 


\section{Elemente moderner Kulturlandschaften}

Es lassen sich integrative und segregative Ansätze in der Gestaltung heutiger Kulturlandschaften unterscheiden, wobei ,,integrativ“" mehrere Funktionen (z. B. Schutz und Nutzung) auf ein und derselben Fläche, ,segregativ“ die räumliche Trennung von Funktionen meint.

$\mathrm{Zu}$ den integrativen gehört der folgende Ansatz, neue Funktionen für vertraute Formen zu schaffen und dabei diese Formen zu vervielfachen, etwa

- Niederwald für Energieholzerzeugung (flächig) (z. B. Helfrich \& Konold 2010; Suchomel \& Konold 2008),

- Gehölzstrukturen für Energieholzerzeugung (linear),

- Grabensysteme für Grundwasseranreicherung und

- Kleinstrukturen (Raine, Hecken usw.) für Oberflächenabflusspufferung und Erosionsschutz (Bronstert et al. 1995) zu nutzen oder nutzbar zu machen.

Davon nicht zu trennen und ebenfalls integrativ ist der Ansatz, neue Formen mit Vertrautheit auszustatten:

- Vertraute Geometrien einbringen über stilvolle und mit dem Relief gehende Wegeführungen, über Schlaggrößen und Schlagführung und Gehölzstrukturen (die gleichzeitig Verbundelemente sein können).

- Sichtbeziehungen erhalten oder neu schaffen, auch durch Gestaltung des Reliefs.

- Von der Funktion, nicht aber vom Bild her neue Nutzungsformen etablieren, z. B. Agroforst-Systeme (Bender et al. 2009; Reeg et al. 2009; Reeg \& Brix 2008), etwa Wertholz- plus ackerbauliche Energiepflanzenproduktion, Wertholz- plus Marktfruchtproduktion (Abb. 18), Wertholzproduktion plus Grünland (auch für Energiebiomasse), Wertholzproduktion plus Kurzumtriebskulturen (diese linear oder flächig).

$\mathrm{Zu}$ den segregativen Ansätzen zählt die Wiederaufnahme ,,altmodischer “ Nutzungsformen unter Auflösung vorhandener Grenzen und Geometrien, etwa in Gestalt großflächiger, extensiver Weiden, in die hier und dort auch Wald einbezogen wird (z. B. Redecker et al. 2002). Dabei sollen auch bewusst eingefahrene Bahnen verlassen werden, was die Tierarten und -rassen angeht. Man könnte hier weiterdenken in Richtung Game-Farming in Großgehegen, von der Nutzung her vergleichbar mit den feudalen Tiergärten, wo Wildtiere zum Zweck der Jagd gehalten werden.

Beides würde sich eignen für Gebiete, in denen sich die Landwirtschaft auf dem Rückzug befindet infolge von Globalisierung, Preisdruck und Agrarstrukturwandel, die jedoch mehr oder weniger offen gehalten werden sollen, sei es aus naturschützerischen oder touristischen Gründen. Hier könnte auch das AllmendePrinzip in der Form wiederaufgegriffen werden, dass private Flächen mit Dienstbarkeiten belegt werden, die es beispielweise einer Gemeinde ermöglichen, Weidekonzepte umzusetzen.

Ein zweifacher Ansatz wäre, Auen (segregativ) und Mulden (integrativ) systematisch für die Wasserretention zu ertüchtigen und damit auf den negativen Trend des Landschaftswasserhaushaltes zu reagieren. So würden Abflüsse abgepuffert 


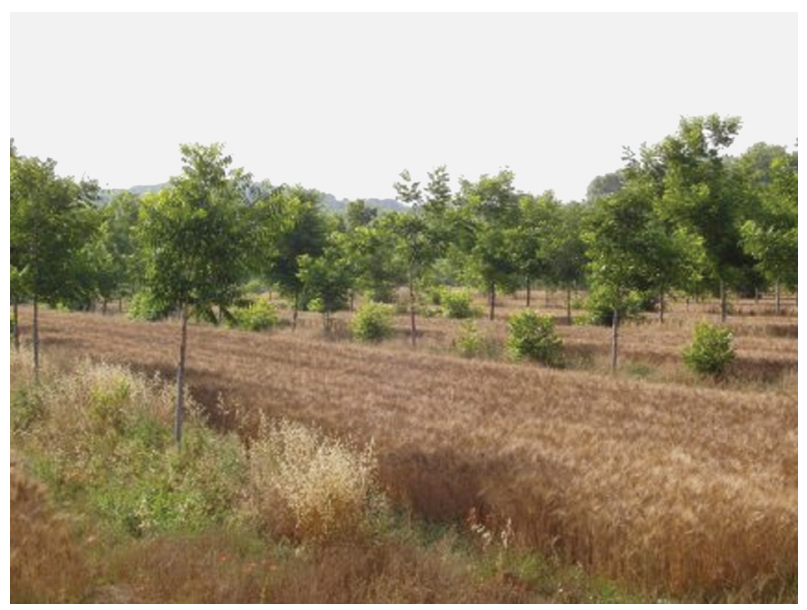

Abb. 18. Neuartiges Agroforstsystem mit Walnuss und Getreide in Frankreich (Foto: T. Reeg)

und dabei wiederum Geometrien in den Auen aufgelöst. Die Gebiete könnten dann extensiv beweidet oder der natürlichen Bewaldung überlassen werden.

Und schließlich: Allen globalen Trends zum Trotz muss auf regionaler und lokaler Ebene, also dort, wo Vertrautheit wirkt und empfunden wird, Landschaft hier und dort bis ins Detail gestaltet und die Eigenart von morgen und übermorgen geschaffen werden. Das bisher Gesagte hängt mit dem Folgenden eng zusammen. Doch geht es nun nicht mehr um die gröberen Strukturen, sondern um die feinen Gesichtszüge der Landschaft, die Geschichte sichtbar machen und die der Landschaft Geschichtlichkeit geben. Das sind beispielsweise dezentrale Materialentnahmestellen, Gruben, Brüche usw., in denen der Unterbau für Wege oder Werksteine für Restaurierungsarbeiten gewonnen werden: Kratzspuren, die immer mal wieder nach Bedarf aufgemacht werden können, um anschließend wieder der Natur überlassen zu werden (Abb. 19). Ungesteuerte Prozesse führen dort zu überraschenden Effekten hinsichtlich der Lebensgemeinschaften und des Landschaftsbildes (Seiffert et al. 1995). Solche kleinräumigen nicht dauerhaften Nutzungen fehlen weitgehend in unseren heutigen Landschaften (Konold et al. 1996).

Das sind Erd- und Steinhaufen, Steinriegel und die kleine Wildnis auf einer Kuppe (trocken), in einer Senke (feucht), am rieselfeuchten Hang. In die landschaftliche Gestaltung einzubeziehen sind die zahlreichen neuen Elemente, die noch keinen kulturlandschaftlichen Status erreicht haben, die jedoch mit dem Blick aus der $\mathrm{Zu}-$ kunft auf das Heute als typische Erscheinungsformen unserer Zeit erkannt werden: Energieleitungstrassen, Versickerungsmulden, Einschnitte und Böschungen von Straßen und Bahntrassen, Deiche, Deponien, Sedimentationsbecken und Halden. Vor diesem Hintergrund rückt die artifizielle Gestaltung der Landschaft in den Blick. Den Rahmen kann man mit ein paar Begriffen andeuten: 


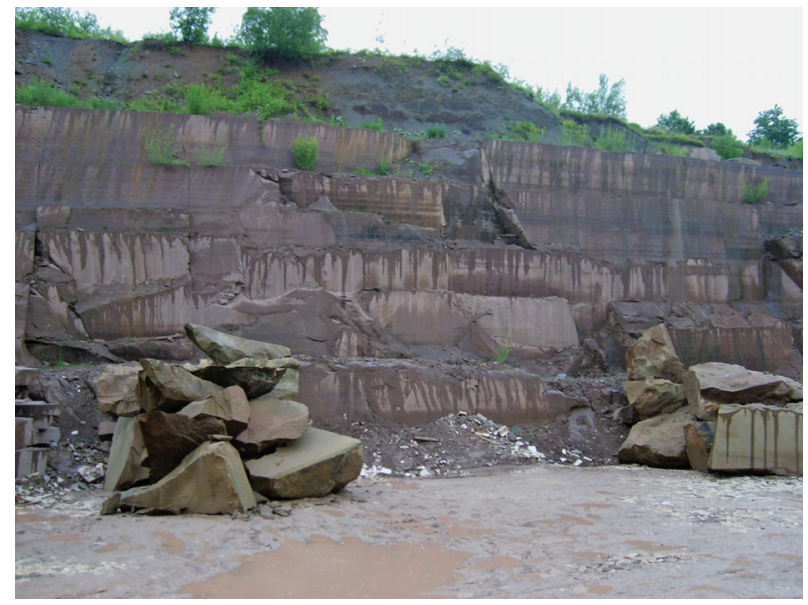

Abb. 19. Steinbrüche sind gleichermaßen „Landschaftswunden“ und reichhaltige Extrembiotope

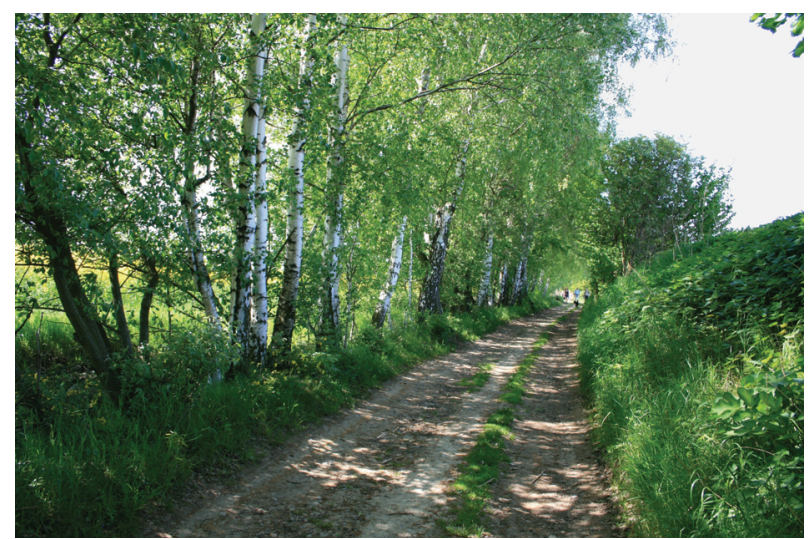

Abb. 20. Wege mit Böschungen und Gehölzsäumen sind nicht nur Verkehrsverbindungen i. w. S., sondern dienen auch der Orientierung und gliedern die Landschaft in spezifischer Weise

- Sichtbeziehungen herstellen,

- für Überraschungen sorgen,

- immer wieder Motive aufgreifen, damit Wiedererkennungswert schaffen,

- Assoziationen hervorrufen,

- markieren, überhöhen,

- vielleicht sogar den genius loci herausfordern.

Für die konkrete Umsetzung bedeutet das, die Wege landschaftlich angepasst und reizvoll zu führen, die Wegehierarchie sichtbar und spürbar werden zu lassen (Abb. 20) und mit Bäumen in Gruppen, Reihen und als Solitären zu arbeiten (Reeg \& Konold 2011). 
Dabei sollten nicht nur die „Klassiker“ Eiche, Linde oder Esche eingesetzt werden, sondern auch Arten, die es in den letzten Jahren als sogenannte Exoten schwer hatten, die jedoch auch manches ältere, vertraute Landschaftsbild nachhaltig geprägt haben, etwa die Schwarzkiefer als Gruppe oder Solitär auf einer Kuppe oder am schwach geneigten Südhang, die Pyramidenpappel (Italienische Pappel), die als Solitär oder in strenger Reihe in der Ebene, im Hügelland, an Hangfüßen mit ihrer zypressenartigen Gestalt Geometrien schafft und unterstreicht und dabei zu einem hohen Wiedererkennungswert beiträgt, die Trauerweide in Siedlungs- und in Wassernähe, die Robinie und andere mehr an Orten, wo es keinen Konflikt mit dem Naturschutz gibt.

\section{Fazit}

Angesichts globalen Herausforderungen ist bei der Gestaltung regionaler Kulturlandschaften vonnöten, sich auf Neues einzustellen, dabei Altes, ja Archaisches einzubeziehen und Kontinuität zu wahren bzw. zu schaffen, neue, zeitgemäße Funktionen für Vertrautes zu suchen, regionale und lokale Spezifika zu erhalten und auch neu zu schaffen, sich dem globalen Wandel, dem Klimawandel, der globalen Ernährungskrise und dem Wandel von Landnutzungen in aller Konsequenz zu stellen und nicht zuletzt viel mehr Mut zur stilvollen Gestaltung zu zeigen.

Damit sich lokal und regional eine je eigene Dynamik, eine Vielfalt von Lösungen entfalten kann, wird mehr Gestaltungsspielraum benötigt, den die Politik schaffen muss. Dann werden sich die Anspruchsgruppen wiederfinden, und auch der Naturschutz wird davon profitieren. 


\section{Strategien zum Integrierten Land- und Wasserressourcenmanagement im märkischen Feuchtgebietsgürtel Oderbruch-Havelland*}

Joachim Quast

\section{Situation der Auen- und Niedermoorstandorte}

Die Fokusregion Berlin-Brandenburg mit ihren sandigen und lehmig-sandigen Grund- und Endmoränen wird von Ost nach West von Feuchtgebietsniederungen im Verlauf des Thorn-Eberswalder Urstromtals und des Warschau-Berliner Urstromtals durchzogen (Abb. 1). In diesen Niederungen kam es in Abhängigkeit von den postglazial ausgeprägten hydrologischen Regimes zu unterschiedlichen Bodenbildungen.

In den Flutungsauen der nach dem Abschmelzen des Eises nach Norden in die Ostsee fließenden Oder kam es bei Hochwasser in den überschwemmten Bereichen durch Sedimentation der mitgeführten Erosionsfrachten zur Bildung von Auelehm-/ Auetonböden. Im $1000 \mathrm{~km}^{2}$ großen Oderbruch am unteren Mittellauf der Oder ist diese Deckschicht 0,5 bis $3 \mathrm{~m}$ dick. Der liegende sandig-kiesige Aquifer hat eine Mächtigkeit von 10 bis $30 \mathrm{~m}$ (Abb. 21). In den übrigen Bereichen der Urstromtäler, die weiterhin in Ost-West-Richtung entwässerten, bewirkte ein sehr geringes Gefälle ganzjährige Vernässungen mit der Bildung von Mooren und Torfböden (Netze- und Warthebruch, Rhinluch und Havelländisches Luch, Drömling und im Berliner Urstromtal die Spreeniederung).

Die Niedermoore (und auch viele Seen) werden aus dem Basisabfluss des unter den sandigen Standorten im Einzugsgebiet gebildeten Grundwassers gespeist (Abb. 22). Diese Landschaftsstrukturen bewirken das scheinbare Paradoxon von Gewässer- und Feuchtgebietsreichtum in einer niederschlagsarmen Region (Quast 1994, 1995, 1997b). Dieses Wirkungsgefüge verdeutlicht aber auch die Vulnerabilität der Feuchtgebiete und Seen. Bereits gegenwärtig beträgt das sommerliche Wasserbilanzdefizit der Feuchtgebiete 300 bis 400 mm (Dietrich \& Quast 2004). Bei geringeren Niederschlägen und höheren Temperaturen würden geringere Grundwasserneubildung und geringere Speisungszuflüsse zu den Feuchtgebieten sowie eine höhere Verdunstung aus den Feuchtgebieten folgen, wodurch deren Bestand gefährdet wäre.

Die landwirtschaftliche Nutzung der kultivierten Niederungsstandorte war und ist unverzichtbar an ein den Nutzungszielen angepasstes Wassermanagement ge-

\footnotetext{
* Eine englische umfangreichere Ausfertigung dieses Textes findet sich in Quast, J. (2011): Strategies for an integrated land and water resources management in the Mark Brandenburg wetland belt Oderbruch - Havelland. Die Erde 142 (1/2), im Druck.
} 


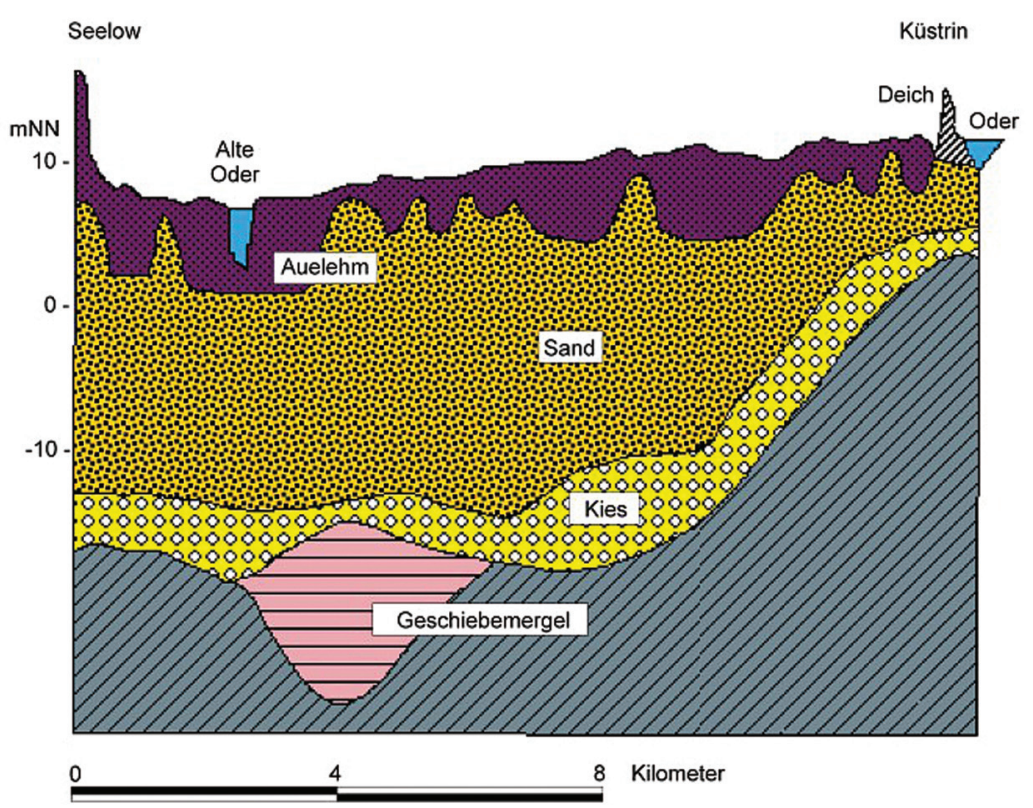

Abb. 21. Geologischer Schnitt zwischen Seelow und Küstrin (Oderbruch)

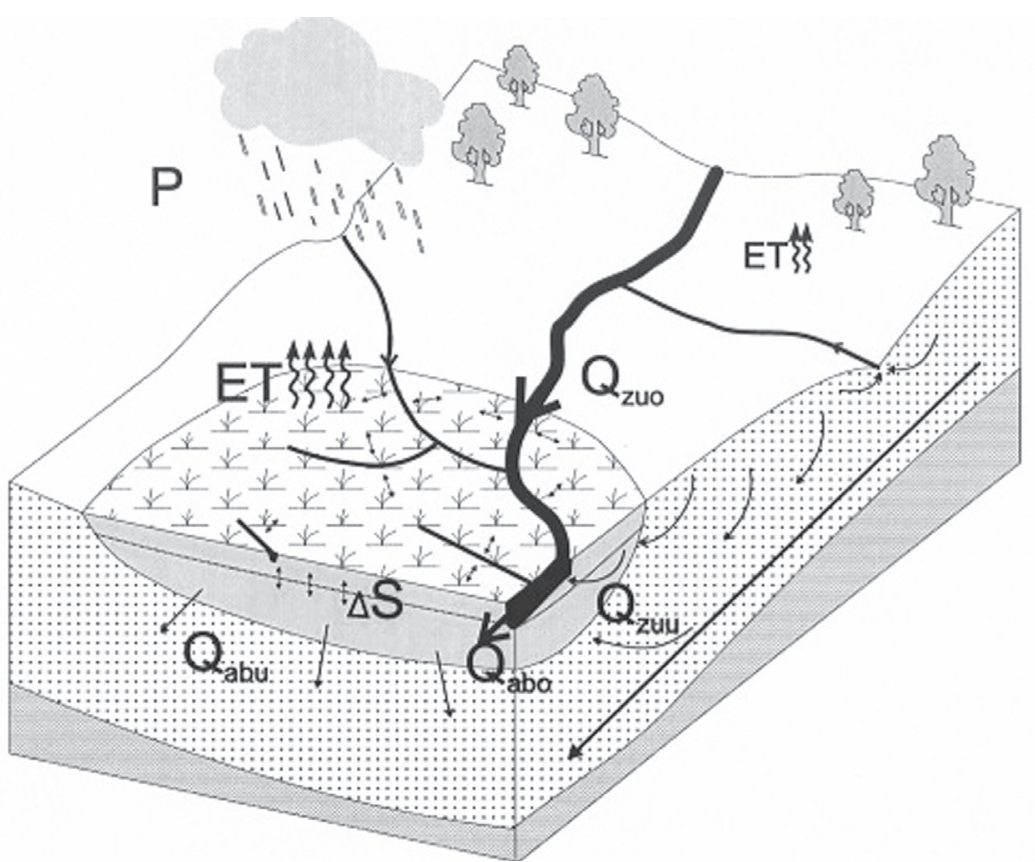

Abb. 22. Wasserbilanz von Niedermooren und Seen im sandigen pleistozänen Tiefland 
bunden. Diese engen Wechselwirkungen begründen eine Sonderstellung der grundwasserbeeinflussten Niederungen im Hinblick auf Landnutzungsmaßnahmen. Vor etwa 300 Jahren begann man, die Flächen im sogenannten märkischen Feuchtgebietsgürtel für eine landwirtschaftliche Nutzung zu erschließen (Berghaus 1854). Nach dem Dreißigjährigen Krieg (1618 bis 1648) galt es, die Entwicklung der Landwirtschaft und die Neubesiedelung des Landes voranzubringen. Die sandigen Standorte genügten diesen Zielen nur unzureichend. Es lag nahe, die potenziell fruchtbaren Niederungsstandorte einzubeziehen. Das erforderte, die Feuchtgebiete gezielt zu entwässern (mittels Gräben und Ableitungskanälen), vor weiteren Überflutungen zu schützen (mittels Deichen), die Flächen von Gehölzen zu beräumen und in Kultur zu nehmen. Die außerordentlich hohen Aufwendungen für diese Maßnahmen wurden vom Fiskus getragen. Das Oderbruch und auch die meliorierten Niedermoorstandorte entwickelten sich im 18. und 19. Jahrhundert zügig zu prosperierenden Agrarlandschaften mit bedeutenden Versorgungsfunktionen vor allem für Berlin (Blackbourn 2006).

Im Oderbruch ist der einst über die gesamte Niederung (65 km Länge, 12 bis 15 km Breite) pendelnde Fluss seit dem 16. Jahrhundert systematisch durch Deiche und den Neuen Oder Canal (erbaut von 1747 bis 1753) am östlichen Talrand fixiert worden (Mengel 1930). Der Polder, eine Eindeichung natürlicher Überflutungsflächen, im Oderbruch war somit hochwasserfrei. Es folgten Entwässerungssysteme im Polder zur Ableitung des aus der nun höher gelegenen Oder einströmenden Dränagewassers als Voraussetzung für die Kultivierung der Flächen und die Besiedlung des Polders.

Folgenreiche Erweiterungen des Wassermanagementsystems gab es in den 1920erJahren durch Installation von Schöpfwerken. Große, bisher noch verbliebene Feuchtgrünlandflächen in Deichnähe und in Geländedepressionen wurden entwässert und in Ackerland umgewandelt. Von 1970 bis 1980 wurde das gesamte Entwässerungssystem nochmals neu strukturiert und durch viele neue Schöpfwerke ergänzt. Der Feuchtgebietsanteil im Polder schrumpfte auf weniger als $5 \%$. Gleichzeitig wurden Beregnungssysteme installiert, um während der regelmäßigen sommerlichen Trockenperioden eine ausreichende Wasserversorgung der Pflanzenbestände sicherzustellen.

Das Oderbruch gehört mit einer mittleren jährlichen Niederschlagssumme von 450 mm (BMU 2003) zu den niederschlagsärmsten Regionen in Deutschland, sodass trotz guter Wasserspeicherung in den tonreichen Böden sommerlicher Trockenstress auftritt. Neben dem Standortrisiko Trockenheit gibt es seit einigen Jahren auch häufiger für die Region ungewöhnliche Starkniederschläge mit lang anhaltenden Überschwemmungen von Ackerflächen, 2010 waren diese sogar ganzjährig. Es kam zu erheblichen Produktionseinbußen (MUGV 2010). Das Hauptrisiko für die Kulturlandschaft Oderbruch besteht in der Überschwemmungsgefährdung, wenn die Deiche im Falle extremer Hochwasserereignisse versagen.

Bei der Nutzung der Niedermoore herrschte lange Zeit eine extensive Wiesen- und Weidewirtschaft bei relativ flacher Entwässerung und winterlicher Überschwemmung der Graslandflächen vor. Auch bei diesem Entwässerungsregime waren bereits Setzungen der Torfböden und Moorschwund durch Mineralisierung der oberen Bodenschichten zu beobachten (Kratz \& Pfadenhauer 2001). Mit Einführung der Schöpfwerkstechnik begann um 1925 eine Periode tieferer Entwässerung, 


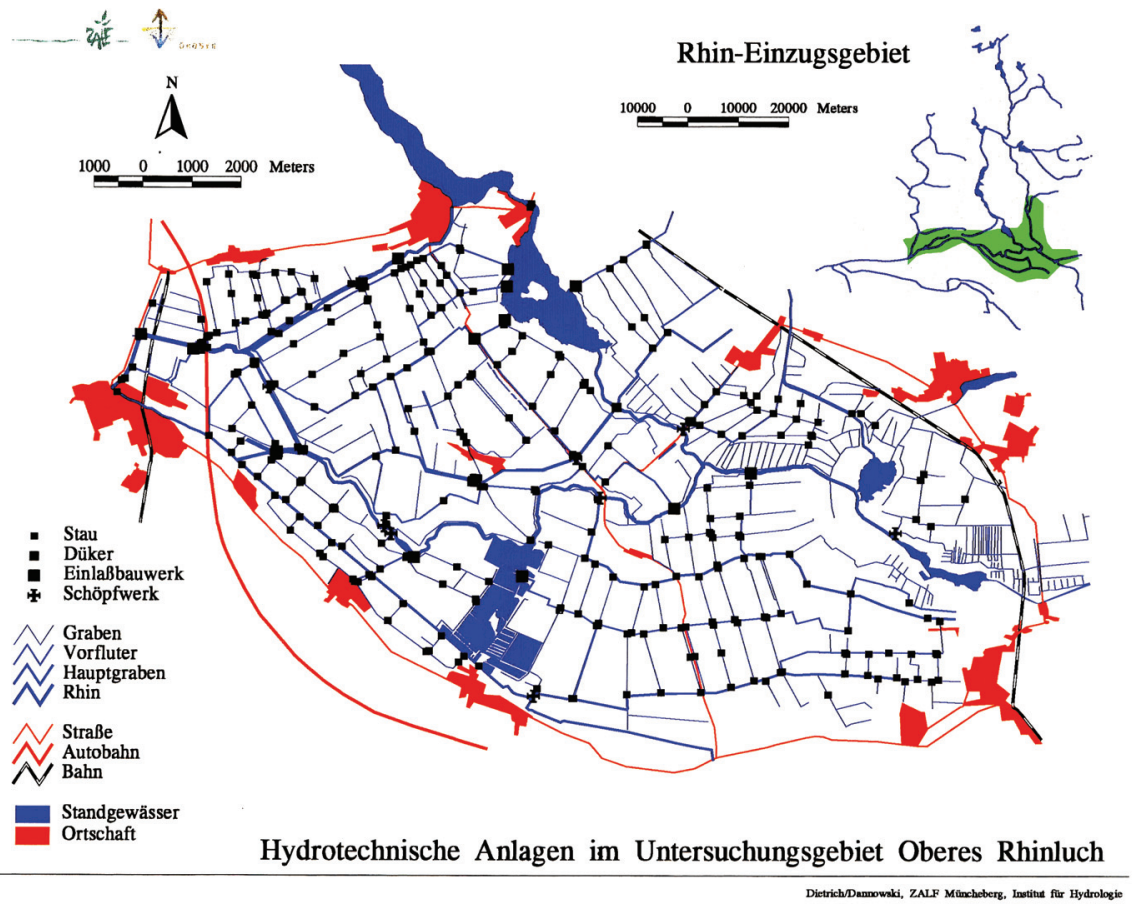

Abb. 23. Grabennetz mit Staueinrichtungen im Niedermoorgebiet Oberes Rhinluch

die auf höhere Graslanderträge und auf eine bessere Befahrbarkeit der Flächen abzielte. In den 1970er-Jahren wurden die Wasserregulierungssysteme neu gestaltet und für eine wechselweise kombinierte Ent- und Bewässerung ertüchtigt (Abb. 23; Quast et al. 1978 ; Leue et al. 1981). Die landwirtschaftliche Nutzung erfolgte überwiegend mit Saatgrasland und Mais.

Diese Nutzung zeitigte gravierende ökologische Defizite. Die Degradierung der Torfböden wurde beschleunigt, die Bodenfruchtbarkeit sank, die bodenhydrologischen Parameter (Durchlässigkeit, Speicherkapazität) verschlechterten sich (Quast et al. 1993). Die Monokulturen und die praktizierten Technologien verringerten die Biodiversität (Kratz \& Pfadenhauer 2001). Die ökologischen Defizite verschärften sich. Im Sommer 2007 führten starke Niederschläge im Havelländischen Luch zu lang anhaltenden Vernässungen mit problematischen Nutzungseinschränkungen.

\section{Stand des Wissens zum hydrologischen Systemverhalten}

Um regionale Handlungs- und Anpassungsoptionen für ein Integriertes Land- und Wasserressourcenmanagement (ILWRM) konzipieren zu können, war und ist zu klären, wie das hydrologische Regime der Feuchtgebiete funktioniert. Systematische Feldmessungen und Modellierungen gibt es seit etwa 1970. Fallstudien zum 


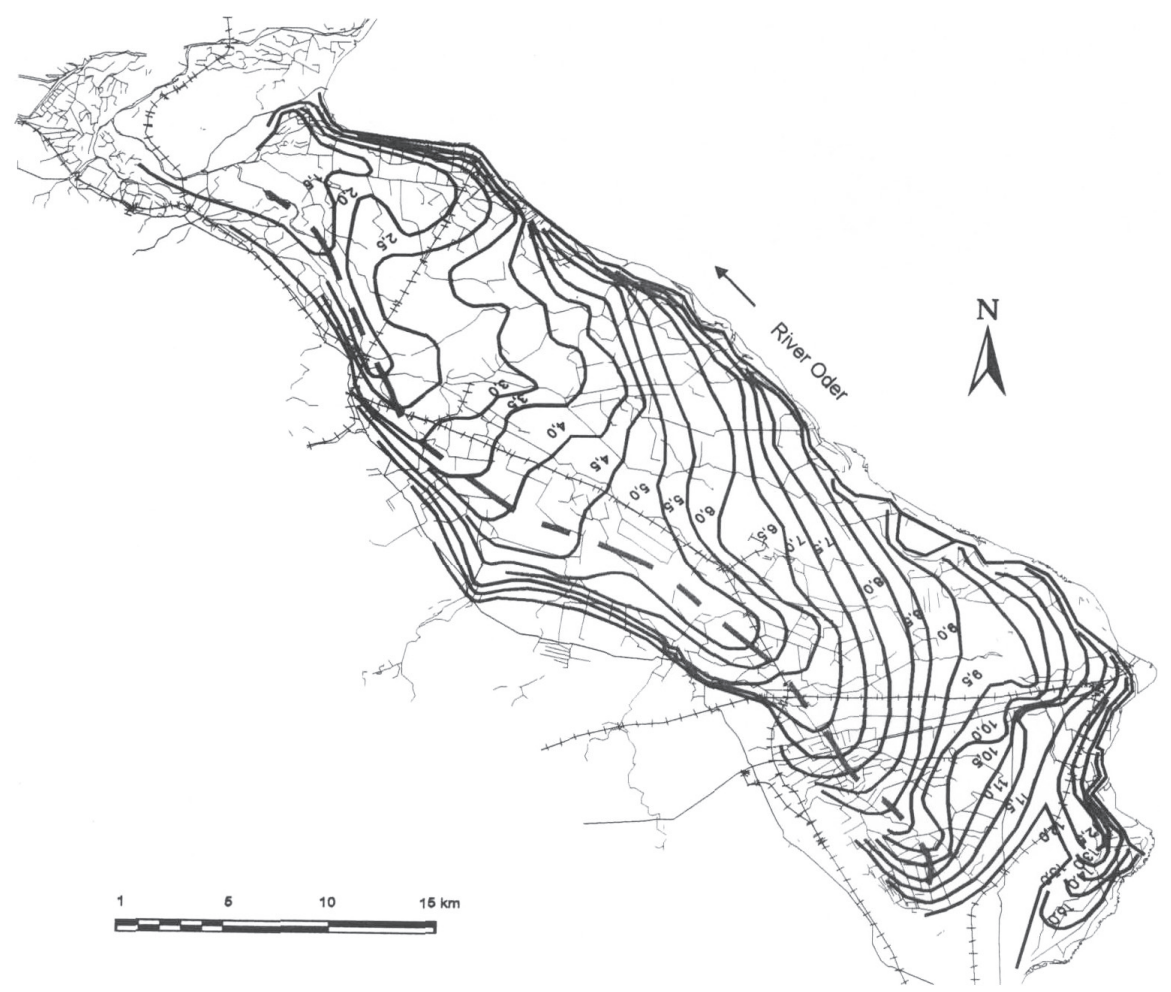

Abb. 24. Hydroisohypsen im Oderbruch (berechnet aus Grundwasserstandsmessungen am 21. März 1971 bei Mittlerem Hochwasser (MHW) der Oder)

Boden- und Gebietswasserhaushalt sowie Erprobungen daraus abgeleiteter Wassermanagementmethoden für das Oderbruch und das Obere Rhinluch sind zahlreich publiziert (Leue et al. 1981; Quast 1983, 1995, 1997a, 1997b, 1998, 1999, 2006, 2008; Quast et al. 1993; Quast \& Böhm 1998; Quast \& Lukianas 1999).

Kalibriert an Feldmessungen, wurden 1971 mit einem regionalspezifischen elektroanalogen geohydrologischen Netzwerkmodell Untersuchungen zum Grundwasserregime im Oderbruch in Abhängigkeit von Hochwasserständen der Oder vorgenommen (Quast 1973; Quast \& Müller 1973). Die unterirdischen Drängewasserzuflüsse dominieren mehr als $90 \%$ des Wasserregimes im Polder (Abb. 24). Entlang der gesamten Deichlinie im Oderbruch beträgt dieser Zustrom ca. $5 \mathrm{~m}^{3} / \mathrm{s}$ bei Mittelwasserständen der Oder und bis zu $20 \mathrm{~m}^{3} / \mathrm{s}$ bei Hochwasser. Diese Ergebnisse wurden durch spätere Feldmessungen und Modellierungen bestätigt (z. B. WASY 1999). Tiefe Grundwasserstände mit Belüftung des Aquifers unterhalb der Auelehmdeckschicht bewirken Oxidationsprozesse und diffuse Stoffausträge (Massmann 2002; Massmann et al. 2003).

Jedwede mit Entwässerung verbundene Nutzung von Niedermoorböden führt durch die Belüftung der organischen Böden zu deren Mineralisierung mit Degradierung der bodenhydrologischen Durchlässigkeits- und Speichereigenschaften sowie der Bodenfruchtbarkeit (Balla \& Quast 2001; Quast et al. 2001). 
Von 1992 bis 1998 wurden in dem BMBF-Fördervorhaben „Ökosystemmanagement für Niedermoore" Chancen und Handlungsoptionen für ein nachhaltiges Miteinander von Schutz und Nutzung norddeutscher Niedermoore untersucht (Kratz \& Pfadenhauer 2001). Das Rhin-Havel-Luch war dabei eine von vier Beispielregionen.

\section{Handlungsoptionen und Anpassungsstrategien}

\section{Oderbruch}

Bei Poldern sollte generell geprüft werden, ob die unter historischen gesellschaftlichen und ökonomischen Rahmenbedingungen geschaffenen Strukturen heutigen Nachhaltigkeitskriterien (sowohl ökologischen als auch ökonomischen) genügen und welche regionalen Anpassungen hinsichtlich des globalen Wandels vonnöten sind. Zwei alternative Optionen bieten sich an:

- Rückbau der Deiche und Verzicht auf die weitere intensive landwirtschaftliche Nutzung der Aueböden zugunsten einer Rückgewinnung natürlicher Überflutungsflächen mit hohem ökologischen Potenzial.

- Erhalt der Polder, insbesondere der besiedelten, mit Erfordernissen zur Hochwasserrisikovorsorge für mögliche extreme Hochwasserereignisse, zur Verbesserung der defizitären ökologischen Situation in den Poldern, zur Optimierung des Wassermanagements in den Poldern bei Orientierung an bedarfsgerechten Zielgrößen und gebotenen Kosteneinsparungen, zur Verbesserung der sozio-kulturellen Infrastruktur und Bewahrung des Kulturerbes in Polderlandschaften wie dem Oderbruch.

Das Oderbruch gehört zu der Kategorie besiedelter Polder mit bemerkenswertem Kulturerbe und einer hochproduktiven Landwirtschaft. Seit Anfang der 1990erJahre wurden Vorschläge für Anpassungsstrategien in einem Konzept ODERBRuch 2010 fortgeschrieben (Quast 1997a, 1998; Quast \& Ehlert 2005). Das Konzept sieht folgende Maßnahmen vor:

- Verbesserung der ökologischen Situation: Ein 200 bis 500 m breiter Feuchtgebietsstreifen am Deich erhöht den Feuchtgebietsanteil und reduziert die geohydraulischen Gradienten in Deichnähe und damit auch das in den Polder einströmende Drängewasser. Eine Revitalisierung von Oderaltarmen als Fließgewässer sowie eine Anbindung an die Strom-Oder mittels steuerbarer Durchleiter im Deich, wie sie bei Reitwein im Süden (2004) und bei Güstebieser Loose im Norden (2009) bereits gebaut und in Funktion sind, werden geschaffen. Ökologische Korridore von der Oder und dem Feuchtgebietsstreifen am Deich entlang der Hauptwasserläufe bis an die westlichen Hänge des Oderbruchs sollten schrittweise gestaltet werden (Quast \& Kalettka 2005).

- Wassermanagement des Binnenentwässerungssystems: Die Entwässerungsgräben im Oderbruch fangen das Drängewasser ab (Abb. 25) und leiten es über Vorfluter und ggf. Schöpfwerke nach Norden in die Alte Oder ab. Für eine schnelle Entwässerung von Oberflächenvernässungen (aus Starkniederschlä- 


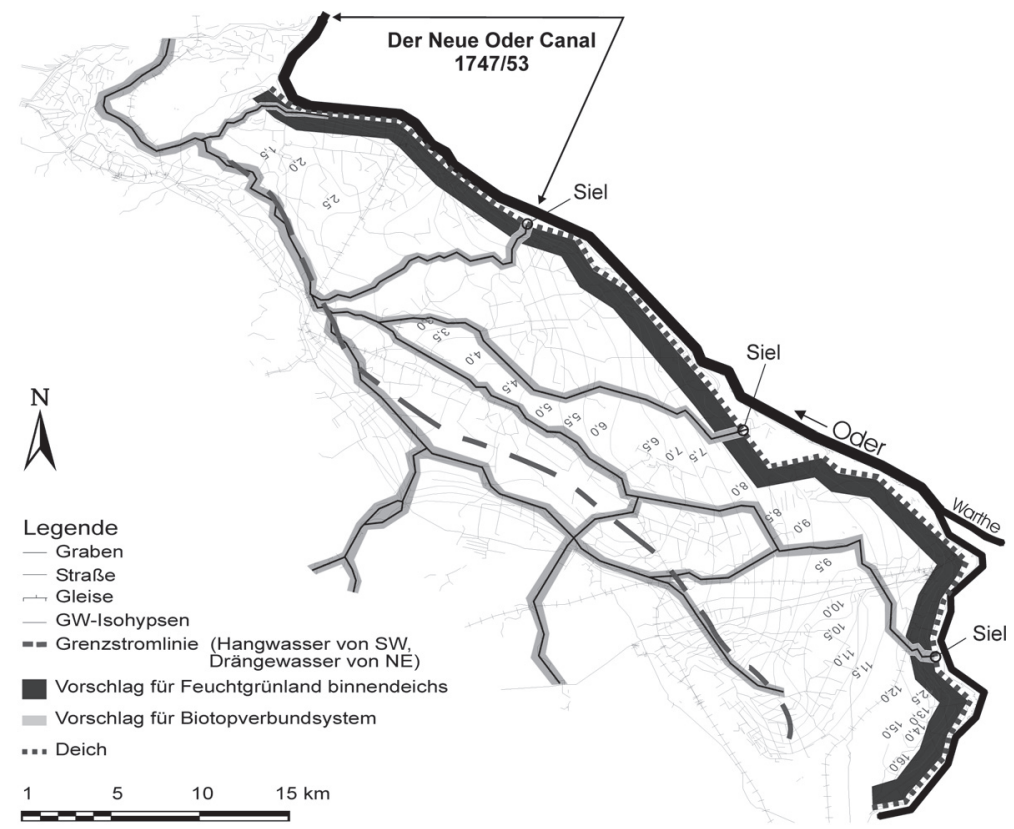

Abb. 25. Übersicht zum KonzePt Oderbruch 2010

gen) ist das Grabensystem nicht wirksam, weil die Substrate der AuelehmDeckschicht eine sehr geringe Wasserleitfähigkeit aufweisen (Müller 1988). Optional sollten flächendeckend landwirtschaftlich günstige Grundwasserstände von 1,20 bis 1,50 m unter Flur eingestellt werden. Zugunsten dieser großflächigen Ziele sollten Feuchtflächen in Senkenlagen in Kauf genommen werden. Das verspricht eine bessere Steuerungsqualität und erhebliche Kosteneinsparungen.

- Risikovorsorge für Extremhochwasser: Falls durch Klimafolgen bisher unbekannte extreme Hochwasserabflüsse auftreten, kann es zum Überströmen der Deiche kommen. Das bedeutet die Gefahr von Deichbrüchen und katastrophalen Flutungen der Polder. Für diesen Extremfall müssen am Deich befestigte Überlaufstrecken mit abgesenkter Deichkrone geschaffen werden, die eine kontrollierte Flutung des Polders zulassen, ohne dass der Deich zerstört wird. Auf der abgesenkten Überlaufstrecke können mobile Schutzwände angebracht werden, die im Notfall geöffnet werden. Im Polder müssen die Gebäude auf zeitweise Überschwemmungen hin angelegt sein. Das betrifft vor allem die Elektro- und andere Ver- und Entsorgungsinstallationen.

- Sozio-kulturelle und touristische Aktivitäten: Die historisch gewachsenen Strukturen der planmäßig angelegten Bauerndörfer für immigrierte Kolonisten stellen ein Kulturerbe von nationalem Rang dar, das es zu erhalten und zu pflegen gilt. Dieses Kulturerbe erhöht die gesellschaftliche Wertigkeit des besiedelten Polders mit hochproduktiver Landwirtschaft und verstärkt die Begründung, das Oderbruch in seinem Bestand nicht zur Disposition zu stellen. 


\section{Niedermoorlandschaften im Rhin-Havel-Luch}

Angesichts der bereits eingetretenen kritischen Degradierung kommen für die flachgründigen Moore mit einer Moorauflage von 0,5 bis $3 \mathrm{~m}$ über Sand zwei grundsätzliche Handlungsalternativen in Frage:

- Fortsetzung der bisherigen Flächennutzung mit Entwässerung im Frühjahr und nachfolgendem Wasserrückhalt mittels der Staue in den Gräben, wobei man eine weitere Moordegradierung akzeptiert. Bei Reduzierung der Moorauflage auf $<0,3 \mathrm{~m}$ entsteht beim Pflügen durch Vermischung mit dem liegenden Sand ein sogenannter Anmoor-Boden. Diese Mischböden haben gute bodenhydrologische Eigenschaften und sind ackerfähig.

- Wiedervernässung der degradierten Moorböden mit erneuter Etablierung moorbildender Vegetation, um naturschutzfachliche Ziele zu realisieren oder aber auch zur Produktion nachwachsender Rohstoffe.

Für die Konzipierung regionaler Anpassungsstrategien sind Kombinationen beider Handlungsoptionen denkbar, so wie es für das Obere Rhinluch auch bereits im ökologischen Entwicklungskonzept vorgeschlagen wurde (Kretschmer 2000; Kratz \& Pfadenhauer 2001). Die in Depressionslagen erst spät und mit besonders hohem Aufwand entwässerten Moorflächen stellen Vorzugsflächen für die Wiedervernässung dar. Sie können am besten mit dem für die Vernässung erforderlichen Wasser versorgt werden und das auch noch, wenn infolge regionaler Temperaturerhöhung und erhöhter Evapotranspiration (s. Cubasch/Kadow, S.30-36, Schaller, S. 37-42) weniger Wasser verfügbar ist, das für das gesamte Gebiet ohnehin nicht mehr ausreichen würde.

\section{Diskussion}

Bei den Optionen für Polder stehen dem Nutzen für relativ kleine regionale Bevölkerungsgruppen hohe staatliche Aufwendungen für den Erhalt der Polder und für das Wassermanagement gegenüber. Daraus folgen die Fragen: „Wie viele Polder kann man sich künftig leisten?“ und „Wie viele Polder sind noch zweckmäßig?“ Das Oderbruch hat nie zur Disposition gestanden. Es wurde mit großzügiger Bundes- und EU-Hilfe durch Ertüchtigung der Deiche für $\mathrm{HQ}_{200}$, d.h. für eine angenommene Eintrittswahrscheinlichkeit von 0,5 \% in seinem Bestand gesichert. Die Realisierung befestigter Überlaufstrecken für eine gesteuerte Flutung der Polder bei Auftreten unbekannt extremer Fluten und Ausstattung der Gebäude für den Fall einer unvermeidbaren kontrollierten Flutung sind dringliche Anpassungsmaßnahmen für die kommenden Jahre.

Grundsätzlich sind die Polderflächen wichtige Produktionspotenziale für die Landwirtschaft und dürften künftig noch an Bedeutung gewinnen. Dies gilt besonders für die Fokusregion Berlin-Brandenburg, wo nur noch die Prignitz und die Uckermark vergleichbar fruchtbare Standorte aufweisen wie die Polder an der Oder und an der Elbe. 
Für die Niedermoorregionen lassen die angeführten Handlungsoptionen nur die zwei Strategien Moorerhaltung durch Wiedervernässung bei Verzicht auf bisherige Nutzung oder Moorvernutzung bis hin zu Anmoor/Grundwassersand zu. Die für die Niedermoorgebiete notwendigen Anpassungslösungen bedürfen einer staatlichen Einflussnahme, die beim Erwerb der aus der Nutzung zu nehmenden potenziellen Wiedervernässungsflächen beginnt.

\section{Schlussfolgerungen}

Nachhaltiges integriertes Land- und Wasserressourcenmanagement (ILWRM) ist erreichbar, wenn sich durch bewusstes Einwirken die gewünschten Strukturen im regionalen Landschaftskontext herausbilden, Möglichkeiten eines korrigierenden Umsteuerns offengehalten werden, Fehlentwicklungen erkannt und benannt und durch vorausschauendes Handeln irreversible Schädigungen der Landschaftsfunktionalität vermieden werden (Quast \& Wenkel 2004). Die Anpassungslösungen sollten auf einen Zeitraum bis 2030/2040 orientieren, in dem generelle regionale Rückkopplungen des globalen Wandels für den Landnutzungssektor und konkret für die Fokusregion Berlin-Brandenburg klimawandelbedingte kritische Wasserhaushaltsentwicklungen zu erwarten sind.

Im märkischen Feuchtgebietsgürtel haben das Oderbruch (und weitere, oberhalb gelegene Polder) gute Entwicklungspotenziale als fruchtbare Agrarstandorte. Die Niedermoorstandorte sollten, soweit eine ausreichende Wasserverfügbarkeit gegeben ist, aus der landwirtschaftlichen Nutzung genommen und als Feuchtgebietsrefugien erhalten werden. 


\section{Wassermanagement in der Landwirtschaft*}

Katrin Drastig, Annette Prochnow, Reiner Brunsch

\section{Problemstellung}

Auf die Landwirtschaft Brandenburgs kommen wachsende Herausforderungen zu: der Klimawandel mit verstärkter (früh-)sommerlicher Trockenheit, ein angespannter Landschaftswasserhaushalt, weltweit zunehmender Nahrungsmittelbedarf sowie Veränderungen bei Nutztierhaltung und -zucht. Innovationen in Hinsicht auf die Produkte, aber vor allem auch die Produktionsprozesse erlangen eine immer größere Bedeutung, um die natürlichen Ressourcen optimal zu nutzen und die Wettbewerbsfähigkeit zu verbessern.

Da Wasser längerfristig zu einem teuren, weil knappen Gut werden wird, werden sich Investitionen zur Schonung der Ressource innerhalb der Landwirtschaft immer mehr lohnen. Die Erhöhung der Effizienz des Einsatzes von Wasser im System landwirtschaftlicher Betrieb hat dabei in Brandenburg besondere Bedeutung, da die hiesigen Standorte durch leichte Böden mit geringer Wasserspeicherkapazität geprägt sind. Die Böden könnten bei häufigeren und lang anhaltenden Trockenperioden zukünftig an Ertragsfähigkeit verlieren, sofern kein Beregnungswasser zur Verfügung steht. Um Möglichkeiten zur Verbesserung des Wassermanagements im System landwirtschaftlicher Betrieb darzustellen, ist es nötig, sich intensiv mit Zielgrößen zur Steigerung der Wassereffizienz innerhalb der Teilbereiche Boden, Pflanzen (Ackerbau und Grünlandwirtschaft), Tierhaltung und deren Interaktionen zu befassen.

Drastig et al. (2010) untersuchen diese Maßnahmen in ihren Auswirkungen auf die Wassereffizienz in der Pflanzenproduktion und in der Tierhaltung systematisch.

\section{Maßnahmen zur Steigerung der Wassereffizienz.}

Der höchste Wasserbedarf der Pflanzen besteht während der Phase der maximalen Blattbildung und des höchsten Massenzuwaches. So sollte im Juli /August Rübenbeständen ein Drittel des gesamten Jahreswasserbedarfs zur Verfügung stehen (Diepenbrock et al. 2009). Die Wassereffizienz bildet die Beziehung zwischen diesem

\footnotetext{
* Eine englische umfangreichere Ausfertigung dieses Textes findet sich in Drastig, K., Prochnow, A. \& Brunsch, R. (2011): Water for agriculture in Brandenburg (Germany) - Wassermanagement in der Landwirtschaft in Brandenburg (Deutschland). Die Erde 142 (1/2), im Druck.
} 
Wasserbedarf und dem entsprechenden Aufbau von Trockenmasse der Kulturpflanzen ab und wird hier also als Zielgröße im Kontext der Ertragsverbesserung bzw. Verbesserung der Wasserproduktivität verwendet.

Eine Vielzahl unterschiedlicher Methoden liegt vor, um die Wassereffizienz zu berechnen und zu beschreiben. Das Verhältnis der Biomasse einer Pflanze zum dafür verbrauchten Wasser wird als Transpirations- bzw. Evapotranspirationskoeffizient bezeichnet. Hauptsächlich unterscheiden sich die Herangehensweisen durch die Berechnung auf a) Basis der für den Bestand schwierig zu ermittelnden Transpiration, der Verdunstung durch die Pflanze, oder b) auf Basis der Evapotranspiration unter Einbeziehung der Verdunstung vom Boden. Der Ernte-Index bildet die Beziehung zwischen dem Wasserbedarf und dem Ertrag der Kulturpflanzen ab. Der Wasserbedarf wird in diesem Kontext über die Evapotranspiration bestimmt.

Einen Überblick über die möglichen Maßnahmen im System landwirtschaftlicher Betrieb, die der Steigerung der Wassereffizienz dienen können, gibt Tabelle 8 . Prozesswasser ist hierbei Wasser, das zur Herstellung der landwirtschaftlichen Produkte verwendet wird. Der Bergriff des green water entspricht dem verfügbaren Niederschlag und Bodenwasser im landwirtschaftlichen Produktionssystem.

Tabelle 8. Überblick über Maßnahmen im gesamten System landwirtschaftlicher Betrieb zur Steigerung der Wassereffizienz und Verminderung des benötigten Prozesswassers innerhalb der Teilbereiche Boden, Pflanzen und Tierhaltung

\begin{tabular}{|c|c|c|c|}
\hline Teilbereich & Boden & Pflanzen & Tierhaltung \\
\hline \multirow[t]{7}{*}{$\begin{array}{l}\text { Maßnahmen zur } \\
\text { Steigerung der } \\
\text { Wassereffizienz }\end{array}$} & $\begin{array}{l}\text { Bodenbearbeitung } \\
\text { - Aufrauen der Ober- } \\
\text { fläche / Aufbrechen von } \\
\text { Krusten } \\
\text { - Saatbettbereitung }\end{array}$ & $\begin{array}{l}\text { Züchtung } \\
\text { - trockenheitstolerante Sorten } \\
\text { - Sorten mit hohen Transpira- } \\
\text { tionskoeffizienten }\end{array}$ & $\begin{array}{l}\text { Reduzierung des Tränkwasser- } \\
\text { bedarfs } \\
\text { - Regelmäßige Wartung } \\
\text { - Dimensionierung der Tränk- } \\
\text { wasseranlagen }\end{array}$ \\
\hline & $\begin{array}{l}\text { Humuswirtschaft } \\
\text { - Ausbringen organischer } \\
\text { Substanz } \\
\text { - Mulchen }\end{array}$ & $\begin{array}{l}\text { Säen } \\
\text { - hohe Bestandsdichte } \\
\text { - Berücksichtigung der aktuel- } \\
\text { len Vegetationsperiode }\end{array}$ & $\begin{array}{l}\text { Steigerung der Wassereffizienz } \\
\text { der Reinigungsprozesse } \\
\text { - Einweichen } \\
\text { - Durchführen von Reinigungs- }\end{array}$ \\
\hline & Brachlandnutzung & $\begin{array}{l}\text { Düngen } \\
\text { • ausreichende Kaliumversor- } \\
\text { gung } \\
\text { • Unterstützung der Wurzelent- } \\
\text { wicklung }\end{array}$ & $\begin{array}{l}\text { arbeiten mit dem Besen } \\
\text { - getrenntes Sammeln, Lagern } \\
\text { und Ausbringen des Melk- und } \\
\text { Milchhausabwassers }\end{array}$ \\
\hline & & $\begin{array}{l}\text { Optimierung der Fruchtfolgen } \\
\text { und Zwischenfrüchte }\end{array}$ & $\begin{array}{l}\text { Steigerung der Wassereffizienz } \\
\text { bei der Kühlung } \\
\text { - Kreislaufführung des Kühl- } \\
\quad \text { wassers }\end{array}$ \\
\hline & & $\begin{array}{l}\text { Vermeidung von Konkurrenzen } \\
\text { durch Pflanzenschutz bzw. } \\
\text { Unkrautvernichtung }\end{array}$ & $\begin{array}{l}\text { - produktiver Gebrauch des } \\
\text { Kühlwassers } \\
\text { - Sprühbefeuchtungskühlung } \\
\text { nur bis zu einer bestimmten }\end{array}$ \\
\hline & & $\begin{array}{l}\text { Wassersparende Bewässerung } \\
\text { - Auswahl effizienter Bewässe- } \\
\text { rungsverfahren } \\
\text { - Präzisionsbewässerung }\end{array}$ & $\begin{array}{l}\text { Luftfeuchtigkeit }(<60 \%) \\
\text { - geeignete Düsen und Ventile } \\
\text { - Reduzierung wasserbasierter } \\
\text { Verfahren }\end{array}$ \\
\hline & & $\begin{array}{l}\text { Wassersparende Lagerung und } \\
\text { Verarbeitung von Feldfrüchten } \\
\text { durch Kreislaufführung des } \\
\text { Wassers }\end{array}$ & \\
\hline
\end{tabular}


Für ihre Untersuchung legten Drastig et al. (2010) und Drastig et al. (2011) fünf Zielgrößen zur Steigerung der Wassereffizienz in Anlehnung an Bouman (2007) und Amede et al. (2009) fest. Die aussichtsreichsten Maßnahmen aus Tabelle 8 werden nun diesen fünf Zielgrößen zugeordnet.

- Erhöhung des Transpirationskoeffizienten: Durch den vermehrten Aufbau von Trockenmasse oder Ernteprodukt relativ zum dafür verwendeten Wasser sollte der Transpirationskoeffizient erhöht werden. Beispielsweise können die Vermeidung von Konkurrenzen durch Pflanzenschutzmittel und die damit einhergehende Unkrautvernichtung der Erhöhung des Transpirationskoeffizienten dienen. Auch züchterische Maßnahmen, Düngung sowie ein optimiertes Timing der Blütezeit erscheinen für diese Zielgröße relevant. Das Lockern des Bodens unterstützt die intensive Durchwurzelung durch die Pflanzen und damit ebenfalls die Erhöhung des Transpirationskoeffizienten.

- Zeitliche oder räumliche Vergrößerung des Wasserspeichers: Einer Pflanze sollte ein potenziell vergrößerter Wasserspeicher verfügbar gemacht werden. Humus speichert das Drei- bis Fünffache seines Eigengewichts an Wasser. Durch höhere Humusgehalte wird dementsprechend der potenzielle Wasserspeicher im Boden vergrößert. Eine ausgeprägte Wurzelmasse, die durch Düngung unterstützt wird, ermöglicht der Pflanze einen Zugang zu weiter entfernten Wasserreserven im Boden. Ein gutes Timing der Saat und damit der folgenden Wachstumsphasen ermöglicht den Pflanzen, Wasserreserven optimal, d.h. zum Bedarfszeitpunkt auszunutzen. Die gezielte Züchtung von Sorten, die schnell abreifen und damit nicht der Trockenheit und Hitze im Sommer ausgesetzt sind, wird in diesem Zusammenhang zunehmend relevant. Für eine frühere Keimung ist außerdem eine Züchtung hin zu einer erhöhten Frosttoleranz erforderlich. Zwischenfrüchte und Hauptfrüchte können dann zur Erhöhung der Wassereffizienz beitragen, wenn sie mit einer Pfahlwurzel, wie beispielsweise die Luzerne, ausgestattet sind und damit tiefere Bodenschichten durchbohren und erschließen können. Diese dienen der räumlichen Vergrößerung des Wasserspeichers. Das Wurzeltiefenwachstum der Nachfrüchte kann dadurch angeregt werden, was zur Verbesserung ihrer Wasserversorgung und Trockenmasseproduktion beiträgt, indem die Versickerung gemindert und die Transpiration erhöht wird (Ehlers 1996).

- Erhöhung des Niederschlagswasseranteils am Wasserspeicher: Niederschlagswasser sollte im Boden oder in einem künstlichen Speicher erhalten werden und damit einer späteren Nutzung zur Verfügung stehen. So wird durch eine Speicherung des Boden- und des Niederschlagswassers in einer Brache der green waterAnteil am Wasserspeicher erhöht. Auf Sandstandorten stehen Unkrautbeseitigung zur Vermeidung von Konkurrenzen und Erhaltung der Bodenfeuchte im Vordergrund. Falls für eine Bewässerung gespeichertes Niederschlagswasser verwendet wird, kann ebenfalls der green water-Anteil am Wasserspeicher erhöht werden.

- Verringerung der nicht über Transpiration auftretenden Wasserverluste: Die sogenannte unproduktive Verdunstung z. B. des Bodenwassers oder durch Unkräuter, durch die keine Trockenmasse von den Kulturpflanzen aufgebaut wird, sollte vermieden werden. Konkurrenzen durch Unkräuter können durch Pflanzenschutzmittel vermieden werden. Auch ein schnell geschlossener, dichter 
Pflanzenbestand vermindert die Verdunstung aus dem Boden, ohne den Weg durch die Pflanze. Eine hohe Bestandsdichte durch die schnelle und lückenlose Entwicklung einer Bodenbedeckung und eine tiefe Durchwurzelung beruht auf einer qualitativ hochwertigen Saatbettbereitung und Aussaat. Bei der Saatbettbereitung erfolgt ein Einebnen, Lockern, Krümeln und erforderliches Verdichten des Bodens. Eine lockere Bodenoberfläche, eine gleichmäßige Einsaattiefe und Samen von guter Qualität dienen dem Aufbau eines lückenlosen Bestandes. Der Abfluss der Wassers an der Oberfläche wird als unproduktiver Verlust betrachtet. Evaporierendes Bodenwasser muss allerdings nicht zwangsläufig als unproduktives Wasser interpretiert werden, da die Evapotranspiration für die Pflanze einen Kühleffekt haben kann. Bei hohen Temperaturen und Sonneneinstrahlung ist die Kühlfunktion der Evaporation eine entscheidende Größe. Die Verdunstungskühlung kann auf Böden eine Differenz von über $25^{\circ} \mathrm{C}$ ausmachen, hinzu kommt eine Nachhaltewirkung in den Abendstunden. Der Kühleffekt durch Evaporation wird bei einer Beregnung von Kulturen unter Glas und auch für Zierpflanzen genutzt, um diese vor Überhitzungsschäden und damit vor Qualitätsverlusten zu schützen. Dieser Effekt wird auch im Freiland im mediterranen Weinbau genutzt, wiederum um bei großer Hitze Blattschäden zu vermeiden (pers. Mitteilung D. Lütkemöller, Universität Lüneburg, 2009).

- Einsparen von Prozess- und Tränkwasser: Im System landwirtschaftlicher Betrieb tritt Prozesswasser bei der Verarbeitung von Ernteprodukten, bei der Pflanzenproduktion und in der Tierhaltung auf und kann durch unterschiedliche Maßnahmen verringert werden. Durch die Auswahl effizienter Bewässerungsverfahren kann Einfluss auf den Wasserbedarf genommen werden und Prozesswasser eingespart werden. Für die Steigerung der Wassereffizienz beim Tränkwasserbedarf sind Verluste des Wassergebrauchs zu berücksichtigen und möglichst einzuschränken, z.B. durch regelmäßige Wartung des Materials. Durch Einweichen reduziert sich der Prozesswasserbedarf für die Reinigung der Ställe. Besonders wirksam gelingt dies mit stationären Sprühanlagen. Dazu kann auch eine Sprühkühlung durch Einsatz entsprechender Düsen genutzt werden. Nach dem Einweichen erfolgt die Reinigung mit dem Hochdruckreiniger (KTBL 2009). Selbst wenn eine regelmäßige Reinigung und Desinfizierung des Tierhaltungsbereiches mit dem Wasserstrahl empfehlenswert ist (KTBL 2008), kann zur Wassereinsparung für die täglichen Reinigungsarbeiten in erster Linie mit dem Besen gearbeitet werden (Hörnig \& Scherping 1993). Durch eine Kreislaufführung von Wasser, das zur Evaporationskühlung der Ställe eingesetzt wird, können Einsparungen erzielt werden. Gut gewartete Tränkwasseranlagen ohne Leckagen vermindern Wasserverluste. Zur Abkühlung des Milchtanks wird Wasser verwendet. Um Prozesswasser einzusparen, darf dieses Wasser nicht ins normale Regenwassernetz umgeleitet werden, sondern sollte über eine Kreislaufführung für Reinigungsarbeiten (Melkstand, Aufzuchtbereich) und als Tränkwasser benutzt werden oder durch ein geschlossenes Kühlsystem zur Wärmerückgewinnung dienen (Hörnig \& Scherping 1993). Der Einsatz wasserbasierter Kühlungsverfahren könnte bei Stallneubauten und bei der Rekonstruktion von Altbauten reduziert werden. So könnte bei der Frischluftansaugung der Einsatz 
von Erdwärmetauschern erfolgen. Andere einfache Maßnahmen können bereits beim Bau dazu beitragen, den Kühlungsbedarf zu reduzieren.

Für eine systematische und ausführlichere Darstellung aller Maßnahmen und der entsprechenden hydrologischen Prozesse sei auf Drastig et al. (2010) und Drastig et al. (2011) verwiesen.

\section{Ausblick}

Wasser ist bei vielen Ackerbausystemen der limitierende Faktor. Welche konkreten Maßnahmen hieraus für Brandenburger landwirtschaftliche Betriebe abzuleiten sind, lässt sich nicht pauschal beantworten. Es ist nicht möglich, Aussagen zu einem „besser“ oder „schlechter“ der verschiedenen Maßnahmen zur Steigerung der Wassereffizienz zu treffen. Es ist immer das gesamte System landwirtschaftlicher Betrieb in Betracht zu ziehen. Bodenbearbeitung und Bodenbestellung, Aussaat, Fruchtarten und Fruchtfolgen und Bewässerung müssen an die Bodenart, die Grundwasserverhältnisse, die Witterung und die aktuelle Marktlage angepasst werden. Eine standortspezifische Bodenbearbeitung und standortspezifische Bodenbearbeitungsfolgen die auch an die aktuelle Witterung angepasst werden, können die Vielfalt der Brandenburger Ackerbausysteme effektiver berücksichtigen.

Für die Entwicklung eines nachhaltigen Wassermanagements in Brandenburg lassen sich folgende Empfehlungen aussprechen:

Um belastbare Ergebnisse für standortspezifische Maßnahmen zu erhalten, muss die Weiterführung der Brandenburger Dauerversuche sichergestellt sein. Die Landwirtschaftlich-Gärtnerische Fakultät der Humboldt-Universität zu Berlin unterhält beispielsweise sechs Dauerfeldversuche, die in den 1920er- und 1930erJahren angelegt wurden. Wie der Ertrag des Bodens verbessert und wie die natürliche Ressource Boden bewahrt werden kann, steht dabei im Mittelpunkt des Interesses.

Das Prüfen und Übernehmen von standortspezifischen Anpassungsstrategien von landwirtschaftlichen Betrieben aus verschiedenen Ländern (Deutschland, Südafrika, Australien und USA), mit denen der Wasserknappheit begegnet wird, kann für Brandenburger Verhältnisse nützlich sein. Ein Beispiel für eine derartige Sammlung stellt das internationale Netzwerk ,,agri benchmark“ dar, das vom Institut für Betriebswirtschaft des Johann Heinrich von Thünen-Instituts (vTI) und der Deutschen Landwirtschafts-Gesellschaft (DLG) koordiniert wird.

Eine Balance zwischen Flexibilität und einem gewissen Maß an Planungssicherheit für landwirtschaftliche Betriebe sollte geschaffen werden. $\mathrm{Zu}$ dieser Planungssicherheit könnte die Unterstützung durch Mehrgefahrenversicherungen (Gaul 2009) zählen sowie das Dürrehilfsprogramm, das heute schon Anwendung findet.

Eine Analyse des Trockenheitsrisikos in Brandenburg und Berlin ist mithilfe einer Modellierung unter Verwendung lokaler Daten und kulturspezifischer Parameter analog zum Verfahren von Fuhrer \& Jasper (2009) möglich. Auf Daten dieser Art könnten eine Trockenheitsrisikokarte, die über den Wasserstress der Kulturpflanzen berechnet wird, und eine darauf aufbauende Maßnahmenkarte für Brandenburger 
Landwirte/-wirtinnen entwickelt werden. Ähnlich hydrologisch gleich wirkenden Einheiten ließen sich gleich wirkende Agrarsystemeinheiten mit standortspezifischer Nutzung ableiten. Interessant scheint auch das Einbeziehen von Wassereffizienzen in eine derartige räumliche Analyse.

Die angewandte Agrarforschung muss ihren Beitrag zu einer wettbewerbsfähigen und ressourcenschonenden Landwirtschaft in Brandenburg leisten. Bei dem Transfer der Forschungsergebnisse in die Praxis sollten die Landwirte/-wirtinnen wissenschaftlich begleitet werden, um die Maßnahmen im Prozess anzupassen. 


\title{
Waldbewirtschaftung unter den Bedingungen des Klimawandels in Brandenburg
}

\author{
Ralf Kätzel, Klaus Höppner
}

\section{Ausgangsbedingungen}

Nach den Auswertungen der regionalisierten Klimamodelle gehört das nordostdeutsche Tiefland zu den am stärksten vom Klimawandel betroffenen Risikogebieten Deutschlands (Zebisch et al. 2005). Bereits jetzt ist das Klima in Brandenburg trocken, im Nordwesten ozeanisch und im Südosten kontinental geprägt. Zwischen den Jahreszeiten und den Regionen treten relativ große Temperaturschwankungen auf. Das Jahresmittel der Lufttemperatur hat im Zeitraum 1951 bis 2000 zwischen $0,7 \mathrm{~K}$ und $1,5 \mathrm{~K}$ zugenommen (Gerstengarbe et al. 2003). Im gleichen Zeitraum ist für die Sommermonate ein Rückgang des Niederschlags zu verzeichnen, im Winter dagegen eine Zunahme (Wechsung et al. 2009).

Land- und Forstwirtschaft, deren Produktion unmittelbar von Klimafaktoren wie Temperatur und Wasserangebot sowie von klimabeeinflussten Sekundärfaktoren abhängt, sind von Klimaveränderungen besonders betroffen. Aufgrund der langen Produktionszeiträume, der eingeschränkten Reaktionsmöglichkeiten, der Naturnähe und der Vielzahl unterschiedlicher und teilweise konkurrierender Zielstellungen (Holzproduktion, Naturschutz- und Erholungsfunktion) sind die Handlungsspielräume der Waldbewirtschaftung dabei weitaus geringer als in der Landwirtschaft. Angesichts der ökologischen und ökonomischen Bedeutung von Wald- und Forstwirtschaft sind die Gefährdungspotenziale durch Klimaveränderungen zu bewerten und Anpassungsstrategien zu entwickeln. Nach gegenwärtigem Wissensstand können diese Betrachtungen nur für wenige Jahrzehnte, die kaum einer halben Waldgeneration entsprechen, im Voraus erfolgen. Diese kurze Zeitspanne muss angesichts der zeitlichen Dimension der Waldentwicklung unbefriedigend bleiben.

Neben den klimatischen und bodenbedingten Besonderheiten des nordostdeutschen Tieflandes wird die Anfälligkeit der Wälder vor allem durch die Waldstruktur bestimmt. Rechtzeitig einsetzende, vorausschauende und variantenreiche Maßnahmen der Risikominderung sind daher dringend erforderlich.

\section{Bewertung der Risikopotenziale}

Ein effizientes Klimawandel-Risikomanagement erfordert, die Anfälligkeit von Waldökosystemen gegenüber Klimastressfaktoren zu bewerten, die sich aus der 
Stärke der Einwirkung, der Stabilität des Systems und dessen Anpassungsfähigkeit ergibt. Aus der Vielzahl der Konzepte zur künftigen Baumartenwahl sollen drei besonders herausgestellt werden.

Dies ist zum einen das Konzept der klimaplastischen Wälder (Jenssen 2009). Danach ist die Klimaplastizität eines Waldbestandes dann besonders groß, wenn sich die ökologischen Amplituden der Baumarten überlappen und eine Vergesellschaftung ermöglichen. Jede Baumart sollte jedoch unterschiedliche Bereiche möglicher Klimaszenarien abdecken. Natürliche Vorbilder sind Linden-Hainbuchenund Eichen-Buchenwälder mit unterschiedlichen Mischungsanteilen.

Ein weiteres Konzept ist die Bewertung der Baumarten auf Basis von „Klimahüllen“ (Kölling 2007). „Klimahüllen“ stellen die Vorkommenshäufigkeit jeder Baumart in der Kombination von Jahresmitteltemperatur und Jahresniederschlagssumme dar. Danach ist die Anfälligkeit einer Baumart gegenüber einer Änderung von Niederschlag und Temperatur gering, wenn sich die Baumart am konkreten Standort möglichst weit von ihrem ,ökologischen Nischenrand“ entfernt befindet und damit der survival buffer möglichst groß ist.

Von diesen beiden Konzepten unterscheiden sich die Bewertungskategorien von Roloff \& Grundmann (2008), da sie zusätzlich die Stresstoleranz und Standortangepasstheit von Gehölzen nach dem jetzigen Kenntnisstand mit einbeziehen.

Alle drei Ansätze für eine zukunftsorientierte Baumartenwahl beruhen auf der Einschätzung der aktuellen Angepasstheit als evolutives Ergebnis früherer und aktueller Umweltbedingungen. Unberücksichtigt bleiben dagegen die Variabilität der Angepasstheit einer Baumart innerhalb ihres Verbreitungsgebiets und die dynamische, evolutive Anpassungsfähigkeit durch Mutation, genetische Rekombination und Selektion. Dynamische Ansätze berücksichtigen daher die Änderung der genetischen Reaktionsnorm der Individuen und Populationen in Raum und Zeit. Evolutionäre Prozesse begünstigen bei erheblichen Umweltveränderungen Populationen, die ihre genetischen Reaktionsnormen schnell variieren können. Bei kurzfristigen Umweltveränderungen sind Typen im Vorteil, die sich mit minimalem Aufwand und hoher Individuenzahl vermehren. Vor diesem Hintergrund soll nachfolgend das Anpassungspotenzial einiger wichtiger Wirtschaftsbaumarten des Landes Brandenburg beleuchtet werden.

Seit Beginn der Waldzustandserhebung zeigt die Wald-Kiefer als die häufigste Baumart des Landes Brandenburg trotz periodisch regionaler Nadelverluste durch Insekten die geringste Kronenverlichtung (MIL 2010). Im Vergleich zu allen anderen Baumarten weist sie die höchste Anpassungstoleranz gegenüber Sommertrockenheit und warmen Wintern auf. Dennoch wird die Kiefer bei höheren Temperaturen und permanent wiederkehrenden Trockenperioden vermehrt mit Absterbeerscheinungen reagieren. Die eigentliche Gefährdung der Kiefer besteht in ihrer Anfälligkeit gegenüber nadelfressenden und holzbrütenden Insekten. Die WaldKiefer wird aufgrund ihrer hohen Angepasstheit und Anpassungsfähigkeit jedoch auch in den nächsten Jahrzehnten das Rückgrat der brandenburgischen Forst- und Holzwirtschaft bleiben.

Die beiden heimischen Eichenarten Trauben- und Stiel-Eiche gehören hinsichtlich ihrer Standortansprüche zu den Zukunftsbaumarten, die im Rahmen des 
Waldumbaus besonders gefördert werden. Aktuell liegt ihr Anteil bei ca. $5 \%$ der Gesamtwaldfläche. Der Anteil wird jedoch ansteigen, da Kiefernreinbestände in den vergangenen zehn Jahren großflächig mit Eichen gemischt wurden. Kritisch zu betrachten ist der hohe Anteil geschädigter Eichen mit Kronenverlichtung, Feinreisigverlust, Schleimfluss etc. Seit mehr als zwei Jahrzehnten gehören die Eichen zu den am meisten geschädigten Baumarten in Europa. Allerdings zeigen sie in Untersuchungen im Gegensatz zur Kiefer keine zunehmende Klimasensitivität. Die Eiche profitiert im Wachstum von starken Juniniederschlägen und von kühlen Sommern (Schröder 2009).

Der Verbreitungsschwerpunkt der Rot-Buche liegt im Norden Brandenburgs. Seit mehr als 30 Jahren werden Kiefernbestände mit der schattentoleranten Buche unterbaut, sodass ihr Anteil zunimmt. Die Buche zählt zu den Baumarten, die an feuchteren und nährstoffreicheren Standorten ihre größte Konkurrenzkraft entwickelt, sodass ihre Anpassungs- und Überlebenswahrscheinlichkeit unter den Bedingungen des Klimawandels häufig kritisch gesehen wird. In unbewirtschafteten Naturwäldern findet zurzeit auch auf trockeneren Standorten eine zunehmende Buchennaturverjüngung statt. Möglicherweise wurde die Anpassungsfähigkeit der Buche also in der Vergangenheit unterschätzt.

Brandenburg hat die mit Abstand größte Robinienfläche Deutschlands. Aufgrund ihrer erfolgreichen Ausbreitungsstrategie (Wurzelbrut, Stockausschlag, Samen) wird ihr Anteil künftig weiter zunehmen. Entsprechend ihrer ökophysiologischen Amplitude ist die Robinie insbesondere für den Anbau auf nährstoffarmen und trockenen Böden geeignet. Die Bedeutung der Baumart könnte angesichts der prognostizierten Klimaänderungen sowohl für die stoffliche als auch für die energetische Nutzung zunehmen.

Die Anpassungstoleranz der Weichlaubholzarten Weide, Birke und Pappel gegenüber Witterungsextremen ist bisher nur unzureichend untersucht. Als Pionierbaumarten mit hohem Verjüngungspotenzial, hohem Lichtanspruch und schnellem Wachstum besitzen einige Arten eine vergleichsweise hohe Anpassungsfähigkeit. Daher könnte der Anteil dieser Arten nicht nur auf landwirtschaftlichen Energieholzplantagen, sondern auch im Wald ansteigen.

Die künftig zunehmende Bedeutung weiterer wärmeliebender und trockenheitstoleranter Baumarten wird diskutiert. Ein Problem dieser Baumarten ist jedoch die verminderte Frosttoleranz. Auch wenn die Häufigkeit von Frostereignissen künftig abnehmen wird, so ist auch weiterhin mit singulären Winter- und Spätfrösten zu rechnen. Hier müssten frosttolerante Sorten durch Selektionszüchtung gewonnen werden. Bis dahin werden Gehölze dieser Arten ein Nischenprodukt bleiben.

\section{Anpassungsstrategien bei der Waldbewirtschaftung}

Wie eingangs dargestellt, fokussiert sich eine entscheidende Anpassungsstrategie auf die gezielte Förderung bestimmter Baumarten und Herkünfte. Bereits Anfang der 1990er-Jahre begann in Brandenburg das „Waldumbauprogramm“. Ziel des Waldumbaus ist es, gleichaltrige Kiefernreinbestände in strukturreiche Kiefern- 
Laubholz-Mischbestände umzuwandeln. Mit der Diversifizierung von Baumarten sollen die Risiken durch Schadereignisse vermindert werden. Allein die geplante Vermehrung der Eichen(misch)wälder ist eine mehrere Jahrzehnte dauernde Schwerpunktaufgabe.

Die aktuelle Klimadiskussion hat bisher nicht zu einer Veränderung in der Baumartenwahl für die Zielbestockungen des Waldumbaus geführt. Hierfür gibt es mehrere Ursachen: Waldbewirtschaftung ist im Gegensatz zur Landwirtschaft auf langfristige Bewirtschaftungszeiträume ausgerichtet. Langlebige Waldbaumarten weisen aufgrund ihrer in evolutiven Zeiträumen erworbenen physiologischen Anpassungsfähigkeit eine hohe Elastizität gegenüber Umweltveränderungen auf. Angesichts der vorliegenden Klimaszenarien stehen derzeit keine Waldbaumarten für einen großflächigen Anbau zur Verfügung, die besser geeignet sind, Klimaextremereignisse zu überstehen, und damit kurzfristige, tiefgreifende Veränderungen mit langfristigen Folgewirkungen rechtfertigen.

Die Mehrzahl künftiger Bestandszieltypen ist auf Mischwälder ausgerichtet. Dabei sind gruppenweise Mischungen wirtschaftlicher, sicherer und wirksamer als Einzelbaumartenmischungen (Bäucker et al. 2007). Horizontale Mischungsformen gewährleisten die Pufferwirkung beim Zuwachs, mindern die interspezifischen Konkurrenzprobleme und verbessern das Mikroklima. Die Erhaltung von alten und sterbenden Bäumen in Biogruppen fördert die Nischenvielfalt, schafft Lebensräume für zoophage Nützlinge und stabilisiert den Gesamtbestand. Eine rechtzeitige Kronenpflege fördert Zuwachs, Blüte und Samenbildung sowie eine optimierte Wurzelentwicklung.

Die genetische Variabilität ist die entscheidende Sicherheitsreserve bei einer Selektion durch extreme Klimafaktoren (Kätzel 2009). Für die Forstpraxis bedeutet dies ein langfristiges Vorgehen bei der natürlichen Verjüngung von Beständen. Auf der Grundlage von Erfahrungen aus zurückliegenden Störungsereignissen oder ggf. anhand genetischer Inventuren ist zu prüfen, ob reproduzierende Bestände als Saatgutquelle für die natürliche Verjüngung und damit für die Zukunftsfähigkeit der Wälder geeignet sind. Möglicherweise kommt künstlichen Verjüngungsmaßnahmen mit zertifizierten Forstpflanzen aus genetisch charakterisierten Erntebeständen zukünftig eine größere Bedeutung zu. Allerdings ist zunehmend mit Schwankungen in der Saatgutversorgung zu rechnen, da die Saatgutproduktion von Witterungsextremen negativ beeinflusst wird. Dies betrifft insbesondere die kritische Phase der Blütenbildung, Wassermangel in der Reifephase sowie die zunehmende Gefahr von Insektenschäden und Infektionen des Saatgutes. Bei einer künstlichen Verjüngung müssen bereits bei der Saatgutgewinnung alle Maßnahmen berücksichtigt werden, die eine hohe genetische Vielfalt gewährleisten.

Die meisten Ergebnisse aus physiologischen Untersuchungen lassen den Schluss zu, dass die Anpassungsfähigkeit der Waldbäume an jeweils einen Stressfaktor meist höher ist als erwartet. Kritisch wird es dann, wenn zu extremen Klimafaktoren weitere Stressfaktoren wie Insektenfraß, Versauerung, Immissionen, Bodenverdichtung oder Grundwasserabsenkungen hinzukommen. Im Rahmen der Risikovorsorge müssen deshalb zusätzliche Belastungen vermieden werden. So müssten Pflanzenschutzmittel eher oder häufiger appliziert werden als zurzeit üblich (Möller 2009). 
Zusätzliche Schadfaktoren sind überhöhte Schalenwildbestände. Wenn sich im Zuge von Ausleseprozessen stresstolerantere Baumindividuen herausbilden, diese jedoch frühzeitig von Pflanzenfressern oder durch Waldbrand vernichtet werden, sind die biologischen Selbstregulationsprozesse erfolglos.

Um forstwirtschaftliche Risiken und Schäden, die sich aus diesen Veränderungen ergeben könnten, rechtzeitig zu erkennen und gegebenenfalls zu mindern, ist ein modernes forstliches Monitoring mit starkem regionalem Bezug unverzichtbar. Dies gilt sowohl für die Frühindikation von Stressreaktionen als auch für die Erfassung von irreversiblen Schäden (Kätzel \& Kallweit 2008). Um Gefahrenpotenziale früh zu erkennen, müssen genetische und waldwachstumskundliche Reaktionen künftig stärker mit Untersuchungen zu anpassungsrelevanten Merkmalen verbunden werden (Kätzel et al. 2005).

Mit der Häufung von Klimaextremen wird die Notwendigkeit bestehen, die Flexibilität der Waldbewirtschaftung zu erhöhen. Dabei ist die Senkung der Durchmesserzielstärken eine Maßnahme, um die Risiken langfristiger Produktionszeiträume zu mindern. Mit dem zunehmenden Anteil schnellwachsender Pioniergehölze sowie dem vorzeitigen Absterben langlebiger Bäume wird dieser Prozess beschleunigt werden.

Die Verfügbarkeit von Bodenwasser während der Vegetationsperiode wird maßgeblich über Ertrag und Überleben entscheiden. Deshalb muss der Verlust von Wasser über oberirdische Wasserleiter verhindert und die Wasserspeicherung etwa in Waldmooren genutzt werden. Die Einbringung von Laubbaumarten soll auch die Grundwasserneubildung für alle Landnutzungsarten verbessern (Müller et al. 2007).

\section{Schlussfolgerungen}

Klimaänderungen und insbesondere Witterungsextreme sind einschneidende Selektionsfaktoren, die künftig die Waldstruktur mitsamt der Baumartenzusammensetzung regional differenziert verändern werden. Selektiv wirksame Witterungsextreme verschieben auf natürliche Weise Konkurrenzbeziehungen und führen zu „Verlierern“, aber auch zu „Gewinnern“ auf allen ökosystemaren Ebenen. Dies wird sich mittelfristig negativ auf den waldwirtschaftlichen Ertrag auswirken.

Unter dem Gesichtspunkt der physiologischen Überlebensfähigkeit verfügen gerade langlebige Baumarten über effiziente Anpassungsreaktionen gegenüber Witterungsstress. Daher ist aus heutiger Sicht für den Zeitraum der vorgelegten Klimaszenarien bis 2070 nicht davon auszugehen, dass sich im nordostdeutschen Raum das Ökosystem Wald in eine Waldsteppe wandeln wird. Für diesen Zeitraum basieren gegenwärtig alle Empfehlungen zur Baumarteneignung und zum Risikomanagement auf einer gutachtlichen Bewertung. Langfristige Strategien brauchen ein "quantitatives Assessment“ der Anpassungskapazität. Doch bislang fehlt es hier an belastbaren Forschungsergebnissen. 


\title{
Erzeugung und Verbrauch von landwirtschaftlichen Produkten aus Brandenburg in Berlin*
}

\author{
Hans Kögl
}

\section{Einführung und Zielsetzung}

Regionale Nahrungsmittel genießen in der Öffentlichkeit ein positives Image, tragen sie doch mit dazu bei, lange Transportwege zu vermeiden und die natürlichen Ressourcen zu schonen. Welchen Anteil regionale Nahrungsmittel heute am gesamten Nahrungsmittelverbrauch haben, ist allerdings kaum bekannt, weil es sowohl an einer einheitlichen Kennzeichnung als auch an einem einheitlichen Verständnis von Regionalität fehlt. Dies macht es schwierig, gezielt Maßnahmen anzubieten, um den Anteil von regionalen Nahrungsmitteln am gesamten Markt für Lebensmittel zu steigern.

Vor diesem Hintergrund will der vorliegende Beitrag für die Fokusregion BerlinBrandenburg den Anteil der aus dem Land Brandenburg stammenden landwirtschaftlichen Produkte am Berliner Markt für Nahrungsmittel ermitteln, Ursachen einer möglichen regionalen Unterversorgung benennen und Vorschläge zur Steigerung des Verbrauchs von Produkten aus Brandenburg in Berlin unterbreiten.

Grundlage sind wissenschaftliche Studien, Statistiken zur Land- und Ernährungswirtschaft und Interviews mit Marktexperten aus den Metropolregionen Berlin, Hamburg und München. Methodisch kommt hauptsächlich das Konzept der Versorgungsbilanz zur Anwendung, das auch die amtliche Statistik einsetzt, um auf nationaler Ebene den Grad der Versorgung mit einheimischen Nahrungsmitteln zu bestimmen (BLE 2008; BMELV 2009a).

\section{Messung der Versorgungslage von Berlin mit regionalen Nahrungsmitteln}

Die Versorgung Berlins aus dem Brandenburger Umland entspricht insofern dem Verständnis eines ,regionalen Nahrungsmittelsystems“" ${ }^{\text {"1 }}$ als die dafür notwendigen

\footnotetext{
* Der Beitrag basiert auf der Studie „Potenziale der Vermarktung von landwirtschaftlichen Produkten aus Brandenburg in Berlin“, die im Auftrag der interdisziplinären Arbeitsgruppe „Globaler Wandel - Regionaler Wandel“ der Berlin-Brandenburgischen Akademie der Wissenschaften erstellt wurde (Kögl 2010).

${ }^{1}$ Zum Begriff der „Regionalität“" von Nahrungsmitteln siehe Demmeler (2008) und Kögl \& Tietze (2010).
} 
Transportwege nicht über einen Radius von etwa $100 \mathrm{~km}$ zum Berliner Zentrum hinausgehen. Dabei wird hier unterstellt, dass von dieser Fläche auch die Brandenburger Bevölkerung mit zu versorgen ist. Tatsächlich liegen aber über die Herkunft der in dieser Region verbrauchten Nahrungsmittel so gut wie keine statistischen Informationen vor (Gurrath 2008). Rückschlüsse auf die regionale Versorgung Berlins lassen sich höchstens indirekt aus der Entwicklung des Berliner Marktes für Bioprodukte ziehen (Nölting \& Boekmann 2005). Der Zusammenhang dieser beiden Produktkategorien wurde auch in Interviews mit Marktakteuren bestätigt. ${ }^{2}$ Danach läge der Anteil von ausdrücklich als regional bezeichneten Nahrungsmitteln noch deutlich unter dem der Bioprodukte, der für Berlin auf 8 bis $9 \%$ geschätzt wird. Eine Verbesserung der Informationslage könnte durch eine genauere Erhebung der Warenströme zwischen Berlin und dem Brandenburger Umland erreicht werden, wie sie zum Beispiel von Ahnsehl et al. (1996) für die Warenlieferungen aus Mecklenburg-Vorpommern nach Berlin vorgenommen wurde.

Einen Anhaltspunkt für die regionale Versorgung erhält man durch die Bilanzierung von regionalem Aufkommen und regionaler Verwendung von Nahrungsmitteln. ${ }^{3}$ Dabei muss mangels besserer Information unterstellt werden, dass der Nahrungsmittelkonsum der Berliner Bevölkerung dem bundesdeutschen Warenkorb entspricht. ${ }^{4}$ Zur Messung der Produktmengen wird eine Umrechnung in Getreideeinheiten (GE) vorgenommen (Becker 1988), um so eine gemeinsame Bezugsgröße für Erzeugung und Verwendung zu haben.

Addiert man zunächst Erzeugung und Verwendung über alle Produktkategorien zusammen, dann zeigt sich, dass die landwirtschaftlichen Ressourcen Berlin-Brandenburgs (ca. 1,33 Mio. ha) im Mittel der Jahre 2005 bis 2007 ausreichten, um den Gesamtbedarf der ansässigen Bevölkerung (ca. 5,95 Mio. Menschen) zu $93 \%$ zu decken (Abb. 26, erste Säule). Der regionale Versorgungsgrad liegt flächenbedingt geringfügig über dem Bundesdurchschnitt, obgleich die Flächenproduktivität BerlinBrandenburgs (45,9 GE/ha) deutlich niedriger ist als im Bundesdurchschnitt (ca. $62 \mathrm{dt}$ GE/ha; BMELV 2009a: 151). Je Kopf werden somit 0,24 ha landwirtschaftliche Nutzfläche (LF) benötigt. Diese Zahlen beruhen auf den derzeitig üblichen Produktionsstandards und damit auch auf einem nicht unerheblichen Einsatz von fossilen Energieträgern und Wasser. Insofern erhebt sich auch für Brandenburg die Frage, wie sich das regionale Lieferpotenzial verändert, wenn die Intensität der Produktion infolge einer allgemeinen Ressourcenverknappung sinken würde (Grünewald 2010).

Ein methodischer Ansatz zur Berücksichtigung der langfristigen Tragfähigkeit der natürlichen Ressourcen ist der „ökologische Fußabdruck“ (Wackernagel \& Rees 1997), der ebenfalls das Konsumniveau einer Gesellschaft anhand des Flächenverbrauchs misst. Für München berechnet Treffny (2003) je Kopf der Bevölkerung ei-

\footnotetext{
2 Die Interviews wurden Anfang des Jahres 2010 mit pro agro, der Berliner Firma Perschke, F. Schreiber, vormals BioCompany, und dem Bayrischen Bauernverband geführt.

3 Wegen fehlender Angaben zum überregionalen Handel, zu Bestandsveränderungen usw. kann nicht der Genauigkeitsgrad der amtlichen Versorgungsbilanzen erreicht werden.

${ }^{4}$ Der Warenkorb wird hier noch um die Produktgruppen reduziert, die in Deutschland aus klimatischen Gründen nicht erzeugt werden können.
} 


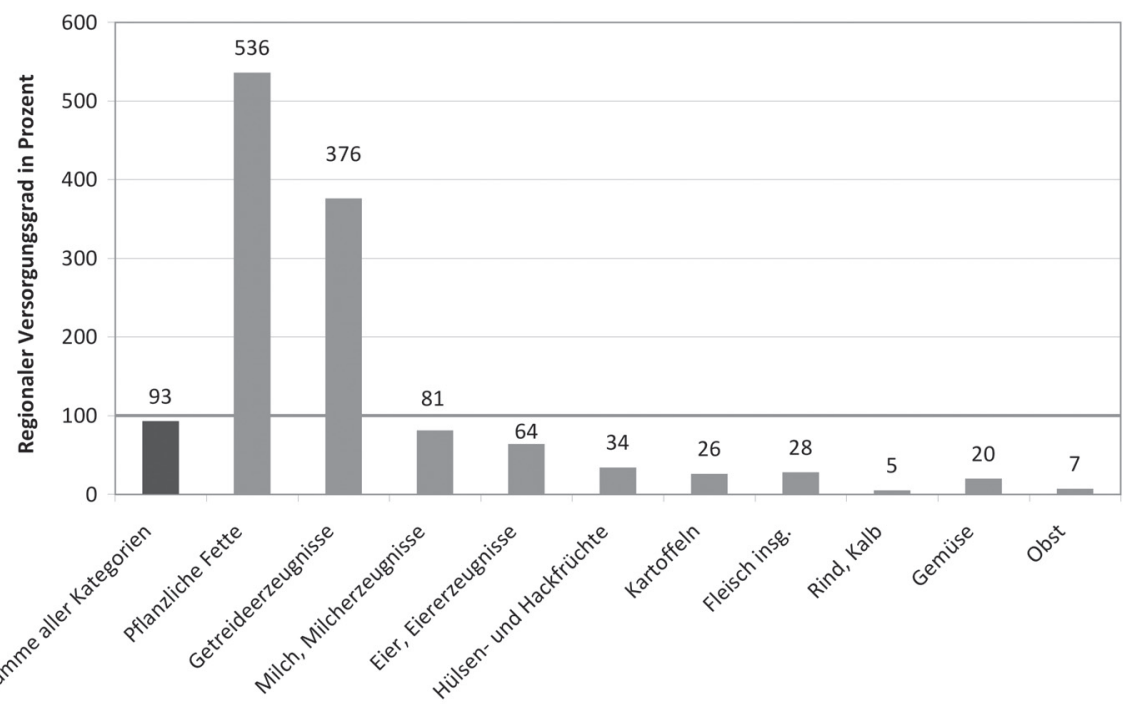

Abb. 26. Erzeugung und Verbrauch der wichtigsten Nahrungsmittel in Berlin-Brandenburg, gemessen durch den regionalen Selbstversorgungsgrad (Quelle: Amt für Statistik Berlin Brandenburg und eigene Berechnungen)

nen Flächenbedarf für Ernährung von 0,81 ha; für die Berliner Bevölkerung ermittelt Schnauss (2001) einen Flächenbedarf von 1,66 ha je Kopf. Die beachtlichen Unterschiede zwischen den Flächenbedarfswerten von Berlin und München einerseits und zwischen den hier für Berlin genannten Zahlen (0,24 und 1,66 ha LF) andererseits sind sicherlich auf die unterschiedliche Methodik der Verbrauchserfassung und auf den Einfluss der Flächenproduktivität auf den Flächenbedarf zurückzuführen.

Eine tiefere Einsicht in das Versorgungspotenzial von Berlin-Brandenburg erhält man, wenn man regionale Erzeugung und Verbrauch gesondert nach Produktkategorien gegenüberstellt.

Diese Selbstversorgungsgrade stellen die Obergrenze für die regionale Versorgung dar. Während bei Getreide und pflanzlichen Ölen und Fetten hohe Überschüsse zu erkennen sind (Selbstversorgungsgrade $>300 \%$ ), liegt gerade bei denjenigen Produkten, die gemeinhin als besonders attraktiv für die regionale Vermarktung gelten, also frische und häufig auch wenig verarbeitete Nahrungsmittel (vgl. Kögl \& Tietze 2010), eine deutliche regionale Unterversorgung vor.

\section{Ursachen für eine mögliche Unterversorgung mit regionalen Nahrungsmitteln in Berlin}

Die Ursachen für die teilweise Unterversorgung können grundsätzlich auf allen Abschnitten des Weges liegen, den die Produkte vom Erzeuger bis zum Verbraucher zurücklegen. Diese Abschnitte lassen sich vereinfachend unterteilen in Erzeugung, Verarbeitung und Handel. 


\section{Hemmnisse auf der Erzeugerstufe}

Auf der Erzeugerstufe fällt Brandenburg nicht nur durch eine unterdurchschnittliche Bodenproduktivität auf, sondern auch durch eine um $45 \%$ geringere monetäre Wertschöpfung je Hektar (Statistische Ämter des Bundes und der Länder 2009). Daraus auf einen allgemeinen wirtschaftlichen Nachteil der Landwirtschaft in Berlin-Brandenburg zu schließen wäre jedoch verfehlt, wie ein Blick auf die einzelbetrieblichen Erfolgszahlen in der Tabelle 9 zeigt. Denn nur in Brandenburg und den übrigen neuen Bundesländern erreichten die landwirtschaftlichen Betriebe im Landesdurchschnitt der Jahre 2007 bis 2009 eine Nettowertschöpfung, die alle eingesetzten Produktionsfaktoren entlohnen kann (Wertschöpfungsrentabilität $>100 \%$ ). Die wirtschaftlich überdurchschnittlich gute Lage der Brandenburger Betriebe wird auch durch die übrigen Zahlen der Tabelle bestätigt.

Tabelle 9. Vergleich von Kennzahlen landwirtschaftlicher Haupterwerbsbetriebe im Durchschnitt aller Betriebsformen und Größenklassen (Quelle: BMELV 2009b, Ergebnisse der Testbetriebe nach Bundesländern).

\begin{tabular}{lrr}
\hline Kennzahl & Brandenburg & Deutschland \\
\hline Gesamtkapitalrentabilität [\%] & 4,6 & 0,6 \\
Eigenkapitalrentabilität [\%] & 5,9 & $-0,1$ \\
Gesamtarbeitsertrag [€/AK] & 24.228 & 14.591 \\
Betriebseinkommen [€] & 109.633 & 62.128 \\
Wertschöpfungsrentabilität [\%] & 105,0 & 75,8 \\
\hline
\end{tabular}

Die Entscheidungen für das derzeit angebotene Sortiment - das sind vor allem arbeitsextensive Kulturen wie Getreide und Ölsaaten und vertikal integrierbare Produkte wie Eier und Geflügel - waren somit für den durchschnittlichen Erzeuger in Brandenburg auch wirtschaftlich sinnvoll. Diese Produktpalette erleichtert es ihm offensichtlich, sich in der Produktion zu spezialisieren, ökonomische Skaleneffekte auszuschöpfen und in Zusammenarbeit mit der ersten Verarbeitungsstufe und dem Erfassungshandel die absatzwirtschaftlichen Aufgaben effizient und risikomindernd zu lösen. ${ }^{5}$

Diese Beobachtungen und Überlegungen lassen den Schluss zu, dass in Brandenburg derzeit von der Erzeugerebene wohl keine starken Impulse ausgehen, die in Zukunft ein verstärktes Angebot an regionalen Produkten auf dem Berliner Markt erwarten lassen.

\footnotetext{
5 Ein zusätzliches Risiko dürften auch hier die langfristigen Klimaveränderungen in Brandenburg bedeuten (vgl. dazu Grünewald 2010), die gerade im intensiven Gemüseanbau die Kosten der Wasserversorgung erhöhen werden; die erforderlichen Investitionen dafür sind so hoch, dass sie kaum von einem einzelnen Betrieb geleistet werden können.
} 


\section{Hemmnisse auf der Verarbeitungsstufe}

Der Hintergrund der Ernährungswirtschaft in Berlin-Brandenburg kann in aller Kürze wie folgt charakterisiert werden:

- unterdurchschnittliche Industriedichte in Brandenburg gegenüber dem Bundesgebiet (MWE 2009),

- abnehmende Zahl der Betriebe im Verarbeitenden Gewerbe bei steigendem Umsatz je Unternehmen (Amt für Statistik Berlin Brandenburg),

- relativ hoher Anteil an Verarbeitungsbetrieben für die „typischen“ Regionalprodukte: Back- und Dauerwaren $44 \%$, Fleischer $25 \%$, Obst, Gemüse und Säfte $5 \%$ (Amt für Statistik Berlin Brandenburg)

Welche Rolle die Ernährungswirtschaft Berlin-Brandenburgs im Kontext eines verstärkten Angebots an regionalen Produkten auf dem Berliner Markt spielt, ist im Rahmen dieses Beitrags nicht leicht zu beurteilen (vgl. auch Schubert 2007: 13-16). Eine Ursache dafür ist die, verglichen mit der Erzeugerstufe, deutlich schlechtere Datenlage (MWE 2009). Von den befragten Akteuren wurden auch keine für regionale Produkte spezifischen Defizite herausgestellt, außer einer etwas geringen Innovationsneigung. Aus der politischen Perspektive kann die Situation des Ernährungsgewerbes in Brandenburg als gut bezeichnet werden, da es eines der 16 Branchenkompetenzfelder des Landes Brandenburg ist (MWE 2009). Negative Tendenzen können aber dadurch entstehen, dass auf der ersten Verarbeitungsstufe (z.B. Schlachtung, Vermahlung und teilweise auch Molkereien) kostenbedingt mit einer weiteren Unternehmenskonzentration und damit unter Umständen auch mit einer weiteren Ausdünnung der Betriebsstandorte zu rechnen ist (vgl. dazu BMELV 2009a: 294-296). Abhilfe kann, von staatlichen Eingriffen abgesehen, eine Steigerung der regionalen Produktionsmengen schaffen, was der Industrie die Ausschöpfung von größenbedingten Kostenvorteilen erlaubt, oder der Umstieg auf kleinere, qualitätsorientierte Verarbeitungseinheiten, die sogenannten Manufakturen.

\section{Hemmnisse auf der Handelsstufe}

Ein wesentliches Kennzeichen des Handels mit Nahrungsmitteln ist die zunehmende Konzentration des Einkaufs in Supermärkten und Discountgeschäften (BMELV 2009a: 304, 308; Schubert 2007: 17-20), auf die heute fast $80 \%$ des gesamten Umsatzes an Lebensmitteln entfallen. Diese Entwicklung hat auch das Bio-Segment nicht verschont und dürfte ebenso für den Absatz von Produkten mit regional definierter Herkunft von Bedeutung sein. Bei der Untersuchung von Hemmfaktoren auf der Handelsstufe ist es sinnvoll, zwischen verschiedenen Vermarktungskonzepten zu unterscheiden:

- regionale Nahrungsmittelversorgung als historisch gewachsenes Konzept, das auch heute noch in Form von Direktvermarktung auf dem Hof oder dem Wochenmarkt existiert, 
- regionale Nahrungsmittelvermarktung durch den Lebensmitteleinzelhandel, was ein gezieltes Marketing voraussetzt, damit die Produkte im großen Angebot auch als „regional“" wahrgenommen werden,

- regionale Spezialitäten im Absatz über den Naturkostfachhandel oder andere ausgewählte Vertriebskanäle, die vom Konsumenten besonders positiv eingeschätzt werden.

Von diesen Vermarktungskonzepten sollten in Zukunft sowohl der Absatz von regionalen Produkten über den Lebensmitteleinzelhandel als auch die Direktvermarktung über den Wochenmarkt weiter verfolgt werden. So ist im Berliner Einzelhandel bereits jetzt die Regionalmarke „Von hier“ erhältlich (Kögl \& Tietze 2010). Hochpreisige regionale Spezialitäten stellen eine besondere Herausforderung dar, deren Realisierungschancen nur bei genauer Marktkenntnis beurteilt werden können. Ohnehin fallen, entsprechend den Kriterien der EU, bisher nur drei Produkte aus Brandenburg in diese Kategorie (EU-KOM 2010). Das sind die mit dem Label „geschützte geographische Angabe“" (g. g. A.) versehenen Produkte wie z. B. Spreewaldgurken. Die beiden zuerst genannten Konzepte erfordern aber offensichtlich ein höheres $\mathrm{Ma} ß$ an Koordination und Professionalität, als es bisher von einzelnen Anbietern und Händlern geleistet werden konnte. Bedenkt man die nicht geringen geographischen Distanzen vom Berliner Umland bis ins Zentrum und die von den befragten Experten genannte zu große Fragmentierung des regionalen Angebotes, dann sollte auch der Großhandel an einer Neustrukturierung der Absatzwege beteiligt werden. $\mathrm{Ob}$ dazu auch eine Bündelung des regionalen Angebotes in Form einer Erzeugergemeinschaft am Berliner Großmarkt nützlich wäre, müsste mit Marktexperten besprochen werden.

\section{Steigerung der Versorgung des Berliner Marktes mit Produkten aus Brandenburg}

Die regionale Unterversorgung von Berlin mit Obst, Gemüse, Kartoffeln und Fleisch kann in erster Linie durch die, verglichen mit dem arbeitsextensivem Ackerbau, relativ schlechte betriebswirtschaftliche Bewertung dieser Produkte durch die Brandenburger Landwirte erklärt werden. Weitere Nachteile dürften im RisikoChancenverhältnis dieser Produkte liegen, das die Erzeuger offensichtlich davon abhält, in diese Märkte einzutreten. Vergleiche mit Hamburg und München legen nahe, auf mittlere Sicht die möglichen Verbundeffekte von regionalen Wertschöpfungsketten stärker zu nutzen, was eine engere Kooperation zwischen Erzeugern, Verarbeitern und dem Handel erfordert. An diesen Kooperationen kann sich auch die Stadt Berlin beteiligen, indem sie die Infrastruktur für den innerstädtischen Absatz regionaler Produkte auf Groß- und Wochenmärkten so verbessert, dass diese Einrichtungen dem Verbraucher einen ähnlichen Service leisten, wie sie ihn von den großen Verbrauchermärkten gewohnt sind. Welchen Beitrag auf längere Sicht technische Fortschritte in der Produktion leisten könnten, z. B. Einsparungen an Wasser und an fossiler Energie, um eine betriebswirtschaftliche Neubewertung der in Frage 
stehenden Produkte durch die Landwirte herbeizuführen, müsste produktspezifisch noch näher untersucht werden.

Da Preisvorteile von Regionalprodukten gegenüber global gehandelten Produkten auch in Zukunft eher nicht zu erwarten sind, sollten die Verbraucher vermehrt durch eine auf Produktqualität ausgerichtete Strategie gewonnen werden. Es ist die Aufgabe der Akteure entlang der Wertschöpfungskette, aus dem breiten Spektrum des Marketingmixes diejenigen Maßnahmen auszuwählen, die dem Verbraucher die besonderen Produkt- und Qualitätseigenschaften regionaler Nahrungsmittel am besten vermitteln. 


\section{Neue Entwicklungen in der Pflanzenzüchtung und System- betrachtungen der Pflanze-Umwelt-Interaktion}

Inge Broer, Reiner Brunsch

\section{Die landwirtschaftliche Situation in Berlin-Brandenburg}

Das Land Brandenburg hat eine sehr intensive Beziehung zum Wasser: Einerseits verfügt es über $33.000 \mathrm{~km}$ Fließgewässer und 3.000 Seen und viele naturnahe Gewässerlandschaften. Erst die Be- oder Entwässerung durch großflächige Meliorationen (Landaufwertungsmaßnahmen) führte dazu, dass viele Gebiete landwirtschaftlich genutzt werden konnten. Andererseits ist der Wasserhaushalt mit Jahresniederschlägen um $600 \mathrm{~mm} / \mathrm{Jahr}$ (Lischeid 2010) angespannt. Die Landwirtschaft muss zwischen einem Wasserüberangebot wie bei der Oderflut 1997 oder dem Hochwasser im Mai 2010 und extremer Trockenheit einen Weg zu einer nachhaltigen Produktion finden. Diese Extreme sollen sich nach aktuellen Klimastudien (vgl. Kapitel I) in Zukunft noch weiter verstärken. Für Brandenburg wird erwartet, dass zum einen die Winter milder und die Sommer heißer werden und zum anderen die Niederschläge regional weiter zurückgehen. Dies kann in einigen Bereichen, besonders auf den weniger fruchtbaren Flächen, die heute hauptsächlich zur Getreideproduktion eingesetzt werden, zu einer erheblichen Ertragsminderung führen, die eine herkömmliche Nutzung dieser Flächen möglicherweise unwirtschaftlich macht. Zugleich konzentriert sich die landwirtschaftliche Produktion im Wesentlichen auf Getreide (vgl. Kögl, S. 122-128), das exportiert wird, und vernachlässigt die Produktion von regional stark nachgefragten Produkten wie Tomaten oder Paprika. Regionale Märkte werden nicht bedient, weil der Anbau von Gemüse und Kartoffeln hohe Investitionen erfordern würde, aber der Absatz nicht ausreichend gesichert ist.

Die Konzipierung einer nachhaltigen Landnutzung unter diesen klimatischen Extremen und starken ökonomischen Zwängen erfordert neue Wege. Erforderlich sind die Verlagerung von Schwerpunkten zwischen Pflanzen- und Tierproduktion, andere Produktionsweisen wie etwa der pfluglose Anbau, innovative Bewässerungssysteme und die gezielte Auswahl von Kulturarten. Die Landwirtschaft, aber auch ihre Produkte wie Tier und Pflanze selbst, müssen flexibel auf sich ändernde Umweltbedingungen und Märkte reagieren können. 


\section{Lösungsansätze}

\section{Anpassung der Nutzpflanzen an wechselnde Umweltbedingungen durch Pflanzenzucht}

Die Anpassung des Pflanzenbaus an die wechselnden Umweltbedingungen erfordert neben Änderungen bei Fruchtfolge und Anbauverfahren den Einsatz von angepassten Kulturarten. Bereits die gegenwärtigen Klimabedingungen wie lange Dürre- oder Hitzeperioden sind eine große Herausforderung für die weltweite Pflanzenproduktion, weil sie das Pflanzenwachstum und den Ertrag vermindern. Die geschätzten jährlichen Verluste gehen in die Millarden (Boyer 1982; Mittler 2006). Die Pflanzen müssen also in der Lage sein, auch bei einem geringen oder sehr stark wechselnden Wasserangebot ähnlich hohe Erträge wie unter Normalbedingungen zu liefern. Eine solche Trockentoleranz kann durch die Optimierung der Wasseraufnahme und durch eine hohe Wassernutzungseffizienz erreicht werden. Die Aufnahme von Wasser erfolgt über die Wurzelsysteme der Pflanzen, die sehr unterschiedlich ausgeprägt sein können. Die Architektur der Wurzel beeinflusst die Effektivität der Wasser- und damit auch der Nährstoffaufnahme z.B. durch die Tiefe, in die die Wurzeln vordringen, um Wasser aus dem Unterboden aufzunehmen, oder durch die Ausbreitung im Oberboden, wo das Wasser nach Regenfällen schneller zur Verfügung steht, es aber auch schneller zu Austrocknungen kommt. Die beste Wasseraufnahme leisten also Wurzelsysteme, die in der Lage sind, die stabileren Wasservorkommen im Unterboden sowie die variablen Wässer im Oberboden auszunutzen. Ebenso bedeutend ist es, die Verdunstung von Wasser so weit wie möglich zu reduzieren, ohne dabei den Transpirationssog und damit die Wasseraufnahme zu schwächen. Aber auch die Verbesserung der Fähigkeit der Pflanzen, Austrocknungen zu vermeiden oder zu überstehen, kann zu einer Erhöhung der Biomasse auf trockenen Standorten beitragen. Diesen Zielen widmet sich die Pflanzenzüchtung seit Jahren. Durch die Identifizierung von sogenannten quantitativ trait loci (QTL) für Trockentoleranzen wird mithilfe der Molekularbiologie versucht, geeignete Kreuzungspartner für eine klassische Züchtung z.B. trockentoleranter Sorten zu finden. Studien an der Modellpflanze Arabidopsis thaliana (Acker-Schmalwand), aber auch an sogenannten Wiederauferstehungspflanzen wie der „Rose von Jericho“ haben dazu beigetragen, Gene zu identifizieren, die an einer Trockentoleranz beteiligt sind. Mittels der Gentechnik können diese Gene auch auf Kulturpflanzen übertragen werden. Bisher erfolgte dies aber nur in geringem Umfang, weil die meisten von ihnen nur eine geringe Steigerung der Trockentoleranz bewirkten (Bartels \& Phillips 2010).

In Anbetracht der zu erwartenden Extreme ist aber nicht nur die Trockentoleranz von Bedeutung. Auch ein Übermaß an Wasser bedeutet Stress für die Pflanzen. Des Weiteren wird im Zuge des Klimawandels das verstärkte Auftreten von Schädlingen erwartet, die unter den bisherigen klimatischen Bedingungen in Brandenburg kein Problem darstellten (Weigel 2005). Auch bereits vorhandene Schaderreger können an den durch den abiotischen Stress geschwächten Pflanzen größere Schäden als bisher hervorrufen. Eine Anbaufläche stellt eine komplexe Umwelt dar, die sich durch sehr heterogene Bedingungen und Kombinationen von verschiedenen abioti- 
schen und biotischen Stressfaktoren auszeichnet. Der globale Klimawandel könnte diese Komplexität noch verstärken. Möglicherweise ist eine Kombination von unterschiedlichen Ansätzen notwendig, um eine wirklich stresstolerante Kulturpflanze zu erzeugen (Mittler \& Blumwald 2010). Die Pflanzenzüchtung muss also mit allen ihr zur Verfügung stehenden Mitteln versuchen, angepasste Sorten zu entwickeln, die auch unter den zu erwartenden Bedingungen hohe Erträge sicherstellen.

\section{Verbesserung der Landnutzung durch optimierte Fruchtfolgen}

Die Möglichkeiten zur Gestaltung von standortgerechten und rentablen Fruchtfolgen haben sich in der jüngsten Vergangenheit sowohl durch agrarpolitische Rahmenbedingungen (Förderpolitik der EU) als auch durch die Veränderungen des Markts erheblich verbessert. So wird bis 2013 schrittweise eine einheitliche Flächenprämie für Acker- und Grünland realisiert. Die früheren Kulturartenprämien wurden zum 1. Januar 2005 ,entkoppelt“", das heißt in von der Frucht unabhängige Flächenprämien umgewandelt, und durch Cross Compliance, also die Einhaltung anderweitiger Verpflichtungen wie etwa Umweltstandards, gebunden an 19 europäische Rechtsvorschriften, die Grundanforderungen an die Betriebsführung in den Bereichen Umwelt, Lebensmittelsicherheit, Tiergesundheit und Tierschutz definieren, sowie an die Erhaltung der landwirtschaftlichen Nutzfläche in gutem landwirtschaftlichen und ökologischen Zustand.

Die Öffnung der Weltagrarmärkte im Rahmen der GATT-Verhandlungen führte zu erhöhtem Kostendruck, dem in der Regel durch Spezialisierung auf wenige (gut bekannte) Fruchtarten begegnet wird. Im gleichen Zeitraum wandelte sich der Markt für Agrarprodukte. So führte das Gesetz über den Vorrang erneuerbarer Energien vom 29. März 2000 und seine Folgegesetze zu einem massiven Anstieg der Erzeugung von Energie aus Biomasse und erreichte im Jahr 2009 eine insgesamt installierte elektrische Leistung von 1893 MW (Fachverband Biogas 2010, Stand 07/2010). 90 \% der Biogasanlagenbetreiber nutzen Mais als Substrat (Pellmeyer 2010). Mais - als eine das Landschaftsbild dominierende, humuszehrende Monokultur - steht in der Kritik und dadurch auch die Energieerzeugung aus pflanzlicher Biomasse. Dass es Alternativen zum Mais gibt, machen aktuelle Forschungsergebnisse deutlich. Ein mehrjähriges Projekt eines nationalen Forschungsverbundes befasste sich mit Anbausystemen für Energiepflanzen zur Biogaserzeugung und bietet standortdifferenziert effiziente Lösungen an, die Alternativen zum Silomais bilden (Vetter et al. 2009).

Neben den Nahrungs- und Energiepflanzen sind noch die sogenannten Industriepflanzen als mögliche Alternative zu berücksichtigen, aus denen beispielsweise Rohstoffe für die chemische Industrie gewonnen werden können. Diese Pflanzen können sowohl aus der Sicht der Wertschöpfung als auch für die Diversifizierung der Kulturen interessant sein. Somit verbreiterte sich das Nachfragespektrum insgesamt, und der Landwirt kann eine für seinen Betrieb nützliche Fruchtfolge erarbeiten. Die Erfahrung vergangener Generationen hat dabei noch immer Bestand: „Am wichtigsten ist die Auswahl unter den zu bauenden Pflanzen, die richtige Auf- 
einanderfolge der ausgewählten bietet keine Schwierigkeit mehr. Zuerst muss man alle Pflanzen ausscheiden, welche unter dem herrschenden Klima nicht sicher gedeihen; dann die, welche bei dem Boden im gegebenen Kulturzustand nicht lohnen; die, welche nach den Markt- und Handelsverhältnissen nicht vorteilhaft erscheinen; endlich die, von welchen man bei der gewählten Einrichtung des Betriebes keinen Gebrauch machen kann oder will. Von dem Rest wählt man die aus, welche frische Düngung lieben oder verlangen; sie stehen an der Spitze; die anderen folgen möglichst so, daß Halm-, Blatt-, Wurzelfrüchte sich ablösen, und so, daß zwischen Ernte und Saat genügend Zeit zur Bearbeitung des Feldes gegeben ist" (Meyers Konversationslexikon 1888).

Diese so einfach klingende Empfehlung umzusetzen erfordert umfangreiches Wissen. Für Deutschland werden beispielsweise 84 Nutzpflanzenarten, die sich noch in Unterarten und Sorten untergliedern, beschrieben (Körber-Grohne 1995), und es existiert eine große Vielfalt in den standörtlichen Gegebenheiten. Dies führt bei den Landwirten aber auch zu neuen Fragestellungen bezüglich der Bedeutung „,neuer" Pflanzenarten in einer bekannten Fruchtfolge. Nährstoffbedarf, -erschlieBung und Auswirkungen auf den Humusgehalt sind nur einige Beispiele für das erforderliche Wissen, dass beim Landwirt vorliegen muss, damit er die Bewirtschaftung ganz im Sinne einer nachhaltigen Landnutzung und in Übereinstimmung mit den oben genannten Verpflichtungen aus der Cross Compliance durchführen kann.

Die standortangepasste Fruchtfolgegestaltung bedarf aufgrund ihrer Komplexität in Forschung und Beratung weitaus stärkerer Aufmerksamkeit, um einen Beitrag zum sparsamen Umgang mit Betriebsmitteln, zur Sicherung der Bodenfruchtbarkeit und zur Verbesserung der Biodiversität zu leisten.

\section{Verbesserung der Landnutzung durch angepasste Anbauformen}

Ein wichtiges Ziel für eine nachhaltige Landnutzung ist die lokale Vermarktung von einheimischen Produkten. Besonders geeignet sind schnell verderbliche Waren wie Milchprodukte und Gemüse, die einen gekühlten und damit energieaufwändigen Transport erfordern. Dennoch liegt der Anteil der lokalen Vermarktung von Gemüse in Brandenburg bei unter 30 \% (Kögl \& Tietze 2010).

Die beliebtesten Gemüse sind nach Angaben der CMA (2003) Tomaten mit 1094 kg/100 Haushalte, Möhren mit 754 kg/100 Haushalte, Gurken mit 736 kg/100 Haushalte und Paprika mit $590 \mathrm{~kg} / 100$ Haushalte. Erstaunlicherweise wird dieser Markt maßgeblich von niederländischen Betrieben bedient. Dort werden Tomaten und Paprika nicht im Freiland angebaut, sondern in Gewächshäusern von mehr als einem Hektar Fläche. Diese Häuser erlauben ein kontrolliertes Klima und die Begasung mit $\mathrm{CO}_{2}$. Im Sommer fordern sie zwar eine energieintensive Kühlung, speichern aber auch die Wärme für den Winter. In den Niederlanden wird intensiv an neuen Verfahren zur Verbesserung der Energieeffizienz gearbeitet. Die Gemüse wachsen häufig in hydroponischen Kulturen. Das Grundmaterial ist in der Regel Steinwolle, die mit einer durchlaufenden Nährlösung versetzt wird. Die Pflanzen wachsen über mehrere Meter in die Höhe. Auf diese Weise ist eine ganzjährige Produktion mit 
22 \% höheren Erträgen, 30 \% Energieersparnis, 80 \% weniger Einsatz von Agrochemikalien und $50 \%$ weniger Wasser möglich (Nederhoff 2006). In halbgeschlossenen Gewächshäusern kann die $\mathrm{CO}_{2}$-Konzentration dauerhaft auf beispielsweise $500 \mathrm{ppm}$ gesteigert werden, was zu Ertragssteigerungen um $22 \%$ auf $56 \mathrm{~kg} / \mathrm{m}^{2}$ Tomaten im Vergleich zu konventionellen Gewächshäusern führt (de Gelder et al. 2004).

Als nachhaltig können diese Entwicklungen aber nur bezeichnet werden, wenn sie in Relation zum Ertrag auch einen geringeren Energieaufwand und vertretbare Investitionskosten bedeuten und für den Landwirt ein überschaubarer und konstanter Absatzmarkt vorhanden ist. Wenn Gewächshäuser ganzjährig und mit fossilen Energieträgern betrieben werden, können sie einen signifikanten Beitrag zur $\mathrm{CO}_{2}$-Emission der Landwirtschaft leisten (6514 $\mathrm{kg} \mathrm{CO}_{2}$-eq/ für $1000 \mathrm{~kg}$ Tomaten). Dabei weisen Tomaten mit 127.32 GJha ${ }^{-1}$ nach Gurken den zweithöchsten Energiebedarf auf (Ozkan et al. 2004). Die steigenden Erdölpreise halten Landwirte daher auch von der Gewächshausproduktion ab (Pena 2005). Es ist also notwendig, den Energiebedarf der Gewächshäuser drastisch zu senken und gleichzeitig alternative Energiequellen zu nutzen.

Mögliche Lösungsansätze sind:

- maximale Nutzung der Sonnenenergie (z.B. durch hohe Lichtdurchlässigkeit, Nutzung der nicht photosynthetisch aktiven Strahlung für die Photovoltaik, Speicherung der Wärme, Erdwärme),

- Reduktion des Energiegebrauchs (z. B. durch Isolierung, Kühlung durch natürliche Ventilation),

- effizienter Energiegebrauch (z. B. durch hohe Feuchtigkeit, reduzierte Transpiration),

- Ersatz von fossilen Brennstoffen (z. B. durch Biogas, Holz, Wind, Geothermie).

Vor diesem Hintergrund stellt sich die Frage, ob Gewächshäuser nach dem niederländischen Beispiel eine Zukunftsoption für magere und trockene Böden in Brandenburg sein könnten, die infolge des Klimawandels nicht mehr nachhaltig zur Getreideproduktion taugen. Dafür sind an die Gewächshäuser folgende Anforderungen zu stellen:

- Nutzung der nicht für die Photosynthese einsetzbaren Sonnenenergie für die Produktion von Strom (Solartechnik) und Wärme,

- Reduktion des Kühlungsbedarfs im Sommer und der Heizenergie im Winter durch effiziente Wärmespeicherung,

- Feuchtigkeitsregulierung bei minimaler Lüftung,

- effiziente Verwertung von in industriellen Prozessen anfallendem $\mathrm{CO}_{2}$ zur Begasung,

- Kultivierung der Pflanzen in Steinwolle, die kontinuierlich mit Nährlösung und $\mathrm{O}_{2}$ versorgt wird, über mehrere Meter Höhe, für zwölf Monate im Jahr,

- Verwertung der abfallenden Biomasse in Biogasanlagen.

Gleichzeitig sind die Züchtung geeigneter Sorten (Zuchtziele: Temperaturtoleranz, Luftfeuchtetoleranz, Geschmack, Konsistenz, Ertrag), effiziente Sonnenenergiemodule und die geschickte Verbindung mit anderen Produktionssystemen wie der 
Tierproduktion $\left(\mathrm{CO}_{2}\right.$, Biogasanlagen) und industrielle Anlagen erforderlich, um ein solches System nachhaltig zu gestalten. Derzeit arbeitet ein Verbundforschungsprojekt daran, technische und kulturtechnische Innovationen in einem Gewächshaus zusammenzuführen, aus dessen Betrieb keine $\mathrm{CO}_{2}$-Emissionen durch fossile Energieträger entstehen ${ }^{1}$.

Auch diese optimierten Systeme sehen sich einer Reihe von Hemmnissen gegenüber, die aber über gesellschaftliche Prozesse überwunden werden könnten. Zum einen ist der Markt bereits besetzt, entweder müssten also die gegenwärtigen Preise unterboten oder das Kaufverhalten in Richtung Regionalprodukt gesteuert werden. Des Weiteren vermindern die enorme Höhe der Investitionskosten und die dauerhafte Festlegung der Flächen die Flexibilität der Landwirte, die außerdem im Vergleich zu den niederländischen Produzenten durch die geringe Erfahrung mit Gewächshausanbau benachteiligt sind. Es bleibt auch abzuwarten, inwieweit die Bevölkerung die Errichtung großflächiger Gewächshäuser in ihrer Umgebung akzeptiert.

Dennoch kann die ganzjährige Produktion von Gemüse wie Tomaten und Paprika in Brandenburg eine nachhaltige Alternative zum Anbau von Getreide auf marginalen Flächen sein, weil sie eine umweltfreundliche, wasser- und flächen-extensive Herstellung von landwirtschaftlichen Produkten erlaubt, die auf dem lokalen Markt stark nachgefragt sind. Hierbei sind jedoch noch zahlreiche Voraussetzungen zu erfüllen und Hemmnisse zu beseitigen, bevor eine solche Technologie in Brandenburg in größerem Maßstab zum Einsatz kommen kann.

\section{Fazit}

Sich verändernde Umweltbedingungen erfordern Anpassungen bei den landwirtschaftlichen Produktionssystemen. Die Anpassungen können am wirksamsten im Gesamtsystem umgesetzt werden. Dazu sind jedoch Expertisen und Entwicklungsarbeiten einzelner Fachdisziplinen nötig, die in einem disziplinenübergreifenden Diskurs zu neuen Systemlösungen führen. Die Verknüpfung mit den konkreten Erfahrungen und Bedingungen in der landwirtschaftlichen Praxis führt zu transdisziplinären Lösungsvorschlägen mit hohem Umsetzungspotenzial. Die züchterische Weiterentwicklung von Pflanzengenomen ist dabei ebenso bedeutsam wie die standortgerechte Fruchtfolgegestaltung oder eine gezielte Gestaltung von Produktionsumwelten, etwa in weitgehend geschlossenen Systemen wie Gewächshäusern.

\footnotetext{
${ }^{1}$ Vgl. http://www.zineg.de
} 


\section{Kernaussagen}

Inge Broer, Alfred Pühler, Mihaiela Rus

\section{Herausforderungen im Zuge des Landnutzungswandels}

Der globale Wandel wirkt sich auf die Landschaft in ihrer Funktion als Wirtschaftsund Kulturraum aus. Ihre Veränderungen stellen neue Herausforderungen für die Nutzung und den Schutz der natürlichen Ressourcen, speziell der Wasserressourcen dar. Obwohl die wirtschaftliche Nutzung des ländlichen Raums und die Kulturlandschaftsentwicklung sich gegenseitig stark beeinflussen, sollen die beiden Bereiche zunächst getrennt betrachtet werden.

\section{Landschaft als Wirtschaftsraum}

Triebkräfte des Wandels in der wirtschaftlichen Landnutzung sind die zunehmende Marktintegration in Entwicklungsländern, die internationale Liberalisierung und Ausweitung der Märkte, der Einfluss von Informationstechnologien und Kommunikationsnetzwerken und Fortschritte im Transport. Dies führt zur Erhöhung der makroökonomischen Verwundbarkeit einzelner Staaten und zu Veränderungen im sozialen Gefüge der Regionen. Folge des Wandels sind vielfältige positive, aber auch negative Effekte auf ökonomischer und sozialer Ebene, die in einer Stärkung der Position der WTO münden, aber auch in einer Reduktion der Grenzen zwischen Systemen und damit einhergehend einer Reduktion der Diversität der Wirtschaftssysteme. Diversität kann im Fall des Scheiterns eines Systems Alternativen bieten, die jedoch im Zuge einer wachsenden Angleichung der Systeme verringert werden. Eine wesentliche Folge dieses Wandels für die Fokusregion ist die Zunahme von Unsicherheit. Der positive Effekt des mit dem Wandel verbundenen Preisanstiegs landwirtschaftlicher Produkte wird durch den Anstieg von Betriebskosten und Bodenpreisen reduziert. Die Kalkulation wird für den Landwirt durch zahlreiche Faktoren, die die Unsicherheit vergrößern, erschwert. Durch multiple Kräfte des globalen Marktes schwanken die Preise zum Teil erheblich und in kurzen Intervallen. Diese Schwankungen werden zurzeit nur durch lokale Protektionen reduziert. Die globale Vernetzung wirkt sich auch auf die Verfügbarkeit von Saisonarbeitern aus, die fast ein Drittel der in der Region in der Landwirtschaft Beschäftigten ausmachen. Die ungleichmäßige Entwicklung der Löhne in den einzelnen EU-Staaten kann sich auf die brandenburgischen Betriebe auswirken, indem ihre Attraktivität 
von Jahr zu Jahr unterschiedlich ausfällt. Dennoch weisen die brandenburgischen Betriebe eine wesentlich höhere Wertschöpfungsrentabilität auf als beispielsweise Betriebe in den westlichen Bundesländern. Ein Grund hierfür kann die Auswahl von arbeitsextensiven Kulturen wie Getreide und Ölsaaten sein. Diese Auswahl beruht jedoch auf den derzeitigen Produktionsstandards, die sich bei einer Ressourcenverknappung, wie z.B. reduzierter Wasserverfügbarkeit, ändern können. Neben diesen Entwicklungen führt auch der Trend zum Anbau nachwachsender Rohstoffe zu einem Anstieg der Bodenpreise, was den Druck auf eine wirtschaftliche Nutzung erhöht.

Die Unsicherheit in der Forstwirtschaft resultiert aus den langen Produktionszeiträumen und der Notwendigkeit, auf lange Sicht zu planen. Die Anfälligkeit der Wälder ist vor allem durch die Wald- bzw. Altersstruktur begründet. Auch hier wirkt Diversität risikomindernd. Das Gefährdungspotenzial der Forstbestände infolge von Klimaveränderungen ist hoch, besonders wenn zusätzlich zu Schwankungen bei der Saatgutversorgung, die durch Witterungsextreme hervorgerufen werden können, weitere biotische und abiotische Stressoren die Gesundheit der Bestände beeinträchtigen. Obwohl die Kiefer als häufigste Baumart der Fokusregion auch die höchste Anpassungstoleranz gegenüber Sommertrockenheit und warmen Wintern zu haben scheint und erwartet wird, dass sie auch noch in den nächsten Jahrzehnten das Rückgrat der brandenburgischen Forst- und Holzwirtschaft bleibt, besteht doch eine Gefährdung der Kiefer durch biotische und abiotische Schadeinflüsse. Folglich strebt man das Ziel an, die monostrukturierten Altersklassenwälder in stärker angepasste bzw. standortgerechte Kiefern-Laubholz-Mischbestände zu wandeln (sog. Waldumbau).

\section{Landschaft als Kulturraum}

Landschaft ist seit Jahrtausenden Wirtschaftsraum und wurde nach den jeweiligen zeitgenössischen Möglichkeiten genutzt und gestaltet und ist damit gleichbedeutend mit Kulturlandschaft. Darüber hinaus besitzt Landschaft eine historische Dimension und eine soziokulturelle Bedeutung. Durch emotionale und soziale Bindung wird Landschaft zur Heimat. Je schneller sich eine Landschaft verändert, umso intensiver wird auch der Verlust an Vertrautheit und Heimat empfunden. Dieser Landschaftswandel wurde in den letzten Jahrzehnten enorm beschleunigt.

Die künftigen Kulturlandschaften werden Spiegelbild der Globalisierung, des Klimawandels (mit Veränderungen des Landschaftswasserhaushaltes), der Klimawandelanpassung, des demographischen Wandels und der Migrationsprozesse sein. Man könnte weitere Trends hinzufügen: Agrarstrukturwandel, Auseinanderklaffen der Einkommensschere (Nachfrage nach Qualität und nach möglichst billigen Lebensmitteln) und Preissteigerungen fossiler Energieträger. Nicht alle dieser Trends sind beeinflussbar. 


\section{Ansatzpunkte für Forschung und Handeln}

\section{Regionale Produktion und Vermarktung}

Regionale Produktion und Vermarktung könnten den Umgang mit Unsicherheiten erleichtern. Allerdings ist der Anteil regionaler Produkte am Markt der Fokusregion extrem gering. Gerade für frische und unverarbeitete Lebensmittel wie Gemüse, Kartoffeln und Fleisch liegt eine deutliche regionale Unterversorgung vor. Neben der arbeits- und investitionsintensiven Produktion und dem hohen Risiko könnte auch die bisher unzureichende Erschließung regionaler Märkte eine Ursache hierfür sein. Engere Kooperation zwischen Erzeugern, Verarbeitern und dem Handel sowie die Bereitstellung der notwendigen Infrastruktur durch die Stadt Berlin könnten den Markt für regionale Produkte öffnen. Die Unterstützung regionaler Vermarktung durch regionale, nationale oder EU-weite Abschottungen der Märkte würde Nachteile für andere Märkte mit sich bringen und wird nicht als zielführend betrachtet. Eine weitere Möglichkeit, die wirtschaftliche Produktion regional vermarktbarer Produkte zu fördern, ist die Optimierung des Anbaus. Auf den nährstoffarmen und sommertrockenen Böden in Brandenburg könnte die Errichtung von großflächigen modernen Gewächshäusern, in denen Gemüse wassersparend und ohne Boden ganzjährig produziert werden, die Produktionskosten mindern und Risiken reduzieren. Voraussetzung ist allerdings die enge Kopplung an regenerative Energieträger wie Solar-, Biogas- und Geothermieanlagen, eine intensivierte $\mathrm{CO}_{2}$-Fixierung und eine schnelle Erschließung von regionalen und überregionalen Märkten, um die hohen Investitionskosten für den Landwirt vertretbar zu gestalten. Die regionale Produktion in Gewächshäusern würde so eine wirtschaftliche Landnutzung mit wesentlich reduziertem Wassergebrauch ermöglichen. Sie wäre verbunden mit einer lokalen Sammlung von Niederschlagswasser, das zum einen zur Bewässerung, zum anderen zur Energiespeicherung eingesetzt wird. Gerade bei Starkregen kann dies jedoch eine enorme Herausforderung für die Wassersammelsysteme bedeuten.

\section{Steigerung der Wassereffizienz}

In der Landwirtschaft sind Maßnahmen zur Steigerung der Wassereffizienz notwendig. Die Erhöhung der Wassereffizienz im System landwirtschaftlicher Betrieb gerade auf den leichten Böden mit geringer Wasserspeicherkapazität, wie sie in Brandenburg dominieren, ist daher eine der wichtigsten Maßnahmen, um den Folgen des Klimawandels zu begegnen. Die Maßnahmen umfassen die Erhöhung des Transpirationskoeffizienten, die zeitliche oder räumliche Vergrößerung des Wasserspeichers, die Erhöhung der Niederschlagswasseranteile am Wasserspeicher, die Verringerung der nicht über Transpiration auftretenden Wasserverluste sowie das Einsparen von Prozess- und Tränkwasser. Neben relativ einfachen Wassereinsparungen im laufenden Betrieb ist auch die Kulturpflanzenzüchtung eine Option, um durch eine höhere Stresstoleranz der Pflanzen sowie eine optimierte Wasseraufnahme und -nutzung trotz schwankender Bedingungen stabile Einträge zu er- 
wirtschaften. Weitere wichtige Schritte sind angepasste Anbau- und Haltungsverfahren und die Wiedereinführung standortgemäßer Fruchtwechsel. Die Optionen sind jedoch nicht auf alle Betriebe und Bedingungen übertragbar, die Nutzbarkeit und Kombination der vorgeschlagenen Maßnahmen muss im Einzelfall geprüft werden.

\section{Veränderung im Waldbau}

Eine weitere Möglichkeit, der Reduktion von Wasserressourcen in der wirtschaftlichen Landnutzung zu begegnen, ist eine Veränderung im Waldbau. Aufgrund der langen Produktionszeiträume, der eingeschränkten Reaktionsmöglichkeiten, der Naturnähe und der Vielzahl unterschiedlicher Zielstellungen sind die Handlungsspielräume bei der Waldbewirtschaftung aber viel geringer als in der Landwirtschaft. Entsprechend ist die durch das Waldumbauprogramm von 1990 vorgesehene Verschiebung von gleichaltrigen Kiefernreinbeständen zu strukturreichen KiefernLaubholz-Mischbeständen bisher nicht erkennbar. Es stehen derzeit keine Waldbaumarten für einen großflächigen Anbau zur Verfügung, die Klimaextremereignissen besser trotzen könnten. Die Verfügbarkeit von Bodenwasser während der Vegetationsperiode wird maßgeblich über Ertrag und Überleben der Bestände entscheiden. Unter dem Gesichtspunkt der physiologischen Überlebensfähigkeit verfügen gerade langlebige Baumarten über effiziente Anpassungsreaktionen gegenüber Witterungsstress.

\section{Land- und Wasserressourcenmanagement}

Land- und Wasserressourcenmanagement sind sowohl im Land- als auch im Waldbau von großer Bedeutung. Aufgrund der geologischen Voraussetzungen ist die Fokusregion Berlin-Brandenburg hinsichtlich des Wasserhaushaltes durch ein hohes $\mathrm{Ma} ß$ an Vulnerabilität gekennzeichnet. Diese wurde durch Entwässerungsmaßnahmen und intensive landwirtschaftliche Nutzungen zusätzlich verstärkt. Jede mit Entwässerung verbundene Nutzung von Niedermoorböden führt durch die Belüftung der organischen Böden zu deren Mineralisierung mit Degradierung der bodenhydrologischen Durchlässigkeits- und Speichereigenschaften sowie der Bodenfruchtbarkeit. Grundsätzlich sind die Polderflächen wichtige Produktionspotenziale für die Landwirtschaft und dürften künftig noch an Bedeutung gewinnen. Dies gilt besonders für die Fokusregion, wo nur die Prignitz und die Uckermark ähnlich fruchtbare Standorte aufweisen wie die Polder an der Oder und an der Elbe. Bezogen auf den märkischen Feuchtgebietsgürtel kann sich das Oderbruch zum fruchtbaren Agrarstandort entwickeln. Zur Erhaltung dieses Potenzials ist bis 2030/2040 die Etablierung eines Integrierten Land- und Wasserressourcenmanagement (ILWRM), notwendig. Die Niedermoorstandorte sollten, soweit eine ausreichende Wasserverfügbarkeit gegeben ist, aus der landwirtschaftlichen Nutzung genommen und als Feuchtgebietsrefugien erhalten werden. 


\section{Wandel der Kulturlandschaft}

Um diesen Wandel der Kulturlandschaft verträglicher zu gestalten, sollten neue Landschaften auch Kontinuen, d. h. Formen der Vertrautheit aufweisen; wobei kleinflächige oder zeitlich befristete Brüche nicht gegen das Kontinuum stehen, sondern Teil davon sind. Solche Kontinuen könnten darin bestehen, dass für vertraute Formen neue Funktionen geschaffen werden, indem man beispielsweise Niederwald für Energieholzerzeugung (flächig) und Gehölzstrukturen für Energieholzerzeugung (linear) anlegt, Grabensysteme für Grundwasseranreicherung und Kleinstrukturen (Raine, Hecken usw.) zur Oberflächenabflusspufferung und als Erosionsschutz nutzt; und neue Nutzungsformen etabliert, die sich gut in das Landschaftsbild integrieren. Dies können moderne Agroforstsysteme sein, in denen Wertholz- mit ackerbaulicher Energiepflanzenproduktion, Wertholz- mit Marktfruchtproduktion, Wertholzproduktion mit Grünland (auch für Energiebiomasse) und Wertholzproduktion mit Kurzumtriebskulturen kombiniert werden. Auen und Geländemulden sollten systematisch für die Wasserretention genutzt werden. Die punktuelle und lineare Einbringung von Gehölzen erschafft ein vertrautes Bild. Dabei sollten nicht nur die „Klassiker“ Eiche, Linde oder Esche eingesetzt werden, sondern auch weitere wirtschaftlich und gestalterisch interessante Arten wie die Schwarzkiefer, die Robinie oder die Pyramidenpappel. Eine spezifische Eigenart erhalten Kulturlandschaften außerdem durch kleinräumige und befristete Nutzungen, die vielen Landschaften heute fehlen. Damit sich lokal und regional eine eigene Dynamik, eine Vielfalt von Lösungen entfalten kann, ist mehr Gestaltungsspielraum vonnöten, den die Politik schaffen muss.

Der Forschungs- und Entwicklungsbedarf in all diesen Bereichen ist groß. Bei der Steigerung der Effizienz der Wassernutzung in den landwirtschaftlichen Betrieben sind sicherlich noch lange nicht alle Möglichkeiten ausgeschöpft und erkannt: Gewächshäuser, die neben einer effizienten ganzjährigen Pflanzenproduktion Energie bereitstellen, Kulturpflanzen, die den zunehmenden klimatischen Extremen widerstehen, angepasste Fruchtwechsel und Agrartechniken müssen entwickelt oder wiederentdeckt werden. Einsparungseffekte sollten quantifiziert und die Kosten der entsprechenden Maßnahmen erfasst werden, um beides in Relation zum wasserwirtschaftlichen Aufwand zu setzen. Für langfristige Strategien im Waldumbau ist ein quantitatives Assessment der Anpassungskapazität unverzichtbar. Auch hierfür fehlt es bislang an belastbaren wissenschaftlichen Grundlagen.

\section{Literatur}

Ahnsehl, A., Bandelin, J. \& Howitz, C. (1996): Die Ernährungswirtschaft Mecklenburg-Vorpommerns und ihre absatzwirtschaftlichen Verflechtungen mit dem Großraum Berlin. Rostocker Beiträge zur Regional- und Strukturforschung 5, 61-140.

Amede, T., Descheemaeker, K., Peden, D. \& van Rooyen, A. (2009): Harnessing benefits from improved livestock water productivity in crop-livestock systems of sub-Saharan Africa: synthesis. The Rangeland Journal 31 (2), 169-178. 
Amt für Statistik Berlin Brandenburg. Verschiedene Reihen und Jahrgänge. Potsdam: Amt für Statistik Berlin Brandenburg.

Arge Future Landscapes (2005): Future Landscapes. Perspektiven der Kulturlandschaft. Bonn, Berlin: Bundesamt für Bauwesen und Raumordnung (BBR), Bundesministerium für Verkehr, Bau- und Stadtentwicklung (BMVBS).

Balla, D. \& Quast, J. (2001): Wassergüte in Niedermooren. Strategien und Verfahren zur Renaturierung. In: R. Kratz \& J. Pfadenhauer (Hrsg.), Ökosystemmanagement für Niedermoore: Verfahren und Strategien der Renaturierung nord- und ostdeutscher Niedermoore. Stuttgart: Verlag Eugen Ulmer, 111-119.

Bartels, D. \& Phillips, J. (2010): Drought stress tolerance. In: F. Kempen \& C. Jung (Hrsg.), Genetic Modification of Plants, Biotechnology in Agriculture and forestry 64. Berlin, Heidelberg: Springer, 139-157

Bäucker, E., Bues, C.-T. \& Schröder, J. (2007): Holzqualität von Traubeneichen aus EichenKiefern-Mischbeständen. Forst und Holz 62 (9), 17-21.

Bayerl, G. (2007): Niederlausitz. In: W. Konold, R. Böcker \& U. Hampicke (Hrsg.), Handbuch Naturschutz und Landschaftspflege. 21. Ergänzungslieferung. Weinheim: WILEY-VCH, 1-21.

Becker, J. (1988): Aggregation in landwirtschaftlichen Gesamtrechnungen über physische Maßstäbe. Dissertation. Gießen: Justus-Liebig-Universität Gießen.

Bender, B., Chalmin, A., Reeg, T., Konold, W., Mastel, K. \& Spiecker, H. (2009): Moderne Agroforstsysteme mit Werthölzern. Leitfaden für die Praxis. Freiburg: Institut für Waldwachstum der Universität Freiburg.

Berghaus, H. (1854): Landbuch der Mark Brandenburg und des Margrafthums Nieder-Lausitz in der Mitte des 19. Jahrhunderts oder geographisch-historisch statistische Beschreibung der Provinz Brandenburg. Brandenburg: Adolph Müller.

Blackbourn, D. (2006): Die Eroberung der Natur. Eine Geschichte der deutschen Landschaft. München: Deutsche Verlagsanstalt.

BLE (2008): Versorgungsbilanz Getreide und Mehl: 2004/2005/2006/2007/2008. Bonn: Bundesanstalt für Landwirtschaft und Ernährung (BLE).

BMELV (2009a): Statistisches Jahrbuch über Ernährung, Landwirtschaft und Forsten der Bundesrepublik Deutschland. Bremerhaven: Wirtschaftsverlag NW - Verlag für neue Wissenschaft.

BMELV (2009b): Agrarbericht. Ergebnisse der Testbetriebe 2009. Bonn: Bundesministerium für Ernährung, Landwirtschaft und Verbraucherschutz (BMELV).

BMU (2003): Hydrologischer Atlas der Bundesrepublik Deutschland. Bonn: Bundesministerium für Umwelt (BMU).

Bock und Polach, C. v. (2011): Die Bedeutung von Sozialkapital und Netzwerken für die saisonale Migration polnischer Arbeitskräfte nach Deutschland. Am Beispiel des brandenburgischen Spargelanbaus. Aachen: Shaker Verlag.

Bouman, B. A. M. (2007): A conceptual framework for the improvement of crop water productivity at different spatial scales. Agricultural Systems 93 (1-3), 43-60.

Boyer, J. S. (1982): Plant productivity and environment. Science 218, 443-448.

Braun, J. v. (2008): Stellungnahme zur Öffentlichen Anhörung des Ausschusses für Ernährung, Landwirtschaft und Verbraucherschutz des Deutschen Bundestages: „Entwicklung der national und international steigenden Lebensmittelpreise und die Anforderungen insbesondere an die Landwirtschaftspolitik zur weltweiten Bekämpfung des Hungers“. Berlin: Deutscher Bundestag.

Breckle, S.-W. (2005): Möglicher Einfluss des Klimawandels auf die Waldvegetation Nordwestdeutschlands? LÖBF-Mitteilungen 2, 19-24.

Bronstert, A., Vollmer, S. \& Ihringer, J. (1995): Die Bedeutung von Flurbereinigungsmaßnahmen für das Abflussverhalten von Starkniederschlägen in ländlichen Gebieten. Wasser \& Boden 47 (9), 29-46.

Buczko, U. \& Bens, O. (2006): Assessing soil hydrophobicity and its variability through the soil profile using two different methods. Soil Science Society of America Journal 70, 718-727.

CMA (2003): Gemüse-Beliebtheitsskala (Onlinepublikation). http://www.flensburg-online.de/ gesundheit/beliebtes-gemuese-der-deutschen.html (15.03.2011). 
de Gelder, A., Heuvelink, E. \& Opdam, J. J. G. (2004): Tomato yield in a closed greenhouse and comparison with simulated yields in closed and conventional greenhouses. In: G. van Straten, G. P. A. Bot, W. T. M. van Meurs \& L. M. F. Marcelis (Hrsg.), ISHS Acta Horticulturae 691: International Conference on Sustainable Greenhouse Systems - Greensys2004. Leuven: Actahort.

Demmeler, M. (2008): Ökologische und ökonomische Effizienzpotenziale einer regionalen Lebensmittelbereitstellung - Analyse ausgewählter Szenarien. Dissertation. München: Technische Universität München.

Diepenbrock, W., Ellmer, F. \& Léon, J. (2009): Ackerbau, Pflanzenbau und Pflanzenzüchtung. 2. Auflage. Stuttgart: Eugen Ullmer.

Dietrich, O. \& Quast, J. (2004): Wirkungen des globalen Wandels auf den Wasserhaushalt von Feuchtgebieten: Modelluntersuchungen am Beispiel des Spreewaldes. Archiv für Naturschutz und Landschaftsforschung 43 (1), 65-76.

Drastig, K., Prochnow, A. \& Brunsch, R. (2010): Wassermanagement in der Landwirtschaft. Materialien der interdisziplinären Arbeitsgruppe Globaler Wandel - Regionale Entwicklung. Diskussionspapier 3. Berlin: Berlin-Brandenburgische Akademie der Wissenschaften.

Drastig, K., Prochnow, A. \& Brunsch, R. (2011): Water for agriculture in Brandenburg (Germany) - Wassermanagement in der Landwirtschaft in Brandenburg (Deutschland). Die Erde 142 (1/2), im Druck.

Driescher, E. (2003): Veränderungen an Gewässern Brandenburgs in historischer Zeit. Studien und Tagungsberichte 47. Potsdam: Landesumweltamt Brandenburg.

Efken, J., Haxsen, G. \& Pelikan, J. (2009): Der Markt für Fleisch und Fleischprodukte. Agrarwirtschaft $58(1), 53-65$.

Ehlers, W. (1996): Wasser in Boden und Pflanze. Stuttgart: Eugen Ulmer.

EU-KOM (2010): Standards of Food Quality (Onlinepublikation). http://ec.europa.eu/agriculture/ quality/door/list.html (18.02.2011). Europäische Kommission (EU-KOM).

Fachverband Biogas (2010): Biogas Branchenzahlen 2010 (Onlinepublikation). http://www. biogas.org/edcom/webfvb.nsf/id/DE_PM_01_11/\$file/11-01-07_Biogas \%20Branchenzahlen \%202010_erw.pdf (11.03.2011). Freising: Fachverband Biogas.

Fock, T. \& Müller, M. (2002): Analyse des landwirtschaftlichen Fachkräfte- und Bildungsbedarfs im Land Brandenburg. Teltow: Schriftenreihe des Landesamtes für Verbraucherschutz und Landwirtschaft.

Fuhrer, J. \& Jasper, K. (2009): Bewässerungsbedürftigkeit von Acker- und Grasland im heutigen Klima. AGRARForschung 16 (10), 396-401.

Gaul, T. (2009): Folgen für den Pflanzenbau. Neue Landwirtschaft 20 (6), 64-65.

Gerstengarbe, F.-W., Badeck, F., Hattermann, F. F., Krysanova, V., Lahmer, W., Lasch, P., Stock, M., Suckow, F., Wechsung, F. \& Werner, P. C. (2003): Studie zur klimatischen Entwicklung im Land Brandenburg bis 2055 und deren Auswirkungen auf den Wasserhaushalt, die Forst- und Landwirtschaft sowie die Ableitung erster Perspektiven. PIK-Report 83. Potsdam: Potsdam Institut für Klimafolgenforschung (PIK).

Grundmann, P. \& Kimmich, C. (2008): Ausbau der Energiepflanzennutzung und regionale Flächenkonkurrenz. Gutachten zur Untersuchung des Büros für Technikfolgen-Abschätzung beim Deutschen Bundestag (TAB). Chancen und Herausforderungen neuer Energiepflanzen. Berlin: Büro für Technikfolgen-Abschätzung beim Deutschen Bundestag (TAB).

Grünewald, U. (2010): Wasserbilanzen der Region Berlin-Brandenburg. Materialien der interdisziplinären Arbeitsgruppe Globaler Wandel - Regionale Entwicklung. Diskussionspapier 7. Berlin: Berlin-Brandenburgische Akademie der Wissenschaften.

Gurrath, P. (2008): Vom Erzeuger zum Verbraucher: Fleischversorgung in Deutschland. Wiesbaden: Statistisches Bundesamt.

Haber, W. (2000): Die Kultur der Landschaft. Von der Ästhetik zur Nachhaltigkeit. In: S. Appel, E. Duman, F. Kohorst \& F. Schafranski (Hrsg.), Wege zu einer neuen Planungs- und Landschaftskultur. Kaiserslautern: Universität Kaiserslautern, 1-19. 
Hagedorn, K. (2008): Integrative and segregative institutions: a dichotomy for nature-related institutional analysis. In: C. Schäfer, C. Rupschus \& U. J. Nagel (Hrsg.), Enhancing the Capacities of Agricultural Systems and Producers. Weikersheim: Marggraf, 26-38.

Hanke, G. (2005): Klimawandel. Herausforderung aus waldökologischer und waldbaulicher Sicht. LÖBF-Mitteilungen 2, 25-28.

Helfrich, T. \& Konold, W. (2010): Formen ehemaliger Niederwälder und ihre Strukturen in Rheinland-Pfalz. Archiv für Forstwesen und Landschaftsökologie 44, 157-168.

Hörnig, G. \& Scherping, E. (1993): Untersuchung von Wasserverbrauch sowie Abwasseranfall und Behandlung in großen Milchviehbetrieben. Projektabschlußbericht. Bornim: Institut für Agrartechnik.

Ikerd, J. E. (2004): The globalization of agriculture: implication for sustainability of small horticultural farms. In: L. Bertschinger \& J. D. Anderson (Hrsg.), ISHS Acta Horticulturae 638. XXVI International Horticultural Congress: Sustainability of Horticultural Systems in the $21^{\text {st }}$ Century. Toronto: ISHS.

Jenssen, M. (2009): Der klimaplastische Wald im Nordostdeutschen Tiefland - forstliche Anpassungsstrategien an einen zu erwartenden Klimawandel. Wald im Klimawandel - Risiken und Anpassungsstrategien. Eberswalder Forstliche Schriftenreihe 42, 101-117.

Kätzel, R. (2009): Möglichkeiten und Grenzen der Anpassung an Klimaextreme - eine Betrachtung zu baumartenspezifischen Risiken aus Sicht der Ökophysiologie. Wald im Klimawandel - Risiken und Anpassungsstrategien. Eberswalder Forstliche Schriftenreihe 42, 22-34.

Kätzel, R. \& Kallweit, R. (2008): Wie sieht das forstliche Monitoring der Zukunft aus? - Anspruch und Realisierungsmöglichkeiten in Brandenburg. Wissenstransfer in die Praxis. Beiträge zum dritten Winterkolloquium am 28. Februar 2008 in Eberswalde. Eberswalder Forstliche Schriftenreihe 35, 26-34.

Kätzel, R., Maurer, W. D., Konnert, M. \& Scholz, F. (2005): Genetisches Monitoring in Wäldern. Forst und Holz 5, 179-183.

Kögl, H. (2010): Potenziale der Vermarktung von landwirtschaftlichen Produkten aus Brandenburg in Berlin. Materialien der interdisziplinären Arbeitsgruppe Globaler Wandel - Regionale Entwicklung. Diskussionspapier 10. Berlin: Berlin-Brandenburgische Akademie der Wissenschaften.

Kögl, H. \& Tietze, J. (2010): Erzeugung, Verarbeitung und Vermarktung von Lebensmitteln. Forschungsbericht 2/2010, Professur Landwirtschaftliche Betriebslehre und Management. Rostock: Universität Rostock.

Kölling, C. (2007): Klimahüllen für 27 Baumarten. AFZ - Der Wald 23, 1242-1245.

Konold, W., Schwineköper, K. \& Seiffert, P. (1996): Zukünftige Kulturlandschaft aus der Tradition heraus. In: W. Konold (Hrsg.), Naturlandschaft - Kulturlandschaft. Landsberg: Ecomed, 289-312.

Körber-Grohne, U. (1995): Nutzpflanzen in Deutschland - von der Vorgeschichte bis heute. Hamburg: Nikol Verlagsgesellschaft.

Kratz, R. \& Pfadenhauer, J. (Hrsg.) (2001): Ökosystemmanagement für Niedermoore: Verfahren und Strategien der Renaturierung nord- und ostdeutscher Niedermoore. Stuttgart: Verlag Eugen Ulmer.

Krausch, H.-D. (2008): Beiträge zur Wald-, Forst- und Landschaftsgeschichte Brandenburgs. Remagen: Verlag Kessel.

Krause, K.-J. (1999): Sicherung und Pflege des Genius loci. In: S. Thabe (Hrsg.), Räume der Identität - Identität der Räume. Dortmunder Beiträge zur Raumplanung 98. Dortmund: Institut für Raumplanung Universität Dortmund, 38-58.

Kretschmer, H. (Hrsg.) (2000): Ökologisches Entwicklungskonzept Oberes Rhinluch. ZALFBericht Nr. 43. Müncheberg: Leibniz-Zentrum für Agrarlandschafts- und Landnutzungsforschung (ZALF) e.V.

KTBL (2008): Wasserversorgung in der Rinderhaltung. Wasserbedarf - Technik - Management. KTBL-Heft 81. Darmstadt: Kuratorium für Technik und Bauwesen in der Landwirtschaft (KTBL).

Leue, P., Quast, J. \& Wenkel, K.-O. (1981): Use of control methods for irrigation systems in the German Democratic Republic. In: ICID-Congress. Grenoble: Congress on Irrigation and Drainage (ICID), 171-191. 
Lischeid, G. (2010): Landschaftswasserhaushalt in der Region Berlin-Brandenburg. Materialien der interdisziplinären Arbeitsgruppe Globaler Wandel - Regionale Entwicklung. Diskussionspapier 2. Berlin: Berlin-Brandenburgische Akademie der Wissenschaften.

LUA (2003): Landschaftswasserhaushalt in Brandenburg - Kurzfassung zum Sachstandsbericht mit Konzeption, Beitrag zum Projekt Stabilisierung und Verbesserung des Landschaftswasserhaushaltes in Brandenburg. Potsdam: Landesumweltamt Brandenburg (LUA), Projektgruppe Landschaftswasserhaushalt.

Massmann, G. (2002): Infiltration of River Water into the Groundwater, Investigation and Modelling of Hydraulic and Geochemichal Processes during Bank Filtration in the Oderbruch, Germany. Freie Universität Berlin. Dissertation. Berlin: dissertation.de - Verlag im Internet $\mathrm{GmbH}$.

Massmann, G., Pekdeger, A., C., M., Quast, J. \& Schafmeister, M.-T. (2003): Infiltration of river water into the groundwater - quantifiying 250 years of iron reduction in an anoxic aquifer (Oderbruch, Germany). In: H. D. Schulz \& A. Hadeler (Hrsg.), Deutsche Forschungsgemeinschaft. Geochemical Process in Soil and Groundwater. Measurement - Modeling - Upscaling. GeoProc 2002. Weinheim: WILEY-VCH, 560-579.

Mengel, P. F. (1930): Das Oderbruch. Eberswalde: Verlagsgesellschaft R. Müller.

Meyers Konversationslexikon (1888): 6. Band. 4. Auflage, 1885-1892. Leipzig, Wien: Verlag des Bibliographischen Instituts.

MIL (2010a): Agrarbericht 2010 des Landes Brandenburg. Potsdam: Ministerium für Infrastruktur und Landwirtschaft (MIL).

MIL (2010b): Waldzustandsbericht 2009 der Länder Berlin und Brandenburg. Potsdam: Ministerium für Infrastruktur und Landwirtschaft (MIL).

Mittler, R. (2006): Abiotic stress, the field environment and stress combination. Trends in Plant Science 11, 15-19.

Mittler, R. \& Blumwald, E. (2010): Genetic engineering for modern agriculture: challenges and perspectives. Annual Review of Plant Biology 61, 443-462.

MLUV (2001): Agrarbericht 2000. Bericht zur Lage der Land- und Ernährungswirtschaft des Landes Brandenburg. Potsdam: Ministerium für Ländliche Entwicklung, Umwelt und Verbraucherschutz (MLUV).

Möller, K. (2009): Aktuelle Waldschutzprobleme und Risikomanagement in Brandenburgs Wäldern. Eberswalder Forstliche Schriftenreihe 42, 14-21.

Moreira, M.-B. (2004): Agriculture and food in the globalisation age. International Journal of Sociology of Agriculture and Food 12 (Special Issue: Globalization), 17-28.

MUGV (2010): Binnenhochwasser im Oderbruch: Situation entschärft sich allmählich (Onlinepublikation). http://www.mugv.brandenburg.de/cms/detail.php/5lbm1.c.99017.de (02.03.2011). Potsdam: Ministerium für Umwelt, Gesundheit und Verbraucherschutz (MUGV).

Müller, J., Lüttschwager, D. \& Rust, S.(2007): Zum Wasserhaushalt in Kiefernbeständen auf grundwasserfernen Sandstandorten. Eberswalder Forstliche Schriftenreihe 32, 78-107.

Müller, L. (1988): Efficiency of subsoiling and subsurface drainage in heavy alluvial soils of the G.D.R. Soil \& Tillage Research 12, 121-134

MWE (2009): Jahreswirtschaftsbericht 2009 Land Brandenburg. Potsdam: Ministerium für Wirtschaft und Europaangelegenheiten Brandenburg (MWE).

Nederhoff, E. (2006): Closed greenhouse and heat producing greenhouse. Grower 61 (10), 67-69.

Nölting, B. \& Boekmann, T. (2005): Struktur der ökologischen Land- und Ernährungswirtschaft in Brandenburg und Berlin - Anknüpfungspunkte für eine nachhaltige Regionalentwicklung. discussion paper Nr. 18/05. Berlin: Technische Universität Berlin, Zentrum Technik und Gesellschaft.

Ozkan, B., Kurklub, A. \& Akcaoza, H. (2004): Corrigendum to „An input-output energy analysis in greenhouse vegetable production: a case study for Antalya region of Turkey“. Biomass and Bioenergy 26, 89-95.

Pellmeyer, J. (2010): Auf der Suche nach Alternativen. Biogas-Journal Sonderheft Energiepflanzen, 78. 
Pena, J. (2005): Greenhouse Vegetable Production Economic Considerations, Marketing, and Financing, Aggie horticulture (Onlinepublikation) http://aggie-horticulture.tamu.edu/ greenhouse/hydroponics/index.html (11.03.2011). College Station: Texas A\&M University.

Quast, J. (1973): Beitrag zur indirekten Parameterquantifizierung verarbeitungsadäquater geohydraulischer Modelle durch Analyse der Grundwasserdynamik. Dissertation A. Dresden: Technische Universität Dresden.

Quast, J. (1983): Beitrag zur Entwicklung von Entwurfs- und Steuerungsmethoden sowie technischer Lösungen für bedarfsgerechte hydrotechnische Systeme der Bodenwasserregulierung. Dissertation B. Dresden: Technische Universität Dresden.

Quast, J. (1994): Wechselwirkungen von Feuchtgebieten und Landschaftswasserhaushalt - Analysen und Management. 26. Hohenheimer Umwelttagung, 17-33.

Quast, J. (1995): Wasserhaushalt und Feuchtgebiete in einer Trockenlandschaft - Zustand - Konflikte - Maßnahmen. Zeitschrift für Kulturtechnik und Landentwicklung 36 (4), 207-213.

Quast, J. (1997a): Trockenlegung und Landnutzung dominieren den Naturhaushalt des Oderbruchs - Anthropogene Veränderungen einer Auenlandschaft; Vortrag zur Historikertagung in Altraft am 21. Januar 1997 anläßlich „250 Jahre Trockenlegung des Oderbruchs“. Tagungsbericht Seelow. Müncheberg: Leibniz-Zentrum für Agrarlandschafts- und Landnutzungsforschung (ZALF) e.V., Institut für Hydrologie.

Quast, J. (1997b): Wasserdargebot in Brandenburgs Agrarlandschaften und gebotene wasserwirtschaftliche Konsequenzen. Archiv für Naturschutz und Landschaftsforschung 35 (4), 267-277.

Quast, J. (1998): Aktuelle wasserwirtschaftliche Fragen des Oderbruchs. In: G. Darkow \& H.-R. Bork (Hrsg.), Die Bewirtschaftung von Niederungsgebieten in Vergangenheit und Gegenwart. ZALF-Bericht 34. Müncheberg: Leibniz-Zentrum für Agrarlandschafts- und Landnutzungsforschung (ZALF) e.V., 57-72.

Quast, J. (1999): Wege zu einem nachhaltigen Miteinander von Landnutzung, Naturschutz und Wasserwirtschaft. Archiv für Acker- und Pflanzenbau und Bodenkunde 44, 323-347.

Quast, J. (2006): Local actions within rural water management - Building blocks in a framework for Integrated River Basin Management. In: Institute of Hydraulics and Rural Water Management (Hrsg.), Proceedings of the International Symposium SOPHYWA am 28./29.9. 2006. In honour of the retirement of Prof. Ferdinand Kastanek. Wien: Department of Water Atmosphere and Environment, University of Natural Ressources and Applied Life Sciences, 107-111

Quast, J. (2008): Wie können wir besser mit dem knappen Landschaftswasser haushalten? In: Ökologische Folgen des Klimawandels, 5. Stechlin-Forum, Mai 2008. Stechlin-Neuglobsow: Leibniz-Institut für Gewässerökologie und Binnenfischerei (IGB), 31-48.

Quast, J. \& Böhm, G. (1998): Die Ermittlung der realen Evapotranspiration von Niedermoorgebieten unter den hydroklimatischen Bedingungen Nordostdeutschlands am Beispiel des Rhinluchs. In: E. Raschke (Hrsg.), Klimaforschungsprogramm des BMBF 1994-1997. Ergänzungsband. Geesthacht: GKSS

Quast, J., Dietrich, O., Blankenburg, J. \& Heidt, P. (2001): Wasserhaushalt. In: R. Kratz \& J. Pfadenhauer (Hrsg.), Ökosystemmanagement für Niedermoore: Verfahren und Strategien der Renaturierung nord- und ostdeutscher Niedermoore. Stuttgart: Verlag Eugen Ulmer \& Co., 31-79.

Quast, J., Dietrich, O. \& Dannowski, R. (1993): Die Folgen der Entwässerung und Nutzung von Niedermooren für den Landschaftswasserhaushalt. Naturschutz und Landschaftspflege in Brandenburg. Sonderheft Niedermoore, 11-14.

Quast, J. \& Ehlert, V. (2005): Concept OderBruch 2010 as an example towards sustainable multifunctional use of polders in the context of integrated land, water and flood management. ICID $21^{\text {st }}$ European Regional Conference integrated land and water resources management - towards sustainable rural development, May 2005, Frankfurt (Oder), Germany and Slubice, Poland. Müncheberg: Leibniz-Zentrum für Agrarlandschaftsforschung (ZALF) e.V., Institut für Landschaftshydrologie.

Quast, J. \& Kalettka, T. (2005): Schritte zur Wiedererlangung eines guten ökologischen Zustandes in den historisch verbauten Altwässern des Oderbruchs und in den Zuflüssen im westlichen Einzugsgebiet. Gewässerentwicklung in der Kulturlandschaft. Schriften der DWhG, Bd. 7. Siegburg: Deutsche Wasserhistorische Gesellschaft e.V. (DWhG). 
Quast, J. \& Lukianas, A. (1999): Rehabilitation of Polder Systems on the Floodplains regions of Oder River/Germany and the Nemunas River/Lithuania. In $17^{\text {th }}$ International Congress on Irrigation and Drainage, Water and Agriculture in the next Millenium, 1-19 September 1999, Granada, Proceedings, Question 49.1.

Quast, J. \& Müller, G. (1973): Untersuchungen der regionalen Grundwasserströmung im Oderbruch. Wasserwirtschaft/ Wassertechnik. 23 (7), 235-241.

Quast, J., Schwarz, H. \& Dannowski, R. (1978): Zur Steuerung großflächiger Grundwasserregulierungssysteme. In: Tagungsbericht Akademie der Landwirtschaftswissenschaften der DDR Nr. 166. Berlin: Akademie der Landwirtschaftswissenschaften, 397-405.

Quast, J. \& Wenkel, K.-O. (2004): Nachhaltiges Landschaftsmanagement: Machbar oder nur wissenschaftlicher Anspruch? In: G. Lutze \& F. Reusswig (Hrsg.), Nachhaltiges Brandenburg: Kulturlandschaft zwischen Funktionalität und Ästhetik. Müncheberg: Leibniz-Zentrum für Argrarlandschaftsforschung (ZALF) e.V., 7-24.

Redecker, B., Finck, P., Härdtle, W., Riecken, U. \& Schröder, E. (Hrsg.) (2002): Pasture Landscapes and Nature Conservation. Berlin, Heidelberg: Springer.

Reeg, T., Bemmann, A., Konold, W., Murach, D. \& Spiecker, H. (Hrsg.) (2009): Anbau und Nutzung von Bäumen auf landwirtschaftlichen Flächen. Weinheim: WILEY-VCH.

Reeg, T. \& Brix, M. (2008): Zielgebietsauswahl für Agroforstsysteme - Vorschläge unter Berücksichtigung der verschiedenen Interessen der Landnutzung. Naturschutz und Landschaftsplanung 40 (6), 173-179.

Reeg, T. \& Konold, W. (2011): Nützlich und schön - Bäume in der Agrarlandschaft in Vergangenheit und Zukunft. Alemannisches Jahrbuch 57, im Druck.

Roloff, A. \& Grundmann, B. (2008): Bewertung von Baumarten anhand der KlimaArtenMatrix. AFZ - Der Wald 20, 1086-1087.

Schnauss, M. (2001): Der ökologische Fußabdruck der Stadt Berlin. Im Auftrag der Enquetekommission „Globale Agenda 21 / Zukunftsfähiges Berlin“ des Berliner Abgeordnetenhauses (KDrs 14/105a) (Onlinepublikation) http://www.agenda21 berlin.de/fussabdruck/ (18.02.2011).

Schröder, J. (2009): Risiken durch Witterungsextreme für Kiefer und Eiche in Nordostdeutschland: Ansätze zur Schätzung des Gefährdungspotentials. Eberswalder Forstliche Schriftenreihe 42, 35-43.

Schubert, H. (2007): Lebensmittelwirtschaft. Materialien der Interdisziplinären Arbeitsgruppe Zukunftsorientierte Nutzung ländlicher Räume, Nr. 17. Berlin: Berlin-Brandenburgische Akademie der Wissenschaften.

Schumacher, K.-D. \& Chilla, B. (2009): Der Markt für Getreide und Ölfrüchte. Agrarwirtschaft $58(1), 15-25$.

Seiffert, P., Schwineköper, K. \& Konold, W. (1995): Analyse und Entwicklung von Kulturlandschaften. Das Beispiel Westallgäuer Hügelland. Landsberg: Ecomed.

Stackebrandt, W. \& Manhenke, V. (Hrsg.) (2004): Atlas zur Geologie von Brandenburg. CDROM. 3. Auflage als digitale Version. Kleinmachnow: Landesamt für Geowissenschaften und Rohstoffe Brandenburg.

Suchomel, C. \& Konold, W. (2008): Niederwald als Energiequelle - Chancen und Grenzen aus Sicht des Naturschutzes. Berichte der Naturforschenden Gesellschaft zu Freiburg i. Br 98, 61-120.

Treffny, R. (2003): Der „Ökologische Fußabdruck“ der Münchner - Eine Analyse der Lebensweise der Einwohner Münchens durch einen Indikator der Nachhaltigkeit. Diplomarbeit. München: Ludwig-Maximilians-Universität München.

Valena, T. (2005): Der gebaute Ort in Zeiten seiner virtuellen Infragestellung. In: Kulturstiftung Dessau Wörlitz, Stiftung Bauhaus Dessau \& Stiftung Luthergedenkstätten in Sachsen-Anhalt (Hrsg.), Biosphärenreservat Flusslandschaft Mittlere Elbe. Genius Loci. Dessau: Cuno, 53-68.

Vetter, A., Heiermann, M. \& Toews, T. (Hrsg.) (2009): Anbausysteme für Energiepflanzen. Frankfurt/Main: DLG-Verlag.

Wackernagel, M. \& Rees, W. (1997): Unser Ökologischer Fußabdruck. Wie der Mensch Einfluss auf die Umwelt nimmt. Basel, Boston, Berlin: Birkhäuser Verlag.

WASY (1999): Erarbeitung von Grundlagen für die wasserwirtschaftliche Rahmen- und Bewirtschaftungsplanung im Oderbruch. Studie für das Landesumweltamt Brandenburg. Potsdam: WASY GmbH. 
Wechsung, F., Gerstengarbe, F.-W., Lasch, P. \& Lüttger, A. (Hrsg.) (2009): Die Ertragsfähigkeit ostdeutscher Ackerflächen unter Klimawandel. PIK-Report 112. Potsdam: Potsdam-Institut für Klimafolgenforschung (PIK).

Weigel, H. J. (2005): Pflanzen unter zukünftigem Klima. Wie beeinflusst der Klimawandel die Pflanzenproduktion? Gesunde Pflanzen 57 (6), 6-17.

Witzke, H. v., Noleppa, S. \& Schwarz, G. (2009): Global Agricultural Market Trends Revisited. Working Paper 89. Berlin: Institut für Wirtschafts- und Sozialwissenschaften des Landbaus Humboldt-Universität zu Berlin.

Young, O. R. (2002): The Institutional Dimensions of Environmental Change: Fit, Interplay and Scale. Cambridge: MIT Press.

Zebisch, M., Grothmann, T., Schröter, D., Hasse, C., Fritsch, U. \& Cramer, W. (2005): Klimawandel in Deutschland Vulnerabilität und Anpassungsstrategien klimasensitiver Systeme. UBAForschungsbericht. (Onlinepublikation). http://www.umweltdaten.de/publikationen/fpdf-1/ 2947.pdf (08.03.2011). Dessau: Umweltbundesamt.

Inge Broer ( $($ )

Universität Rostock

inge.broer@auf.uni-rostock.de

Katrin Drastig ( $\bowtie)$

Leibniz-Institut für Agrartechnik Potsdam-Bornim e.V. (ATB)

kdrastig@atb-potsdam.de

Konrad Hagedorn (凶)

Humboldt-Universität zu Berlin

k.hagedorn@agrar.hu-berlin.de

Ralf Kätzel (两)

Landeskompetenzzentrum Forst Eberswalde (LFE), Landesbetrieb Forst Brandenburg

ralf.kaetzel@lfe-e.brandenburg.de

Hans Kögl (凶)

Universität Rostock

hans.koegl@uni-rostock.de

Werner Konold (两)

Albert-Ludwigs-Universität Freiburg

werner.konold@landespflege.uni-freiburg.de

Joachim Quast (凶)

Institut für Landschaftswasserhaushalt am Leibniz-Zentrum für Agrarlandforschung (ZALF) e.V., Müncheberg

jquast@zalf.de

Reiner Brunsch

Leibniz-Institut für Agrartechnik Potsdam-Bornim e.V. (ATB)

Klaus Höppner

Landeskompetenzzentrums Forst Eberswalde (LFE), Landesbetrieb Forst Brandenburg

Annette Prochnow

Leibniz-Institut für Agrartechnik Potsdam-Bornim e.V. (ATB)

Alfred Pühler

Universität Bielefeld

Mihaiela Rus

Humboldt-Universität zu Berlin 